NBER WORKING PAPER SERIES

\title{
THE LONG-RUN LABOR MARKET EFFECTS OF THE CANADA-U.S. FREE TRADE AGREEMENT
}

\author{
Brian K. Kovak \\ Peter M. Morrow \\ Working Paper 29793 \\ http://www.nber.org/papers/w29793 \\ NATIONAL BUREAU OF ECONOMIC RESEARCH \\ 1050 Massachusetts Avenue \\ Cambridge, MA 02138 \\ February 2022
}

We especially thank Allison Devlin for all of her important contributions to the analysis presented in this paper. We also thank our discussants at conference presentations for very helpful comments and suggestions: David Autor, Teresa Fort, Keith Head, and Brian McCaig. We appreciate helpful comments and suggestions from Nate Baum-Snow, Winnie Chan, Gordon Hanson, Ig Horstmann, Felix Koenig, Kory Kroft, James Lake, Thomas Lemieux, Kevin Lim, Phil Luck, Rene Morissette, David Price, John Ries, Kadee Russ, Lowell Taylor, Daniel Trefler, Eric Verhoogen, and seminar participants at the 2021 ASSA Meetings, 2020 Atlanta Fed International Economics Workshop, Chinese University of Hong Kong, Dartmouth, EIIT, FGV Sao Paulo, Georgetown, Groningen, Johns Hopkins (SAIS), Maryland, the NBER Summer Institute (2021), the Nordic International Trade Conference (2020), and Syracuse. We especially thank Yukman Cheung, Danny Leung, and Beryl Li at Statistics Canada and Shenjie Chen and Emily Yu at Global Affairs Canada for all their help, without which this project would never have gotten off the ground. We are also indebted to Philippe Kabore at Statistics Canada for timely and professional disclosure. We thank Global Affairs Canada for generous funding. Results in this paper have been screened by Statistics Canada to ensure that no confidential results have been released. Any opinions and conclusions expressed herein are those of the authors and do not necessarily represent the views of Global Affairs Canada or Statistics Canada. All remaining mistakes are those of the authors alone. The views expressed herein are those of the authors and do not necessarily reflect the views of the National Bureau of Economic Research.

NBER working papers are circulated for discussion and comment purposes. They have not been peer-reviewed or been subject to the review by the NBER Board of Directors that accompanies official NBER publications.

(C) 2022 by Brian K. Kovak and Peter M. Morrow. All rights reserved. Short sections of text, not to exceed two paragraphs, may be quoted without explicit permission provided that full credit, including $\odot$ notice, is given to the source. 
The Long-Run Labor Market Effects of the Canada-U.S. Free Trade Agreement

Brian K. Kovak and Peter M. Morrow

NBER Working Paper No. 29793

February 2022

JEL No. F13,F16,F66,J23,J31

\begin{abstract}
$\underline{\text { ABSTRACT }}$
This paper assesses the long-run effects of the 1988 Canada-U.S. Free Trade Agreement (CUSFTA) on the Canadian labor market using matched longitudinal administrative data for the years 1984-2004. We simultaneously examine the labor market effects of increased export expansion and import competition, generally finding adverse effects of Canadian tariff cuts and favorable effects of U.S. cuts, though both effects are small. Workers initially employed in industries that experienced larger Canadian tariff concessions exhibit a heightened probability of layoffs at large firms, but little impact on long-run cumulative earnings. Lower earnings and years worked at the initial employer are offset by gains in other manufacturing industries, construction, and services. Canadian workers quickly transitioned out of industries facing import competition, with the majority of industry adjustment occurring among new entrants to the labor market.
\end{abstract}

Brian K. Kovak

H. John Heinz III College

Carnegie Mellon University

4800 Forbes Avenue, HBH 3012

Pittsburgh, PA 15213

and NBER

bkovak@cmu.edu

Peter M. Morrow

Department of Economics

University of Toronto

150 St. George St., Room 336

Toronto, Ontario

M5S 3G7, Canada

peter.morrow@utoronto.ca 


\section{Introduction}

While international economists have long studied the distributional consequences of trade liberalization, traditional approaches assumed full employment and costless worker transitions (Stolper and Samuelson, 1941). However, recent empirical findings by Autor, Dorn, Hanson and Song (2014), Dix-Carneiro and Kovak (2017), and many others have documented persistently depressed labor market outcomes for workers and regions facing increased import competition. ${ }^{1}$ The consistency of this finding across different research designs, trade shocks, and countries has led to growing pessimism regarding the path of worker adjustment following trade shocks.

In this paper, we document the short- and long-run labor market effects of the 1989 Canada-U.S. Free Trade Agreement (FTA). While this shock generated changes in trade flows that were at least as large as those studied in prior research (see our discussion of Figure 1 below), we find starkly different effects on Canadian workers than one might expect given the recent literature. While Canadian tariff cuts led to an increased likelihood of layoff and reduced earnings from workers' initial employers, workers quickly recovered lost earnings by transitioning to other firms, industries, and sectors. Canadian tariff reductions did not lower total years worked or cumulative earnings for workers during the 16 years following the FTA's enactment, and the reciprocal U.S. tariff reductions tended to offset the modest negative effects of Canadian tariff cuts on average. In other words, the tariff cuts had the expected effects, but worker adjustment to changing labor demand was relatively speedy and successful.

We carry out this study using 21 years of high-quality, longitudinal, matched worker-firm administrative data from Statistics Canada covering 1984-2004. We apply the research design of Autor et al. (2014) to the context of bilateral changes in trade policy by comparing the career trajectories of otherwise similar workers initially employed in industries that were subsequently subject to dif-

\footnotetext{
${ }^{1}$ Autor et al. (2021) and Dix-Carneiro and Kovak (2017) focus explicitly on the long-run persistence in the regional impacts of import competition, while Autor et al. (2014), Dix-Carneiro and Kovak (2019), Pierce et al. (2020), and Utar (2018) show similarly persistent effects at the worker level. Many other papers document depressed labor market outcomes in regions facing increased import competition but do not focus on persistence, including Autor et al. (2013a), Dauth et al. (2014, 2021), Hakobyan and McLaren (2016), Kovak (2013), Topalova (2010), Utar (2014), and many others (see Autor et al. (2016) for a survey).
} 
ferent Canadian and United States tariff concessions legislated by the FTA. The bilateral nature of this agreement allows us to study the effects of both import competition and export expansion in response to a policy change. We examine a large number of individual-level labor market outcomes including displacement, years worked, cumulative earnings, and transitions into other firms, other industries, or unemployment during the 16 years following the FTA's implementation. Because our sample starts in 1984, we can control for a variety of initial conditions and pre-trends including worker, firm, and industry wage trajectories, firm and industry employment trajectories, and capital intensity.

The CUSFTA provides a nearly ideal setting in which to study the causal effects of changing bilateral trade policy (Trefler, 2004). The Agreement cut tariffs to zero on nearly all non-agricultural trade between Canada and the U.S., with minimal changes to non-tariff barriers or other hard-tomeasure aspects of trade policy. The FTA was not part of a larger reform package, nor was it passed in response to a crisis or other macroeconomic shocks. As we will show, the tariff changes were not confounded by pre-existing trends in industry performance. Given the large size of the U.S. economy in comparison to Canada's, the FTA drove substantial increases in trade from the Canadian perspective. Figure 1 shows that U.S. import penetration in Canada increased by 40 percentage points from 1988 to 2004 . This is more than 4 times larger than the growth in Chinese import penetration in Canada during this period and the growth in Chinese import penetration in the U.S. during 1991-2011 (Autor et al., 2014, Table I).

We find that workers initially employed in manufacturing industries that subsequently lost tariff protection in Canada experienced an increased probability of a job separation, while those facing U.S. tariff concessions had lower probabilities of separation. For example, an interquartile $\left(25^{\text {th }}\right.$ to $75^{\text {th }}$ percentile) increase in the size of the Canadian tariff cut caused a 3 percentage point higher layoff probability for workers with low labor force attachment initially employed at large firms. For the same group, an interquartile increase in the U.S. tariff concession led to a 1.9 percentage point lower layoff probability. Thus, the adverse effects of increased import competition and the favorable effects of increased access to the U.S. export market partly offset each other on average. 
Figure 1: Import Penetration Ratio for Canadian Imports from China and the U.S.

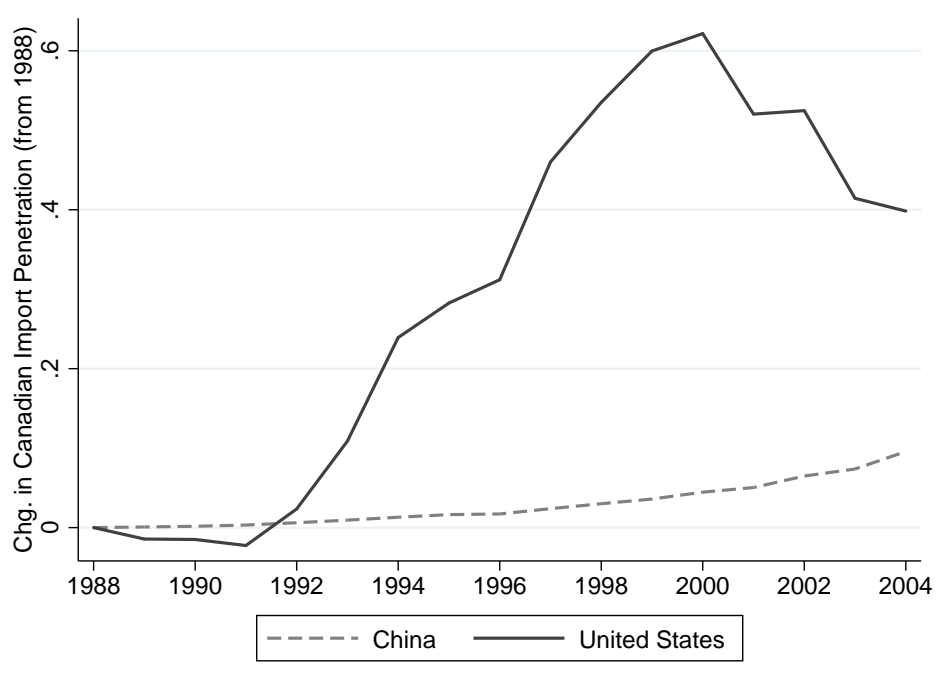

Notes: The y-axis plots the change in Canadian import penetration accounted for by Chinese or U.S. imports from 1988 to the year on the x-axis. Specifically, it follows Autor et al. (2014) equation (1) by plotting (imports $_{t}^{c}-$ imports $\left._{1988}^{c}\right) /\left(\right.$ absorption $\left._{1988}\right)$, where $c \in\{$ China,U.S. $\}$ and absorption is industry output plus imports minus exports. All values deflated to 1988 dollars using the Canadian CPI.

These effects on workers' outcomes at their initial firms are consistent with the large effects of the FTA on plant exit and plant employment documented in Head and Ries (1999) and Trefler (2004).

In spite of the changes in the probability of separating from one's initial employer, we find little effect on total years worked or on cumulative earnings during the 16 years following the FTA's implementation. Consistent with the separation results, larger Canadian tariff cuts did indeed reduce years worked and earnings at the initial employer and at other firms in the initial industry. However, these losses were largely offset by increased earnings from sources in other manufacturing industries, construction, and services. Moreover, the favorable effects of U.S. tariff reductions also offset the losses from Canadian cuts on average, leading to a very small net impact on workers' employment and earnings.

These findings contrast with the large and persistent effects of the China Shock in Autor et al. (2014) or of Brazilian trade liberalization in Dix-Carneiro and Kovak (2017). ${ }^{2}$ Instead, our results

\footnotetext{
${ }^{2}$ As discussed in Section 5.4, the earnings effects we document for high attachment workers are an order of
} 
are more in line with those of Dauth et al. (2014, 2017, 2021), who find offsetting effects of import and export flows with China and Eastern Europe in the German context, although our study is distinct in examining an explicit change in trade policy. To understand these contrasting results, we first rule out three potential explanations for our findings: i) FTA tariff changes were too small to drive substantial effects, ii) U.S. and Canadian tariff changes offset within each industry, and iii) Canada's industrial geography (relative to the U.S.) facilitated transitions across industries. We then present three supplementary findings documenting how labor market adjustment occurred in Canada. First, Canadian workers quickly moved from industries facing large increases in import competition to industries facing smaller shocks. Second, the CUSFTA tariff changes did not induce mass layoffs. Third, total industry-level employment responded to import competition, but these adjustments occurred primarily among new entrants to the labor market rather than among incumbent workers. We also find that the China Shock in Canada increased mass layoffs and affected both incumbent and newly entering workers' employment, suggesting that the Canadian labor market does not adjust smoothly to all trade shocks.

As in the prior empirical work on the CUSFTA, firm size plays an important role (see literature review below). Canonical models of heterogeneous firms and trade, such as Melitz (2003) and its asymmetric-country extension in Demidova and Rodríguez-Clare (2013), predict that larger Canadian firms should benefit most from increased access to the U.S. export market because those more productive firms can bear the fixed costs of exporting. Our results confirm this prediction: workers initially employed at larger firms experience bigger reductions in the probability of separation when facing larger U.S. tariff reductions. However, in contrast to the canonical models, larger firms also exhibit the biggest increases in separations when facing larger Canadian tariff reductions. As discussed below, this surprising result is consistent with the empirical findings of Head and Ries (1999), Autor et al. (2013b), and Pierce et al. (2020), and can be rationalized by the niche-market mechanism formalized by Holmes and Stevens (2014) and the complementary product-cycle argumagnitude smaller than the parallel effects of the China Shock in the U.S. documented by Autor et al. (2014). In addition, Autor et al. (2021) extend the results of Autor et al. (2013a) forward 12 years to 2019. They find persistent regional effects of the China Shock through the end of this sample period in spite of U.S. imports from China plateauing after 2012. 
ments of Eriksson et al. (2021). Our heterogeneity analysis also reveals that while the tariff cuts had small effects on average, a relatively small group of workers, those with low labor force attachment initially employed at large firms, have nontrivial effects of both Canadian and U.S. tariff cuts. However, the adverse effects of Canadian tariff reductions and the favorable effects of U.S. cuts have very similar magnitudes for this group of workers, so the net effects of the FTA remain close to zero on average.

This study possesses three virtues relative to the existing literature. First, it examines the effects of a well-defined policy change, so our findings can inform ongoing trade policy debates. In this sense, it is most closely linked to studies analyzing the effect of the NAFTA on various aspects of the American, Canadian, and Mexican economies (see literature review below), the effect of trade liberalization in developing countries (e.g. McCaig (2011) and McCaig and Pavcnik (2018) for Vietnam, Topalova (2007, 2010) for India, and Kovak (2013) and Dix-Carneiro and Kovak (2017) for Brazil), and the end of the Multi Fibre Arrangement (e.g. Harrigan and Barrows (2009) and $\operatorname{Utar}(2014,2018)) .^{3}$

Second, because of the bilateral nature of the CUSFTA, we are able to examine the effects of increased access to U.S. export markets along with the effects of increased import competition in Canada. All of our analyses simultaneously include measures of Canada's tariff cuts facing U.S. exports and measures of U.S. tariff cuts facing Canadian exports. Studies examining unilateral trade liberalizations are often restricted to studying the effects of imports alone, and those studying both imports and exports generally examine changes in trade flows rather than explicit trade policy changes. ${ }^{4}$ We contribute an analysis of an explicit trade policy change that substantially and simultaneously affects both import competition and access to an important export market. ${ }^{5}$

Third, by relying on longitudinal matched employee-firm data, we are able to examine not just

\footnotetext{
${ }^{3}$ Brambilla et al. (2012) also study the effects of U.S. anti-dumping duties imposed on Vietnamese fish exports.

${ }^{4}$ See, for example, Baziki et al. (2021), Biscourp and Kramarz (2007), Costa et al. (2016), Dauth et al. (2014), Dauth et al. (2021), and Hummels et al. (2012). In addition, Feenstra et al. (2019) study the effect of increased exports to China from the U.S.

${ }^{5}$ In this regard, our analysis is most closely related to a robustness test in McCaig and Pavcnik (2018) that considers the effects of tariff changes in the U.S. and Vietnam as part of the U.S.-Vietnam Bilateral Trade Agreement. However, in contrast to this paper, they use repeated cross-sections for four years (2001-2004) rather than longitudinal data.
} 
whether workers were displaced by import competition (for example) but also where they went and whether these displacements affected their long-run earnings. In this sense our work is distinct from all the papers we are aware of examining the effects of the CUSFTA on the Canadian economy, which focus on outcomes at the plant or industry level (e.g. Gaston and Trefler (1997), Head and Ries (1999), Beaulieu (2003), Trefler (2004), and Lileeva (2008)), and the vast majority of papers studying other trade liberalization episodes, although Utar (2014, 2018) and Dix-Carneiro and Kovak (2017) are notable exceptions.

\section{Additional Literature}

A large body of work documents that the CUSFTA had measurable effects on Canadian plant outcomes. Using industry-level data on the number of manufacturing establishments, total output, and output per establishment, Head and Ries (1999) find increased establishment exit and output per establishment. Trefler (2004) uses plant-level data from the Canadian Annual Survey of Manufactures for 1980-1996 to show that firms most adversely affected by Canadian tariff concessions suffered employment losses, and that there was, on average, no effect of U.S. concessions on Canadian plant-level employment. However, this null result for U.S. concessions is a combination of a positive effect for Canadian exporting firms and a negative effect for non-exporting firms. ${ }^{6}$ Beaulieu (2003) documents job losses concentrated among lower-paid production workers rather than higher-paid managers. In contrast to this study, neither Beaulieu (2003) nor Trefler (2004) observes whether these contractions in industry-level employment were accompanied by reallocations to other sectors, whether these reflect transitions into prolonged unemployment, or whether there were cumulative long-run effects on worker incomes. ${ }^{7}$

\footnotetext{
${ }^{6}$ While Trefler finds that Canadian industries that lost protection subsequently had relatively higher average earnings, this result conditions on workers remaining employed and does not take into account workers whose income disappeared due to being laid off. See Trefler (2004), section IX for more details. Autor et al. (2013a) demonstrate that increased transitions into unemployment are extremely important for understanding the effect of Chinese import competition on U.S. labor markets.

${ }^{7}$ Trefler (2004) only makes use of plants that were in existence in 1980, 1986, 1988, and 1996 and is unable to make corrections for entry and exit due to data limitations. Trefler also notes that many of these panel-based studies (including Gaston and Trefler (1997)) fail to correct for auto-correlation in standard errors. Lileeva (2008) explicitly accounts for entry and exit. Chan (2019) examines how CUSFTA affected self-employment in Canada. He finds
} 
A number of papers also examine how NAFTA affected Mexican and U.S. workers, but these papers do not follow long-term outcomes. Chiquiar (2008) finds that regions in Mexico that were more exposed to NAFTA exhibited increased wage levels, but decreased inequality, relative to other parts of the country. Hanson (2003) engages in a more general discussion of the effect of NAFTA on Mexico's wage structure and finds that wage gains were largest in regions most exposed to globalization. Hakobyan and McLaren (2016) use a local labor markets analysis for the United States, but only focus on industries' vulnerability to Mexican imports and localities' dependence on these industries. They find evidence of lower wage growth for blue-collar workers in the most affected industries and localities. ${ }^{8}$

Canonical models of firm heterogeneity such as Melitz (2003) also motivate our exploration of how the CUSFTA affected firms of different sizes. Demidova and Rodríguez-Clare (2013) extend the Melitz model to the case when countries and trade policies are asymmetric, which is applicable in our context given that the U.S. is roughly ten times the size of Canada and had lower levels of protection prior to the FTA. These models predict that Canadian tariff concessions should increase exit and worker displacement among smaller firms and that U.S. concessions should benefit larger firms. Note, however, that Melitz (2003) and Demidova and Rodríguez-Clare (2013) present single-industry models, while our empirical setting leverages variation across multiple industries. In this context, a multi-industry version of the model would require some degree of input market segmentation to capture differences in outcomes for small firms in industries facing different U.S. tariff cuts. ${ }^{9}$

that Census Divisions that experienced larger Canadian tariff cuts against US imports experienced higher rates of self-employment while those with larger American tariff cuts against Canadian goods correspondingly experienced lower rates of self-employment. Hsieh et al. (2016) offer a structural assessment of variety creation/destruction due to the agreement. Thompson (1993), Breinlich (2014), and Greenland et al. (2020) use event-study approaches to examine the effects of news regarding the CUSFTA's passage on Canadian or U.S. firms' stock returns.

${ }^{8}$ Unfortunately, such a local labor markets approach is infeasible as our data described in section 3 do not include detailed location information. However, in section 5.6, we use supplementary data to measure regional tariff shocks in Canada and how the Canadian industrial landscape might have affected their impact.

${ }^{9}$ Chaney (2008) shows how to add many countries and asymmetric trade barriers to the Melitz (2003) framework but relies on an outside good to pin down factor prices. This precludes the possibility that lower tariffs abroad cause non-exporting firms to contract as we find here. Melitz and Redding (2014) derive results for many symmetric countries without an outside good. Egger and Kreickemeier (2009) and Felbermayr et al. (2011) introduce fair wages and search-based unemployment, respectively, into heterogeneous firms models but both rely on symmetric countries. Helpman et al. (2010) introduce search and matching frictions into a Melitz model with costly screening to show how trade can affect wage inequality within sectors and within groups of ex-ante identical workers. 
As mentioned above, both our results and those of the prior literature on the CUSFTA find that Canadian concessions led to larger degrees of exit and job displacement at larger firms, rather than at smaller firms as predicted by these canonical models. Baldwin and Gu (2004) and Lileeva (2008) argue that this surprising finding reflects contraction at multi-plant firms and increased specialization at the firm level. The effects of U.S. tariff cuts on Canadian firms are more in line with these models. Exporters experienced employment growth, whereas non-exporting firms actually contracted due to within-industry reallocation of workers (Lileeva, 2008). ${ }^{10}$ Our empirical results are also consistent with the empirical work of Verhoogen (2008) who finds that large Mexican firms were most able to take advantage of the 1994 Peso devaluation relative to the U.S. Dollar.

By explicitly examining the importance of sectors outside of manufacturing, our paper is also linked to recent work assessing the importance of the service sector in adjustment to import competition. Fort et al. (2018) and Bloom et al. (2019) each emphasize the importance of services in how the United States responded to the China Shock documented in Autor et al. (2013a). ${ }^{11}$

The paper is organized as follows. Section 2 discusses the Agreement in more detail. Section 3 describes our data. Section 4 discusses our empirical approach. Section 5 presents results. Section 6 examines heterogeneous effects across firms and within-industry worker reallocations. Section 7 offers concluding comments.

\section{The Canada-U.S. Free Trade Agreement}

The Canada-US Free Trade Agreement was signed on January 2, 1988 by Canadian Prime Minister Brian Mulroney and U.S. President Ronald Reagan, culminating more than 100 years of proposals and negotiations seeking free trade between the two neighbors. ${ }^{12}$ The Agreement went into effect on

\footnotetext{
${ }^{10}$ Like Trefler (2004), Lileeva (2008) uses the Canadian Annual Survey of Manufactures.

${ }^{11}$ More generally, Harrison (2017) argues that understanding the role played by service sectors in globalization is extremely important for understanding how trade affects labor markets.

${ }^{12}$ Because Canadian passage of the FTA was far from certain and prior attempts at passing free trade agreements between Canada and the U.S. were unsuccessful, we do not expect to observe anticipatory effects. The Canadian Senate rejected the bill after it passed the House of Commons, something that had not happened in the preceding 40 years (Forsey, 2020). The FTA dominated the ensuing November 1988 election, in which the Conservatives won enough seats for a majority (although they lost the popular vote), which led the Senate to pass the FTA (Lileeva and
} 
January 1, 1989, phasing out tariffs for nearly all non-agricultural goods traded between Canada and the U.S. In addition to tariff cuts, the agreement liberalized foreign investment in Canada, required nondiscrimination in new regulations applying to the service sector and to foreign investment, and created an appeals mechanism to ensure appropriate application of treaty commitments, along with a variety of other minor provisions (Copeland, 1989).

The tariff cuts were phased in from 1989 to 1998. Figure A1 in the Appendix presents the evolution of Canadian tariffs on U.S. manufacturing exports and U.S. tariffs on Canadian manufacturing exports between 1988 and 1998. ${ }^{13}$ For simplicity, we refer to Canadian tariffs on U.S. exports as "Canadian tariffs" and U.S. tariffs on Canadian exports as "U.S. tariffs" except where explicitly stated. In 1988, Canadian tariffs varied greatly, with those in the 95th percentile seeing protection of more than 20 percent, while the least protected industries already had zero tariffs. Average Canadian tariffs declined from approximately 10 percent in 1988 to zero in nearly all product categories in 1998. Figure A1 also graphs the corresponding U.S. tariff cuts. While U.S. tariffs were initially much lower $(\approx 3$ percent), their mean and variance fell similarly.

Because of the linear phase-in of the tariff cuts, there is minimal variation in the timing of cuts across industries. All of our analyses therefore rely on cross-industry variation in tariff cuts between 1988 and 1998 to examine the effects of the CUSFTA on the Canadian labor market. In order to interpret our results as the causal effect of the tariff changes, it must be the case that i) the observed tariff cuts were unrelated to counterfactual industry performance and ii) the tariff cuts were uncorrelated with other aspects of the FTA that might have affected industry outcomes. We address the former requirement in Section 5.1, showing that the tariff cuts were unrelated to preFTA industry performance. On the latter point, the CUSFTA is nearly ideal relative to other large liberalization episodes (Trefler, 2004). While most large-scale trade liberalizations, particularly those in lower-income countries, involved significant reductions in non-tariff barriers and other

Trefler, 2010; Sears, 2012). In addition, prior agreements had fallen apart before enactment. Under the Elgin-Marcy Treaty of 1854, the two countries engaged in duty-free trade in a variety of primary products from 1854 to 1866 , with failed attempts at subsequent agreements in the 1870s, 1910s, and 1940s (Morici, 1990).

${ }^{13}$ Tariffs on the majority of Canadian imports experienced linear tariff reductions during a 10-year period (schedule $\mathrm{C}$ tariff lines), with the remainder phased in linearly over a 5-year period (schedule B), implemented immediately in January 1989 (schedule A), or having no cut due to pre-existing free trade (schedule D) (Head and Ries, 1999). 
Figure 2: Tariff Cuts and Bilateral Trade: Canada (left) and United States (right)
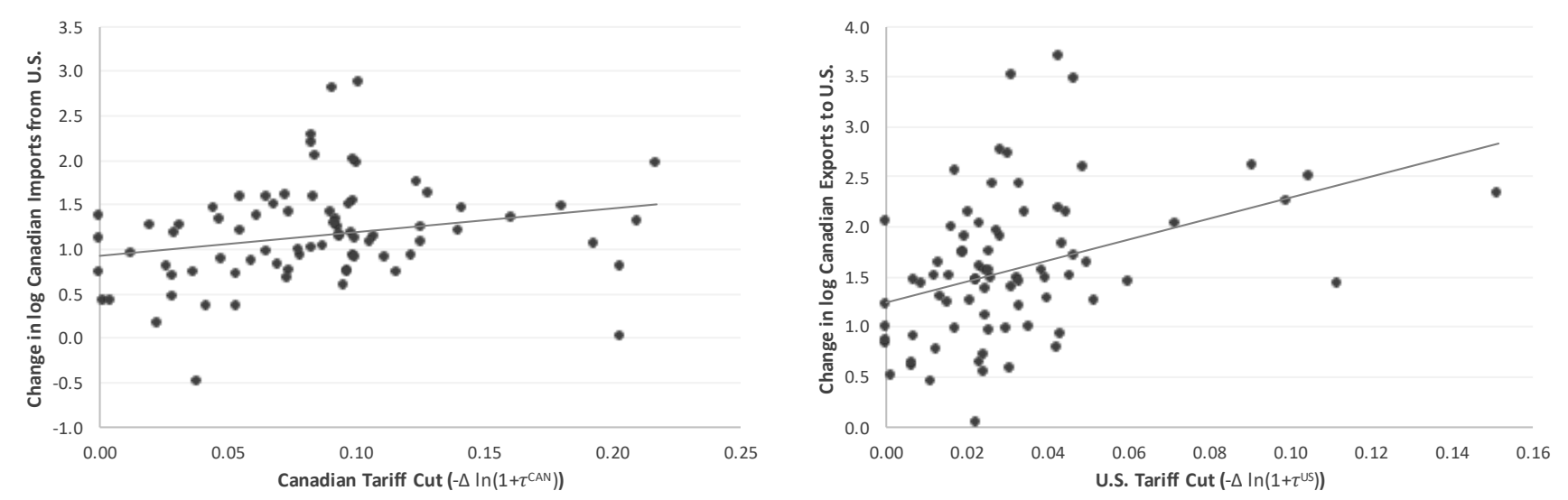

Notes: Each figure plots the change in log bilateral trade against the tariff cut in the importing country from 1988 to 1998 for each of 78 4-digit NAICS manufacturing industries. Each dot is an industry. The left panel plots the change in log imports into Canada from the U.S. against negative one times the change in log one plus the Canadian tariff; the associated regression line has a slope of 2.66 (s.e. 1.33, $\mathrm{p}=0.05$ ). The right panel plots the change in log exports from Canada to the U.S. against negative one times the change in log one plus the U.S. tariff from 1988-1998; the associated regression line has a slope 10.48 (s.e. 2.44, $\mathrm{p}<0.01$ ).

reforms, the non-tariff provisions of the FTA primarily focused on limiting new non-tariff barriers and prohibiting new discriminatory regulations (Copeland, 1989). The CUSFTA tariff cuts were also incorporated into the subsequent NAFTA agreement, so they were relevant throughout our study period, which extends through $2004 .^{14}$

Figure 2 shows that the tariff cuts expanded bilateral trade across industries as expected. The left panel shows that industries with larger Canadian tariff cuts saw increased imports from the U.S., while the right panel shows that larger U.S. tariff cuts drove increased Canadian exports to the U.S. In both cases, the estimated coefficients are consistent with the related literature. ${ }^{15}$

\footnotetext{
${ }^{14}$ NAFTA accelerated the tariff cuts prescribed by the CUSFTA for some products, but this accounted for a relatively small share of trade (Besedes et al., 2020).

${ }^{15}$ For Canadian imports, the estimated slope is 2.66 and, for U.S. imports, the estimated slope is 10.48 . The first is significant at the 5 percent level and the second is significant at the 1 percent level. Results are stronger if we control for the change in MFN tariffs. Using a more formal CES framework, Romalis (2007) finds an elasticity of substitution between 2 and 5 for Canadian imports, and between 6 and 9 for U.S. imports in response to the CUSFTA tariff cuts. Appendix Figure A2 confirms that Canadian imports from the U.S. grew more quickly for HS-6 products with larger Canadian tariff cuts and that this difference grew steadily over time. We thank Teresa Fort for suggesting this figure.
} 


\section{Data}

Our main research design compares labor market outcomes for Canadian workers whose initial industries faced different tariff cuts in Canada or the U.S. as a result of the FTA. We observe individual workers' labor market outcomes over time using Statistics Canada's matched T2-LEAPLWF data set, which covers 1984-2004. The heart of this database is the Longitudinal Worker File (LWF), which assembles individual T4 tax records providing longitudinal employment and earnings information. ${ }^{16}$ The LWF represents a 10 percent random sample of Canadian workers appearing in the underlying tax records during 1984-2004, and we observe complete labor market histories for the workers in our sample. ${ }^{17}$ As discussed below, we restrict attention to workers initially employed in manufacturing, but we are able to follow them even if they move into other sectors, including agriculture, mining, and services.

The LWF contains yearly data on each worker's employer(s), wage income, basic demographic information, province of employment, and industry affiliation at the 4-digit NAICS level. There are 328 of these industries, of which 86 are within manufacturing. As discussed below, we drop 2 industries that do not map onto our tariff data and 6 additional industries subject to quantitative trade restrictions. ${ }^{18}$ This provides us with 78 manufacturing industries in our sample. The LWF also includes a unique field based on Records of Employment (ROE), which Canadian employers must submit whenever a worker experiences an interruption in earnings. ${ }^{19}$ The ROE classifies each separation as either temporary (returned to the firm in the year of separation or the following year) or permanent (otherwise) and provides a reason for the separation, including firing, returning to school, ending seasonal work, quit, or work shortage (equivalent to layoff). This information allows

\footnotetext{
${ }^{16}$ All references to "income" and "earnings" refer to wage income reported on tax form T4. This is the Canadian equivalent of the W2 form that U.S. workers receive from each employer.

${ }^{17}$ The 10 percent random sample is taken over unique Social Insurance Numbers for workers appearing in the data at any point. If a worker's SIN number is in the 10 percent sample, they are included in all years in which they received T4 income.

${ }^{18}$ The two industries that do not map onto HS product codes are 3151 ("Clothing Knitting Mills") and 3328 ("Coating, Engraving, Heat Treating and Allied Activities").

${ }^{19}$ The Canadian Employment Insurance Act requires every employer to issue an ROE when an employee working in insurable employment has an interruption in earnings. The ROE information is used to determine eligibility for Employment Insurance (EI) benefits, the benefit rate, and the claim duration, and the ROE must be issued even if the employee does not intend to file a claim. Morissette et al. (2013) describe ROEs in detail.
} 
us to focus our main analysis on permanent layoffs, which avoids diluting effects by inadvertently including temporary or voluntary separations (Flaaen et al., 2019).

Statistics Canada merges the longitudinal worker-level information in the LWF with firm-level data for their employers. T2 corporate income tax returns report interest, sales, gross profits, equity, assets, etc. for all incorporated firms in Canada, and the Longitudinal Employment Analysis Program (LEAP) database reports firms' total employment over time. Unlike Trefler (2004) who uses the Canadian Annual Survey of Manufactures, we possess data on firms (tax entities) rather than plants. Consequently, changes in continuing firm employment can be due to either plant entry and exit or changes in employment within continuing plants. In addition, a firm disappears from our sample if all of its workers in our sample experience separations despite it continuing to employ workers not in our sample. This limits our ability to undertake firm-level analyses and further motivates our focus on worker-level outcomes.

While the LWF data are very rich, particularly in their ability to track workers across employment status and different jobs over time, they have a few important limitations. First, the T2-LEAP-LWF data have relatively coarse geographic information at the province level, precluding us from using these data to implement local labor market analyses by commuting zone. Second, we cannot observe non-labor income except Employment Insurance payments and have no information on occupation or education. To account for heterogeneity in worker skill in our empirical analysis, we normalize workers' earnings by their pre-FTA earnings and control for the share of workers in the industry earning less than the national median income. We also stratify our samples in some analyses by labor force attachment or by initial earnings.

We calculate tariff changes in each worker's initial industry primarily using data provided by Global Affairs Canada. Legislated tariffs from 1988 through 1998, including tariffs facing Canadian exports to the U.S., U.S. exports to Canada, and Canadian Most Favored Nation (MFN) tariffs facing other exporters are taken directly from the CUSFTA agreement. ${ }^{20}$ U.S. MFN Tariffs are

\footnotetext{
${ }^{20}$ We are extremely grateful to Emily $\mathrm{Yu}$ at Global Affairs Canada for providing us with digitized data that describes the phase-in schedule for the CUSFTA tariff cuts between 1988-1998.
} 
derived from Feenstra (1997). ${ }^{21}$ In both cases, we aggregate tariffs to the 4-digit NAICS industry level using concordances from Pierce and Schott (2012) and the U.S. Census Bureau. ${ }^{22}$ We set the initial tariff in Auto Pact sectors to zero. ${ }^{23}$ We drop from our sample six 4-digit NAICS industries that were subject to quantitative restrictions, as described in Lester et al. (1988), because legislated tariff changes do not accurately capture changes in protection in these industries. ${ }^{24}$

\section{Empirical Approach}

Our empirical analysis compares labor market outcomes of otherwise similar Canadian workers who were initially employed in industries facing different Canadian or U.S. tariff cuts. We measure the tariff cuts as negative one times the change in log one plus the tariff rate from 1988 to 1998 : $-\Delta \ln \left(1+\tau_{j}^{c}\right)$, where $c \in\{\mathrm{CAN}, \mathrm{US}\}$ is the country imposing the tariff in industry $j .{ }^{25}$ Because tariffs went to zero in all industries, this measure is equivalent to the initial value of $\ln \left(1+\tau_{j}^{c}\right)$.

We relate these tariff changes to labor market outcome $Y_{i f j k}$ for worker $i$ initially employed in firm $f$ in manufacturing industry $j$ using the following worker-level specification.

$$
Y_{i f j k}=\beta_{0}-\beta_{1} \Delta \ln \left(1+\tau_{j}^{\mathrm{CAN}}\right)-\beta_{2} \Delta \ln \left(1+\tau_{j}^{\mathrm{US}}\right)+\mathbf{X}_{i}^{\prime} \beta_{3}+\mathbf{X}_{f}^{\prime} \beta_{4}+\mathbf{X}_{j}^{\prime} \beta_{5}+\epsilon_{i f j k}
$$

The subscript $k$ represents time windows over which we calculate the worker's post-FTA outcomes: 1989-1993, 1989-1998, or (most frequently) 1989-2004. The first time span covers the initial phase-in

\footnotetext{
${ }^{21}$ To proxy U.S. MFN tariffs, we divide total duties paid by total customs imports in 1989 from Austria, Denmark, Finland, France, Germany, Greece, Ireland, Italy, the Netherlands, Norway, Spain, Sweden, and the U.K.

${ }^{22}$ When calculating average tariffs at the 4-digit NAICS level, we weight 8-digit HS codes by 1988 imports to the relevant country. See Appendix A for details.

${ }^{23}$ Sectors 3361,3362 , and 3363 . While there were strictly positive statutory tariffs in these sectors, waivers were easily obtained, leading to free trade in practice. See Trefler (2004) for more details.

${ }^{24}$ The relevant industries are Meat Products, Poultry Products, Dairy Products, Flour and Breakfast Cereals, Sugar, Distilleries and Breweries, Wineries, Tobacco and Tobacco Products (Lester et al., 1988), which we concord to 3112 ("Grain and Oilseed Milling"), 3113 ("Sugar and Confectionery Product Manufacturing"), 3115 ("Dairy Product Manufacturing"), 3116 ("Meat Product Manufacturing"), 3121 ("Beverage Manufacturing), 3122 ("Tobacco Manufacturing").

${ }^{25}$ We measure tariff changes using $\Delta \ln \left(1+\tau_{j}^{c}\right)$ because this measure reflects the proportional price change faced by competitive producers under a small-country assumption. See Kovak (2013) for a model in which this is the appropriate tariff measure.
} 
of tariff cuts until the year before NAFTA came into force, the second covers the full phase-in of the CUSFTA tariff cuts, and the third extends to the final year of the sample. Because we multiply the tariff changes by negative one, a positive estimate of $\beta_{1}$ implies that workers whose initial industry faced larger Canadian tariff cuts experienced more positive values of the outcome $Y$. The vectors $\mathbf{X}_{i}^{\prime}, \mathbf{X}_{f}^{\prime}$, and $\mathbf{X}_{j}^{\prime}$ are worker, initial firm, and initial industry level controls, described below. $\epsilon_{i f j k}$ is an error term, clustered by the worker's initial four-digit NAICS industry.

Tariff cuts are assigned to workers based on their initial industry of employment, so even if a worker switches industries after 1988, the same initial-industry tariff cuts remain associated with that worker, analogous to Autor et al. (2014) and Utar (2018). To assign an initial firm and industry, we define the worker's base year as the final year in 1986-1988 in which the worker had strictly positive earnings and a valid industry code. We then define the initial industry as the industry of employment in that base year. The initial firm and initial province are defined analogously.

Our sample consists of workers initially employed in manufacturing who were born between 1940 and 1964, ensuring they were of working age (22-64) during 1986-2004. We require that workers had positive earnings in at least one year during 1986-1988 to assign an initial firm and industry of employment. We drop workers initially employed in the Canadian Territories. ${ }^{26}$ Following Autor et al. (2014), we examine both high and low labor force attachment workers. High attachment workers are defined as those who earned at least the equivalent of 1,600 annual hours of work at the nominal provincial minimum wage in every year between 1985 and 1988 (inclusive). Low attachment workers are the remainder of workers meeting other sample requirements. Section 5 discusses the characteristics of these workers in more depth, and Appendix B describes the sample and variable construction in detail.

We include extensive controls in equation (1) to ensure that we are comparing outcomes for otherwise similar workers facing different tariff cuts. $\mathbf{X}_{i}^{\prime}$ is a vector of worker level controls including the worker's gender, birth year indicators, log real average earnings during 1986-1988, the change

\footnotetext{
${ }^{26}$ We omit workers in the Territories (Yukon, Northwest Territories, and Nunavut) to avoid disclosure concerns due to their very small populations, totaling 0.33 percent or less of Canada's overall population during our sample period.
} 
in $\log$ real earnings from 1986 to 1988, indicators for labor market experience and tenure in the worker's initial firm, and the initial province of employment. All nominal earnings are converted into real 2002 dollars using the Canadian CPI. A worker is defined as having "low" labor market experience if they had positive earnings in two or fewer years in the period 1984-1988, "medium" if they had positive earnings in three or four years, and "high" if they had positive earnings in all years in the period 1984-1988. Tenure is distinct from experience in that it refers to the worker's tenure in a given firm whereas labor market experience measures employment regardless of employer. A worker is defined as "low" tenure if they have fewer than two years of experience at their initial firm, "medium" if they have two or three years, and "high" if they have four or more years as of their base year. In addition, we control for an interaction between the worker's age and their log real average earnings during 1986-1988.

Initial-firm controls, $\mathbf{X}_{f}^{\prime}$, include indicators for firm size. Following Autor et al. (2014), "small" firms are defined as those with 99 or fewer workers, "medium" sized firms have 100 to 999 workers (inclusive), and "large" firms are those with 1000 or more workers. ${ }^{27}$ We also include average log real earnings per worker in 1988 within the firm as well as the average of the change in log worker real income within the firm between 1986 and 1988 .

We also include extensive initial-industry controls, $\mathbf{X}_{j}^{\prime}$. These include the log share of workers earning less than the aggregate median income in 1988, average log earnings per worker in 1988, the $\log$ industry capital-labor ratio in 1988, the change in the log of the share of aggregate employment accounted for by the industry between 1986 and 1988, and the mean change in log income for those employed in the industry between 1986 and 1988. While our data cannot directly distinguish between skilled and unskilled workers, the share of workers below the median income proxies for the industry's unskilled labor intensity. The change in the log of the industry's share of aggregate employment captures whether certain industries were already shedding or gaining employment for reasons unrelated to the CUSFTA. We also control for a measure of industry responsiveness to the business cycle to avoid confounding the changes in bilateral trade policy with the early-1990s

\footnotetext{
${ }^{27}$ This measure is based on the Statistics Canada national average labour units (nalus) measure.
} 
Canadian recession. ${ }^{28}$ We control for the 1988 to 1998 change in log one plus the MFN tariff facing non-FTA countries in Canada and the U.S. to account for substitution between potential trading partners. When considering heterogeneous results by initial firm size, we interact both the CUSFTA and MFN tariff changes with the firm size indicators. In all of our specifications, we include industry-level pre-trends in the dependent variable and its interactions with initial firm size indicators and indicators for the worker's tenure at their initial firm. ${ }^{29}$ We also address the rise of China by controlling for the change in Chinese import penetration in Canada in the worker's initial industry, following Acemoglu et al. (2016). ${ }^{30}$ Finally, we include 2-digit NAICS fixed effects, so we compare outcomes for workers initially in different 4-digit industries within the same 2-digit manufacturing industry.

Our empirical analyses examine workers' labor market outcomes. We first examine an indicator for whether a worker experienced a permanent work-shortage related separation (layoff) from their initial employer during the relevant time period. This dependent variable allows us to measure how Canadian and U.S. tariff cuts in the worker's initial industry affected their probability of a layoff by their initial firm. We also examine cumulative years worked $T_{i f j k}$ as well as years worked in the initial firm, initial industry outside the initial firm, in other manufacturing industries, and outside manufacturing. 31

We also study the FTA's effects on workers' cumulative earnings, $\tilde{E}_{i f j k}$, where

$$
\tilde{E}_{i f j k} \equiv \frac{\left[\sum_{t=1989}^{2004} \sum_{j^{\prime}} \sum_{f^{\prime}} E_{i f^{\prime} j^{\prime} t}\right]}{\bar{E}_{i, 88-86}} .
$$

\footnotetext{
${ }^{28}$ One of the major objects of interest in Gaston and Trefler (1997), Beaulieu (2003), and Trefler (2004) was to estimate the independent effects of the CUSFTA on Canadian employment relative to recession. Using the NBER manufacturing database for 1958-1989, we regress log industry employment on log GDP and a linear time trend, and use the coefficient on GDP as our measure of cyclicality. Ex-ante, it is not obvious that more sensitive industries would have worse employment outcomes, as our study also covers the late 1990s expansion.

${ }^{29}$ For example, when we examine the determinants of the probability of a work-shortage related separation between 1989 and 2003, we control for the unconditional probability of a separation in the same industry in the years 1984 through 1988.

${ }^{30}$ Specifically, we control for the change in real imports into Canada from China between 1989 and 2004, divided by 1988 real industry absorption (output plus imports minus exports) in Canada.

${ }^{31}$ The maximum number of years worked between 1989 and 2004 inclusive is 16 . When decomposing years worked into industries, each year's employment is assigned to the industry of primary employment (that with the most earnings).
} 
The numerator is worker $i$ 's cumulative real earnings from 1989 to 2004 from employment in any firm $f^{\prime}$ and in any industry $i^{\prime}$, including those other than the worker's initial firm and industry. ${ }^{32}$ We focus only on earnings, so results are not affected by public programs. ${ }^{33}$ To account for unobserved worker heterogeneity, we normalize these cumulative earnings by the worker's pre-FTA yearly earnings, $\bar{E}_{i, 88-86}$, calculated as average yearly real earnings in 1986-1988 (averaging over years with strictly positive earnings). Given this normalization, $\tilde{E}_{i f j k}=16$ means that the worker on average earned their real pre-period income in each of the 16 years spanning 1989-2004. Because the numerator of (2) decomposes additively into earnings from different firms, industries, and sectors, we additionally investigate how the sources of workers' earnings adjusted in response to the FTA tariff changes. ${ }^{34}$

In some specifications, we consider heterogeneous effects by the size of the worker's initial employer, interacting the tariff cut variables with indicators for small (1-99 employees), medium (100999), and large $(\geq 1000)$ initial firms. This analysis is motivated by the findings of Head and Ries (1999), Lileeva (2008), and Autor et al. (2013b) who emphasize the firm reallocation effects that trade can induce. We also examine workers' labor market transitions by observing their employment status in the year following a permanent separation. For the purposes of this transition analysis, and because our earnings information is reported at the yearly level, we define a worker as being unemployed if their yearly earnings fall below the equivalent of 1600 hours worked at the relevant provincial minimum wage. ${ }^{35}$ For employed workers, we then observe whether they are working for a different firm in the same industry, a different industry within manufacturing, or in a different sector in the year following separation. Because the indicators for each of these post-separation conditions sum to the overall separation indicator, we perform an additive decomposition revealing how workers transitioned following a permanent separation.

\footnotetext{
${ }^{32}$ Because many workers earn labor income from multiple employers in a given year, we follow Autor et al. (2014) and define the worker's primary employer as the one from whom a worker earns the most income in a given year.

${ }^{33}$ Our data do allow us to observe Employment Insurance receipts. See Stepner (2019) for a full treatment of how redistributive taxes and transfers offset earnings losses in Canada.

${ }^{34}$ We use scaled cumulative earnings rather than the change in log earnings because i) it allows for an exact additive decomposition of its components, ii) it does not drop observations with zero earnings in the final year.

${ }^{35}$ Note the distinction between this unemployment measure and those in surveys such as the U.S. Current Population Survey and the Canadian labor Force Survey, which ask about employment and job search activity within a specified reference period.
} 
Finally, to provide context for the results that follow, we ask the question "who are high and low attachment workers?" Overall, the majority of our sample is high-attachment: our sample contains 63,128 high-attachment workers and 20,577 low-attachment workers. Columns (1)-(3) of Appendix Table A1 examine the features of high-attachment status, regressing an indicator for high labor force attachment on the worker, firm, and industry controls just discussed. We omit the experience and tenure indicators, which are mechanically correlated with the high-attachment indicator. Columns (1) and (2) show that women and younger workers are unconditionally less likely to be high attachment. Column (3) adds the full set of controls. Workers with higher average initial wage income and lower pre-FTA wage income growth are more likely to have high attachment status. Workers at large firms are less likely to be high attachment, as are workers at firms with stronger pre-FTA wage growth. Workers in industries with lower average wages and lower average wage growth are more likely to be high attachment.

\section{Results}

We present six sets of results in this section. Section 5.1 rules out the possibility that Canadian tariff cuts were substantially related to observable industry characteristics or pre-existing trends. Section 5.2 asks whether workers initially employed in industries that subsequently experienced different Canadian and American tariff concessions experienced different probabilities of separating from their initial employer. Sections 5.3 and 5.4 present results for years worked and cumulative earnings, respectively. Section 5.5 investigates the implications for inequality by stratifying the results by workers' initial income levels. Section 5.6 discusses possible explanations for these results.

\subsection{Exogeneity of Trade Policy}

The main threat to interpreting our results as the causal effects of the FTA is that the tariff changes may have been correlated with unobserved factors affecting workers' outcomes. Since all of the tariffs fell to zero (Appendix Figure A1), the relevant question is whether the initial tariff 
levels were correlated with counterfactual industry performance. To assess the importance of this concern, we estimate the following specification examining the correlates of the initial tariffs at the four-digit NAICS industry level:

$$
\ln \left(1+\tau_{j, 1988}^{c}\right)=\beta_{0}+\beta_{1} \ln \left(1+\tau_{j, 1988}^{-c}\right)+\mathbf{X}_{j}^{\prime} \beta_{2}+\epsilon_{j}
$$

where $c,-c \in\{\mathrm{CAN}, \mathrm{US}\}, \mathbf{X}_{j}$ is the vector of industry level controls discussed in Section 4 , and we present specifications with and without controlling for the other country's $(-c)$ initial tariff.

The results in columns (2) and (4) of Appendix Table A2 show that the strongest correlate of a country's initial tariff is the other country's initial tariff; other factors are far less important. ${ }^{36}$ To assess whether industries facing larger tariff cuts were on similar trajectories prior to the FTA, we examine how the initial tariff level related to growth in the industry's share of employment from 1984 to $1988\left(\Delta_{1984-1988} \ln \left(e m p_{j} / \sum_{j^{\prime}} e m p_{j^{\prime}}\right)\right)$ and the growth in the industry's average earnings from 1986 to $1988\left(\Delta_{1986-1988}\right.$ Mean $\log$ earnings $\left.{ }_{j}\right)$. For Canadian tariffs (columns $(1)$ and $\left.(2)\right)$, the associated coefficients on pre-FTA growth are statistically indistinguishable from zero and are economically small. ${ }^{37}$ For U.S. tariffs (columns (3) and (4)), we find a statistically significant negative relationship between growth in the industry's share of employment and the initial tariff level, implying that industries with larger U.S. concessions had relatively declining shares of employment prior to the FTA. However, the relationship is again economically small. While these estimates rule out the presence of substantial confounding pre-trends, our analyses nonetheless control for pre-FTA firm- and industry-level pre-trend measures to allay remaining endogeneity concerns, as discussed in Section 4.

\footnotetext{
${ }^{36}$ Although the initial Canadian and U.S. tariff levels are closely related, there are far from perfectly collinear, making it possible for us to separately identify their effects (see Section 5.6). The $R^{2}$ from an industry-level bivariate regression of initial Canadian tariffs on initial U.S. tariffs is 0.35 , although this rises to 0.61 when weighted by the number of workers in each industry.

${ }^{37}$ Very large changes in the industry's share of employment or average wage are associated with small tariff changes. Even a 25 percent increase in an industry's employment share (say from 1 to 1.25 percent) is associated with less than a one percentage point difference in tariff.
} 
Table 1: Probability of Separation from Initial Firm (1989-2003)

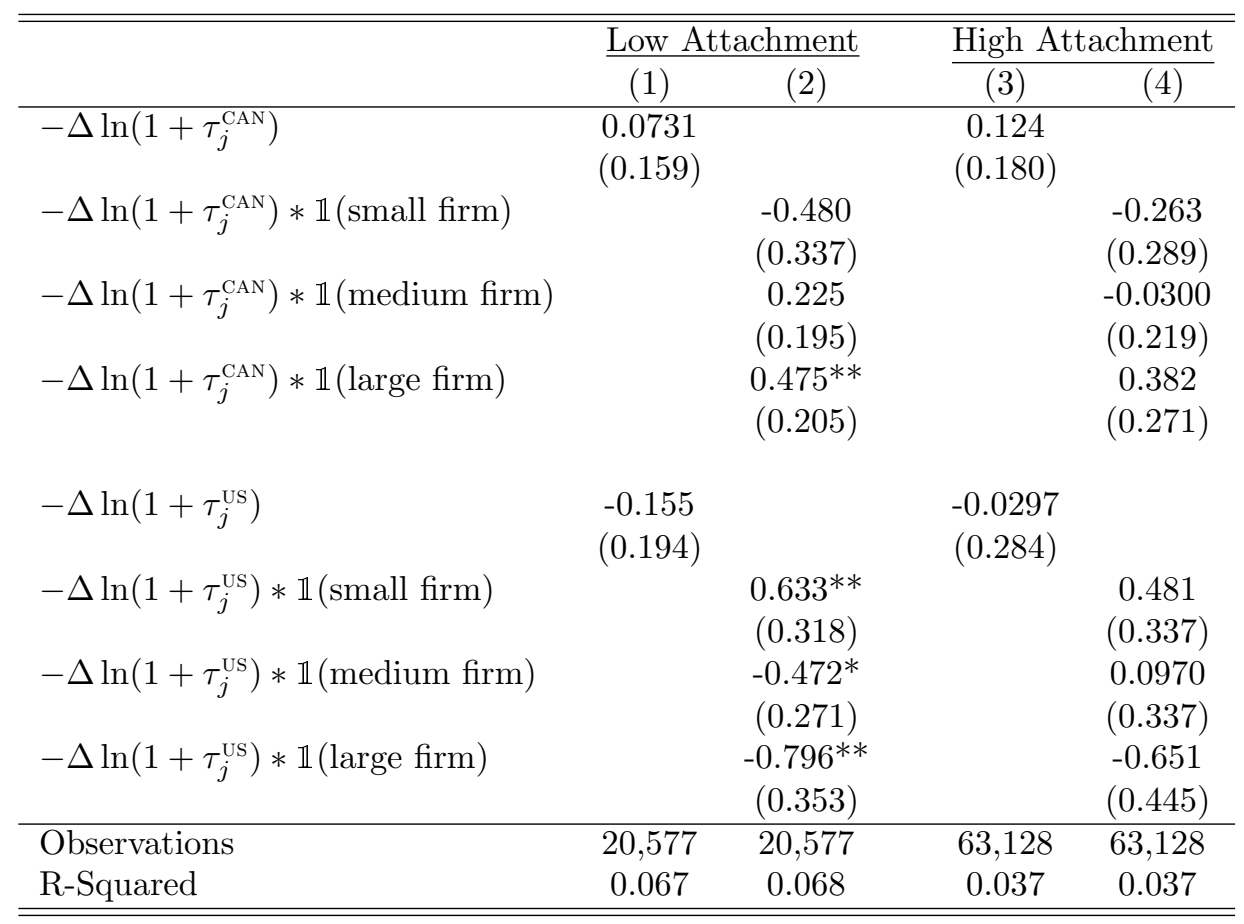

Notes: Dependent variable is an indicator for experiencing a permanent work-shortage based separation from the worker's initial firm during 1989-2003. The independent variables of interest are the 1988-1998 tariff cuts facing U.S. exports to Canada $\left(-\Delta \ln \left(1+\tau_{j}^{\mathrm{CAN}}\right)\right)$ or facing Canadian exports to the U.S. $\left(-\Delta \ln \left(1+\tau_{j}^{\mathrm{US}}\right)\right)$ in the worker's initial industry. A positive (negative) coefficient means that larger tariff cuts in the worker's initial industry lead to increased (reduced) probability of separation. Columns (1) and (3) present results of estimating equation (1) for low and high labor force attachment workers, respectively. Columns (2) and (4) present analogous regressions interacting the tariff cuts with initial firm size (small=1-99, medium=100-999, large $=1000+$ ). All specifications include extensive worker, initial firm, and initial industry controls, described in Section 4. Standard errors clustered by 4-digit NAICS industry. $* * * p<0.01, * *$ $\mathrm{p}<0.05,{ }^{*} \mathrm{p}<0.1$.

\subsection{Permanent Work-Shortage Related Separations}

We start by examining whether bilateral tariff cuts affected the likelihood of a permanent layoff.

We estimate equation (1), setting $Y_{i f j k}=1$ if worker $i$ was initially employed at firm $f$ in industry $j$, and had a permanent work-shortage related separation from initial employer $f$ between 1989 and 2003 (inclusive), and zero otherwise. ${ }^{38}$ We do this separately for low attachment and high attachment workers, with results in Table 1.

\footnotetext{
${ }^{38}$ For separations alone, we stop our analysis in 2003 for two reasons. First, we cannot tell if separations in the final year of our data set (2004) are temporary or permanent. Second, we cannot see where separated workers go in the subsequent year. We do not consider permanent separations from a firm that was not their initial employer. For example, if they quit their initial employer and then had a permanent separation from a second employer, $Y_{\text {ifjk }}=0$ for this worker. We do not consider temporary separations, as suggested by Statistics Canada. We thank René Morissette for this guidance.
} 
Columns (1) and (3) estimate homogenous effects and find the expected signs for both low and high attachment workers: increased import competition due to a Canadian tariff cut raises the probability of a permanent layoff, while increased access to the U.S. export market due to a U.S. tariff cut lowers the probability. However, neither of these effects can be statistically distinguished from zero and (as discussed below) they are very small. A possible explanation is that trade liberalization affected large and small firms differently, as predicted by standard models of firm heterogeneity and trade. For example, Melitz (2003) and Demidova and Rodríguez-Clare (2013) predict that trade liberalization reduces employment at smaller and less productive domestic firms while increasing employment at larger and more productive exporting firms. These opposite-signed effects for different size firms may therefore partly offset, potentially leading to small and statistically insignificant average effects.

With these theoretical predictions in mind, columns (2) and (4) of Table 1 interact the tariff changes with an exhaustive set of initial firm size indicators. The effects of U.S. tariff concessions on low attachment workers (column (2)) are statistically significant and consistent with standard firm heterogeneity models. Workers initially at large firms are less likely to be laid off when their industry gains freer access to the U.S. market, but workers at small firms in the same industry are more likely to be laid off. The effects for high attachment workers (column (4)) are similar, but have smaller magnitudes and larger standard errors leading to insignificant estimates. These results are consistent with the empirical findings of Trefler (2004) and Lileeva (2008) who find positive effects of U.S. tariff concessions for Canadian exporters but negative effects for Canadian non-exporters. ${ }^{39}$

Turning to Canadian tariff cuts, we find displacement effects that are concentrated among workers initially employed at large firms, with statistically significant increases in separations for low attachment workers (column (2)). This pattern of heterogeneity runs counter to standard models of heterogeneous firms, which predict employment reductions at small firms when facing increased import competition. Yet, our finding parallels similar results in prior empirical work on the effects of the CUSFTA in Canada (Head and Ries, 1999; Baldwin et al., 2001; Baldwin and

\footnotetext{
${ }^{39}$ See Trefler (2004) pg. 858. The Canadian Annual Survey of Manufactures contains plant-level export data while the matched T2-LEAP-LWF data set used here does not.
} 
$\mathrm{Gu}, 2004$; Lileeva, 2008) and more recently on the effects of Chinese import competition in the U.S. (Autor et al., 2013b; Holmes and Stevens, 2014; Pierce et al., 2020), each of which finds larger effects of import competition at large firms. ${ }^{40}$

We now assess the magnitudes of these results by comparing the predicted layoff probabilities for workers whose initial industries faced tariff cuts at the $75^{\text {th }}$ percentile vs. the $25^{\text {th }}$ percentile of the tariff cut distribution. This interquartile range is 6.4 log points for Canadian tariff cuts and 2.4 log points for U.S. tariff cuts. ${ }^{41}$ We focus on the effects for workers at large firms, as these generally have the largest magnitudes. The estimates in column (2) suggest that low attachment workers at large firms facing larger Canadian tariff cuts had a 3 percentage point higher probability of separation than otherwise similar workers in less affected industries. This difference is an 18 percent increase over the unconditional mean separation rate of 17 percent during 1989-2003. ${ }^{42}$ Low attachment workers initially at large firms who faced larger U.S. concessions had a 1.9 percentage point (11 percent) lower probability of separation. The effects for high attachment workers at large firms are smaller than those for low attachment workers and are statistically insignificant. The interquartile difference in Canadian tariff cuts increased the separation probability by 2.4 percentage points relative to a mean separation probability of 11.5 percent. The stabilizing effect of U.S. concessions is more comparable to that of low attachment workers at approximately 1.6 percentage points. ${ }^{43}$

While the effects of the change in bilateral policy on separations for workers initially at large firms are nontrivial, the homogenous effects in columns (1) and (3) of Table 1 are much smaller. Our subsequent results will reinforce the conclusion that the bilateral tariff cuts had relatively small

\footnotetext{
${ }^{40}$ Lileeva (2008) finds that Canadian concessions tend to decrease the number of plants at multi-plant firms, especially those that produce goods outside the core competency of the firm. Baldwin and Gu (2004) document plant closure at multi-plant firms, while Baldwin et al. (2001) document a substantial increase in the degree of specialization of multi-plant firms across four-digit (SIC) manufacturing industries after the signing of the CUSFTA. See Lileeva (2008), especially pg. 378-379, for additional detail.

${ }^{41}$ These cuts differ slightly from those in Figure A1 because these correspond to percentiles in our worker sample. To avoid disclosure concerns, the reported interquartile ranges reflect the difference in mean tariff cut in narrow windows around the $75^{\text {th }}$ and $25^{\text {th }}$ percentiles.

$42 \frac{0.064 * 0.475}{0.17}=0.179$

${ }^{43}$ For completeness, an interquartile comparison of Canadian tariff concessions increases the mean probability of separation by 0.5 percentage point ( 2.8 percent) and 0.8 percentage point $(6.9$ percent $)$ for low and high attachment workers, respectively, while the same comparison for U.S. concessions reduces the mean probability of separation by 0.3 percentage points ( 2.2 percent) and 0.1 percentage point ( 0.6 percent) for the same groups, respectively.
} 
overall labor market effects. ${ }^{44}$ The remainder of this section presents homogenous effects of the tariff cuts on additional outcomes, while Section 6 returns to the topic of heterogeneous worker responses across firm sizes and within-industry reallocations.

\subsection{Years Worked}

Did these bilateral cuts and their ensuing changes in worker separations affect the total number of years affected individuals worked? To answer this question, we estimate equation (1) in which the dependent variable is the number of years in 1989-2004 with strictly positive earnings. Table 2 presents results for low attachment workers in Panel A and for high attachment workers in Panel B. In column (1) we estimate the effect on total years worked, while in columns (2)-(9) we additively decompose this overall effect into years at the initial firm of employment, at other firms in the same 4-digit NAICS industry, in other manufacturing industries, in construction, mining, agriculture, services, and in firms with missing industry codes, respectively. ${ }^{45}$ Because the maximum potential years worked is the same for all workers (16), the effect of tariff cuts on years unemployed is equal to the estimated coefficient in column (1) times negative one.

Again we find small overall effects: the bilateral cuts did not lead to substantial effects on years worked for either type of worker (column 1). However, these small overall effects reflect offsetting effects on time spent in different employment situations. Low attachment workers facing larger Canadian tariff cuts spent less time employed at their initial firm (column 2) or employed at other firms in their initial industry (column 3). This lost time was largely made up for with more time in other manufacturing industries (column 4), construction (column 5), and services (column 8). Low attachment workers facing larger U.S. tariff cuts spent more time employed at their initial firm and at other firms in the same industry, but this was offset by reductions in time spent employed in other

\footnotetext{
${ }^{44}$ Appendix Table A3 further reinforces a causal interpretation of the findings in Table 1 by showing qualitatively different results for non-layoff separations (firing, quits, etc.), ruling out various potential sources of spurious correlations between the tariff cuts and labor supply. In Appendix Tables A9-A11, we also present results for separations, years worked, and cumulative earnings controlling for the tariff cuts facing Mexican imports to Canada under NAFTA, yielding similar conclusions to our main results. While separations results are less precise in some specifications, estimated coefficients of interest for years worked and earnings are larger and more precisely estimated.

${ }^{45}$ See the Table 2 notes for details on the firm/industry category definitions.
} 
Table 2: Years Worked (1989-2004)

\begin{tabular}{|c|c|c|c|c|c|c|c|c|c|}
\hline & $\begin{array}{c}(1) \\
\text { Total }\end{array}$ & $\begin{array}{c}(2) \\
\text { Initial Firm }\end{array}$ & $\begin{array}{c}(3) \\
\text { Initial Ind. }\end{array}$ & $\begin{array}{c}\text { (4) } \\
\text { Manuf. }\end{array}$ & $\begin{array}{c}(5) \\
\text { Constr. }\end{array}$ & $\begin{array}{c}\text { (6) } \\
\text { Mining }\end{array}$ & $\begin{array}{c}(7) \\
\text { Agric. }\end{array}$ & $\begin{array}{c}(8) \\
\text { Services }\end{array}$ & $\begin{array}{c}(9) \\
\text { Unknown }\end{array}$ \\
\hline \multicolumn{10}{|c|}{ Panel A: Low Attachment $(\mathrm{n}=20,577)$} \\
\hline$-\Delta \ln \left(1+\tau_{j}^{\mathrm{CAN}}\right)$ & $\begin{array}{l}-1.013 \\
(1.284)\end{array}$ & $\begin{array}{c}-6.477^{* *} \\
(2.701)\end{array}$ & $\begin{array}{l}-2.661 \\
(1.712)\end{array}$ & $\begin{array}{c}2.598 \\
(1.766)\end{array}$ & $\begin{array}{c}1.635^{* *} \\
(0.766)\end{array}$ & $\begin{array}{c}0.467 \\
(0.358)\end{array}$ & $\begin{array}{l}-0.657 \\
(0.549)\end{array}$ & $\begin{array}{c}4.014^{* *} \\
(1.567)\end{array}$ & $\begin{array}{c}0.0686 \\
(0.0445)\end{array}$ \\
\hline$-\Delta \ln \left(1+\tau_{j}^{\mathrm{US}}\right)$ & $\begin{array}{l}-3.030 \\
(2.319)\end{array}$ & $\begin{array}{c}4.551 \\
(3.884)\end{array}$ & $\begin{array}{c}6.807^{* *} \\
(3.064)\end{array}$ & $\begin{array}{c}-9.483^{* * *} \\
(2.844)\end{array}$ & $\begin{array}{c}0.841 \\
(1.731)\end{array}$ & $\begin{array}{l}-0.181 \\
(0.576)\end{array}$ & $\begin{array}{c}-0.0663 \\
(0.993)\end{array}$ & $\begin{array}{l}-5.425^{*} \\
(2.955)\end{array}$ & $\begin{array}{l}-0.0728 \\
(0.0689)\end{array}$ \\
\hline R-squared & 0.096 & 0.132 & 0.048 & 0.048 & 0.046 & 0.022 & 0.027 & 0.062 & 0.008 \\
\hline \multicolumn{10}{|c|}{ Panel B: High Attachment $(\mathrm{n}=63,128)$} \\
\hline$\overline{-\Delta \ln \left(1+\tau_{j}^{\mathrm{CAN}}\right)}$ & $\begin{array}{c}2.338^{*} \\
(1.206)\end{array}$ & $\begin{array}{l}-1.602 \\
(4.364)\end{array}$ & $\begin{array}{c}-2.899^{*} \\
(1.724)\end{array}$ & $\begin{array}{c}4.907 \\
(3.254)\end{array}$ & $\begin{array}{c}0.955 \\
(0.737)\end{array}$ & $\begin{array}{c}0.460 \\
(0.427)\end{array}$ & $\begin{array}{c}-0.588^{*} \\
(0.325)\end{array}$ & $\begin{array}{c}1.054 \\
(1.410)\end{array}$ & $\begin{array}{c}0.0521 \\
(0.0368)\end{array}$ \\
\hline$-\Delta \ln \left(1+\tau_{j}^{\mathrm{US}}\right)$ & $\begin{array}{l}-3.071 \\
(1.890)\end{array}$ & $\begin{array}{c}8.532 \\
(7.705) \\
\end{array}$ & $\begin{array}{c}5.095 \\
(4.677) \\
\end{array}$ & $\begin{array}{l}-9.907^{*} \\
(5.376)\end{array}$ & $\begin{array}{c}0.385 \\
(1.499) \\
\end{array}$ & $\begin{array}{l}-0.292 \\
(0.479)\end{array}$ & $\begin{array}{l}-0.734 \\
(0.522)\end{array}$ & $\begin{array}{c}-6.132^{* *} \\
(2.525)\end{array}$ & $\begin{array}{c}-0.0186 \\
(0.0616)\end{array}$ \\
\hline R-squared & 0.058 & 0.102 & 0.035 & 0.042 & 0.022 & 0.028 & 0.015 & 0.061 & 0.004 \\
\hline
\end{tabular}

Notes: Dependent variable is the number of years worked (with nonzero earnings) during 1989-2004. The independent variables of interest are the 1988-1998 tariff cuts facing U.S. exports to Canada $\left(-\Delta \ln \left(1+\tau_{j}^{\mathrm{CAN}}\right)\right)$ or facing Canadian exports to the U.S. $\left(-\Delta \ln \left(1+\tau_{j}^{\mathrm{US}}\right)\right)$ in the worker's initial industry. A positive (negative) coefficient means that larger tariff cuts in the worker's initial industry lead to increased (decreased) years worked. Column (1) examines total years worked, (2) years worked at the initial firm, (3) at firms other than the initial firm, but in the same initial 4-digit industry, (4) in manufacturing industries (NAICS=3xxx) other than the initial industry, (5) in construction (NAICS $=22 x x, 23 x x),(6)$ in mining (NAICS $=21 x x),(7)$ in agriculture (NAICS $=1 \mathrm{xxx}$ ), (8) in services (NAICS $\geq 4 \mathrm{xxx}$ ), or (9) in a firm with unknown industry code. Each worker-year is assigned to only one category in columns (2) through (9) based on the primary (highest-earning) job, so the coefficients in columns (2) through (9) sum to the overall effect in column (1). All specifications include extensive worker, initial firm, and initial industry controls, described in Section 4. Standard errors clustered by 4-digit NAICS industry. ${ }^{* * *} \mathrm{p}<0.01,{ }^{* *} \mathrm{p}<0.05,{ }^{*} \mathrm{p}<0.1$.

manufacturing industries and in services. Results for high attachment workers are qualitatively similar except that the effect of Canadian tariff cuts on years worked at the initial firm is muted, and the effects of U.S. concessions are less precisely estimated in most cases. These findings provide direct evidence that Canadian workers offset gains or losses in employment in the initial firm or industry by moving across firms, industries, and sectors in response to the tariff changes.

Figure 3 presents the magnitude interpretation for the effects in Table 2 and also shows how the effects evolved over time. We explain the layout of Panel (a) in detail, as other panels and subsequent figures are interpreted similarly. The black bars correspond to the results in Table 2, examining years worked during 1989-2004. The height of each bar represents the predicted change in the outcome for an interquartile difference in tariff cuts, expressed as a share of the unconditional mean outcome for the relevant group. For example, the interquartile difference in Canadian tariff cut reduced low attachment workers' years worked at the initial firm by 0.41 years $(=-6.477 \cdot 0.064)$. 
Since the unconditional mean of years worked is 11.6 for low attachment workers, the interquartile gap in tariff cuts drove a 3.6 percent reduction in years worked at the initial firm. ${ }^{46}$ The light and medium gray bars show parallel results for the 1989-1993 and 1989-1998 periods, respectively. ${ }^{47}$ To make the results for these shorter time windows comparable to the 16-year window 1989-2004, we multiply the predicted values by 16 over the window length to predict the effect magnitude that would have been observed if it had persisted for 16 years. ${ }^{48}$ Stars represent whether the associated regression estimate is statistically different from zero at the $1\left(^{* * *}\right), 5\left(^{* *}\right)$, or $10\left(^{*}\right)$ percent level.

The results in Figure 3 suggest that the effects of the FTA gradually grew over time. ${ }^{49}$ Examining the Initial Firm bars in Panel (a), an interquartile difference in Canadian tariff cut induces a 2.3 percent reduction in years worked at the initial firm between 1989 and 1993, and a 3.6 percent reduction between 1989 and 2004. Because these are scaled to 16-year equivalents, this difference is not driven by the longer time window for 2004. Yet, as with the separation results, the magnitudes are small: an interquartile difference in Canadian tariff concessions induces only 5 fewer months employed at the initial firm over 16 years. Offsetting this small effect are more years spent in other manufacturing industries, construction, and services. Because it takes time for workers to shift into these other industries, the magnitude of the overall reduction in years worked in Panel (a) falls by more than half from 1993 to 2004 (from -1.4 to -0.6 percent).

Panel (b) presents the effect of U.S. concessions. As expected, most signs are reversed relative to Panel (a): a worker more exposed to larger U.S. concessions worked more years at the initial firm and in the initial industry, and fewer years in other sectors. Panels (c) and (d) present results for high attachment workers. As with separations, the estimates for high attachment workers are generally somewhat smaller than for low attachment workers, particularly for years worked at the initial firm and industry, and many are indistinguishable from zero.

\footnotetext{
${ }^{46}$ These estimates correspond to the second black bar from the left in panel (a) of Figure 3.

${ }^{47}$ The associated regression results for these shorter time periods appear in Appendix Tables A4 and A5.

${ }^{48}$ Specifically, we multiply the $1989-1993$ values by $16 / 5$, and the $1989-1998$ by $16 / 10$.

${ }^{49}$ This is consistent with the results of Besedes et al. (2020) who find gradual increases in trade in response to the CUSFTA, even in industries in which tariffs immediately went to zero.
} 

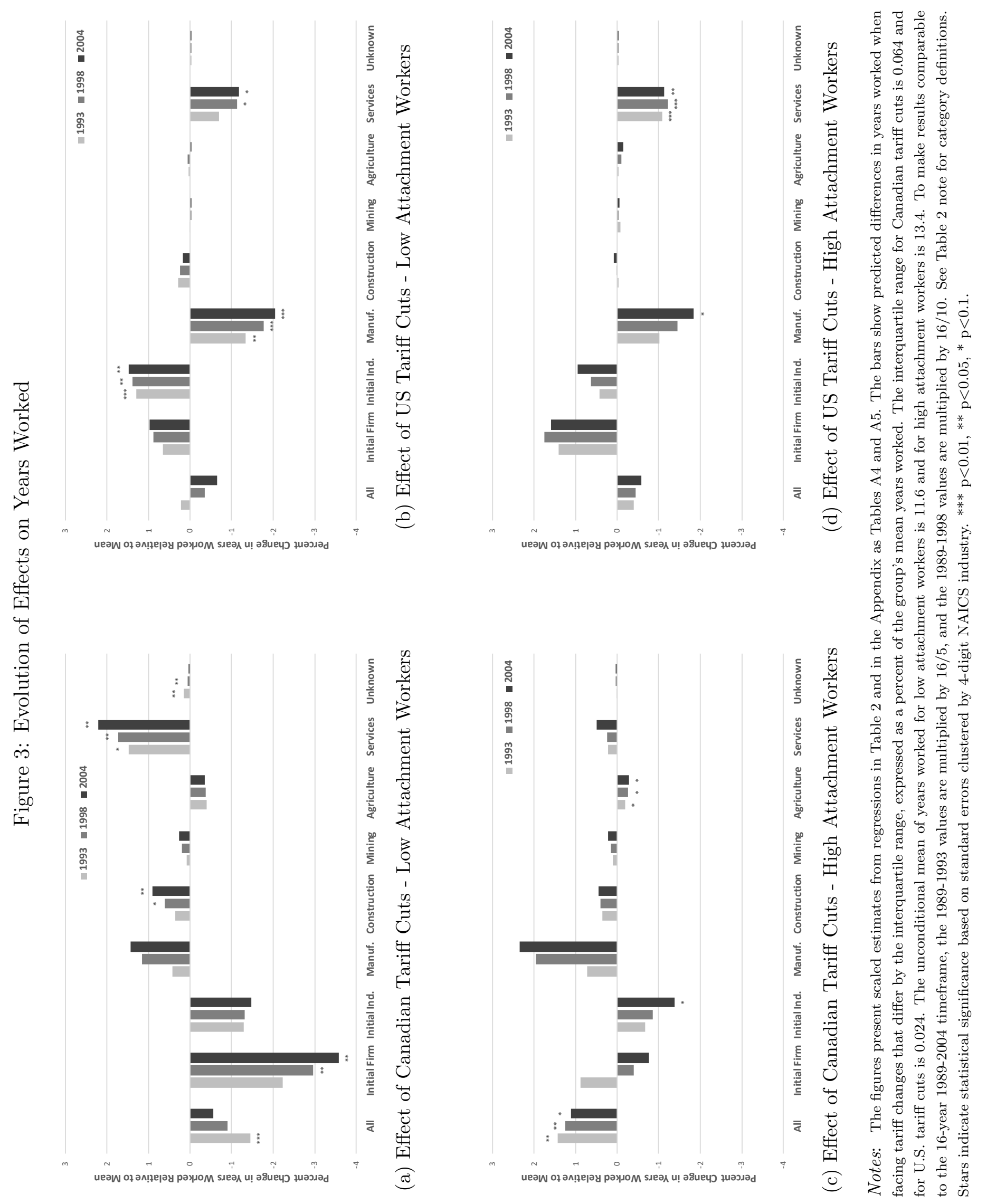


\subsection{Cumulative Earnings}

We now examine the effects of the bilateral CUSFTA tariff cuts on cumulative earnings of Canadian workers. Recall that the cumulative normalized earnings measure is defined in equation (2) as total earnings during the relevant period divided by the worker's average yearly earnings in the pre-FTA period. The mean cumulative normalized earnings during 1989-2004 is 21.01 for low attachment workers and 14.64 for high attachment workers. This means that low attachment workers earned 21 times their initial yearly earnings during 1989-2004, while high attachment workers earned 14.6 times their initial yearly earnings. This difference partially reflects the fact that low attachment workers tended to be younger in 1988 and hence were on a steeper portion of their lifecycle earnings profile (Mincer, 1974; Lemieux, 2006). We estimate equation (1) with cumulative normalized earnings as the dependent variable, and present regression results in Appendix Tables A6-A8 and associated magnitudes in Figure 4.

Figure 4 is constructed in the same way as Figure 3, showing differences in predicted cumulative normalized earnings for workers facing interquartile differences in tariff changes as a proportion of the unconditional average outcome, scaled to make the different timeframes comparable. As with years worked, we find earnings adjustments that intensify over time but with small and statistically insignificant effects on long run earnings for both worker types. ${ }^{50}$ Significant earnings losses at low attachment workers' initial firms in response to Canadian tariff cuts (Panel a) are consistent with a heightened probability of separation from the initial firm in Table 1 and reductions in years worked at the initial firm in Figure 3. This negative effect of Canadian concessions on initial-firm income is substantially offset by higher earnings in other manufacturing industries, construction, and services, consistent with workers successfully transitioning across industries and sectors to make up for earnings losses at the initial firm. Comparing the overall effects in Panel (a) of Figures 3 and 4, we see that although low attachment workers facing larger Canadian tariff cuts steadily recover

\footnotetext{
${ }^{50}$ To map our regression results to this figure, consider the black bar for "All Earnings" in Panel (a) of Figure 4. The associated regression coefficient in Appendix Table A8 is -6.142. Multiplying by the interquartile Canadian tariff cut of 0.064 and dividing by low attachment workers' mean cumulative normalized earnings of 21.04 yields -1.86 percent, shown in the figure.
} 

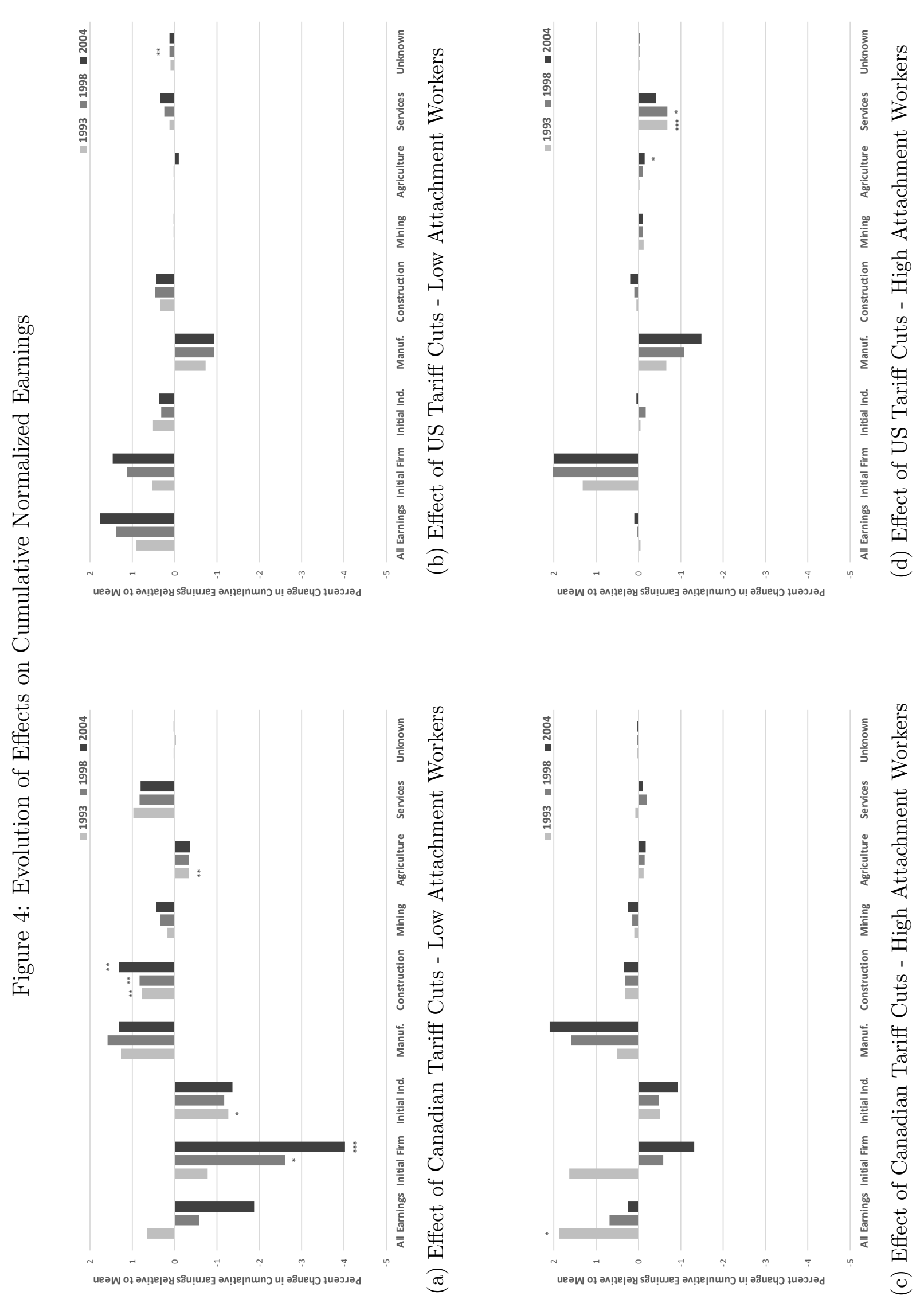

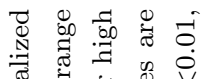

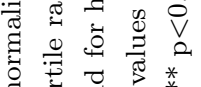

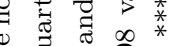
颌 当

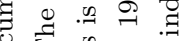
$\exists$ F

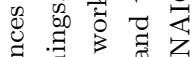
跣 원 范 च

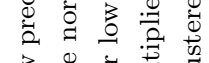

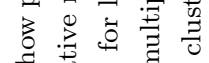

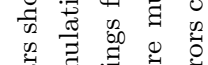
界署 월 $\infty$. क ४

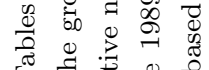

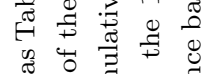
츨 㻤 요의 स 啳

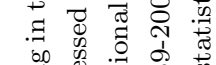

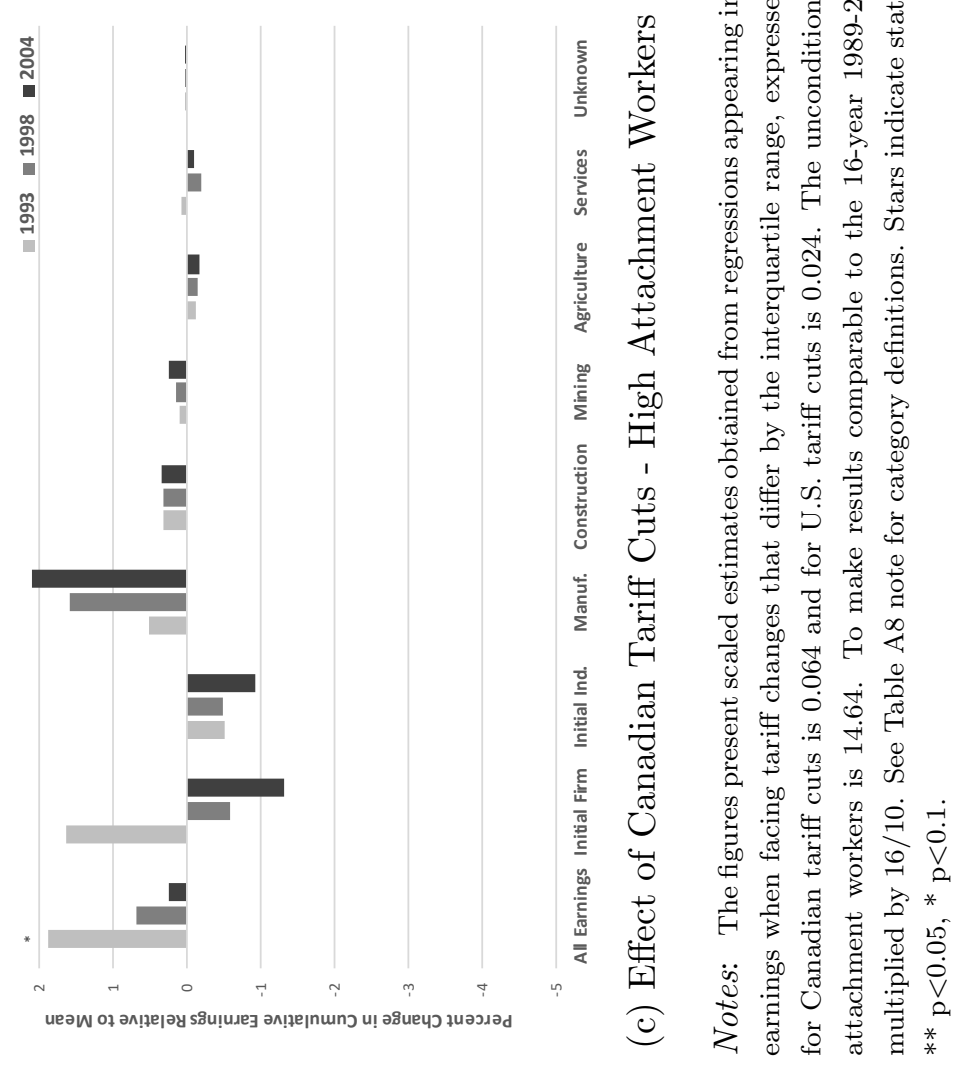


over time in terms of years worked as they transition across industries and sectors, their relative earnings effects fall over time, showing that transitions do not fully offset the lost earnings in the initial firm. That said, the overall earnings effects of import competition remain quite small at all time horizons. Estimates for the effect of U.S. concessions in Panel (b) are small and generally indistinguishable from zero.

For high attachment workers (Panels c and d), we find little overall effect on long run earnings, although the effects on initial firm earnings have the expected signs. These small and statistically insignificant results for high attachment workers contrast sharply with those of Autor et al. (2014), who find inter-quartile effects of the China shock on high attachment U.S. workers' earnings that are more than an order of magnitude larger than those we find for Canadian workers. ${ }^{51}$

\subsection{Low Income and High Income Workers}

In this section, we examine years worked and cumulative earnings separately by workers' initial income rather than by labor force attachment. This alternative split allows us to directly examine the effects of the CUSFTA on earnings inequality among initial manufacturing workers. We split workers into terciles based on their pre-FTA average yearly income $\left(\bar{E}_{i, 88-86}\right.$ in $\left.(2)\right)$ and run separate regressions for workers in the top and bottom terciles. ${ }^{52}$ The regression results appear in Appendix Tables A12-A17 and the magnitude figures for years worked and cumulative earnings are in Appendix Figures A3 and A4, respectively.

Comparing the effects on years worked in Figures A3 and 3, we find nearly identical impacts for low income and low attachment workers, while the effects are qualitatively similar but somewhat larger in magnitude for high income workers than for high attachment workers. Low income workers are employed for fewer years overall in response to Canadian concessions; this overall effect is driven by fewer years worked in the initial firm and industry, which are only partially offset by more years

\footnotetext{
${ }^{51}$ An inter-quartile difference in the U.S. China shock led to an average reduction in earnings equivalent to 38 percent of initial annual earnings (Autor et al. (2014), p.1816). The same calculation using our overall earnings effect for high attachment workers in column (1), row 3 of Table A8 (0.542) and the inter-quartile difference in Canadian tariff cuts (0.064) yields an average earnings reduction of only 3.5 percent of initial annual earnings. Note that both papers examine cumulative earnings over a 16-year time horizon, so the results are comparable.

${ }^{52}$ Results for the middle tercile are roughly a mixture of results for the top and bottom terciles.
} 
working in services. For high income workers, fewer years worked in the initial industry are more than offset elsewhere elsewhere in manufacturing. U.S. tariff concessions lead low income workers to spend more years in their initial firm and industry, with this effect almost exactly offset by fewer years in manufacturing and services. For high income workers, more years at the initial firm are offset by fewer years at other firms in the initial industry, elsewhere in manufacturing, and in services.

Comparisons of the cumulative earnings effects in Figures A4 and 4 again yield very similar conclusions. Low attachment and low income workers have very similar patterns and magnitudes of effects. High income workers and high attachment workers also have similar patterns of effects, but high income workers often exhibit larger magnitudes, particularly in terms of increased earnings from other manufacturing industries when facing larger Canadian tariff cuts and increased earnings from the initial firm when facing larger U.S. tariff cuts.

These results emphasize the close link between workers' initial income and their degree of labor force attachment and reinforce our earlier findings that stratified by labor force attachment. They also make explicit the effects of the FTA tariff cuts on earnings inequality. Based on the long-run point estimates for total earnings, Canadian tariff cuts exacerbated earnings inequality by slightly reducing low income workers' long-run earnings and slightly raising them for high income workers, while U.S. tariff cuts reduced earnings inequality by raising low income workers' earnings more than those of high income workers. Yet, none of these point estimates is statistically significantly different form zero, and all are quantitatively small (less than 3 percent), so the FTA likely had minimal effects on manufacturing workers' earnings inequality.

\subsection{Understanding Our Results}

In the preceding subsections, we find small and (on average) offsetting effects of Canadian and U.S. tariff cuts on the probability of permanent layoff from the worker's initial firm, on total years worked, and on cumulative earnings of low and high attachment workers. Although low attachment and low income workers facing larger Canadian tariff cuts experienced meaningful reductions in time 
employed at their initial firm and had reduced earnings from that firm, these losses were largely offset by higher levels of income in other sectors, suggesting relatively smooth transitions between firms and industries.

These modest effects and smooth transitions stand in contrast to a large literature finding substantial and persistent consequences of job displacement, including pioneering work on mass layoffs by Jacobson et al. (1993). They also contrast with more recent research on the effects of trade on workers' labor market outcomes, including Autor et al. (2014) and Dix-Carneiro and Kovak (2017). Both papers find large and growing effects of import competition over long periods of time, suggesting slow and costly worker transitions into more favorable employment situations. ${ }^{53}$

To help understand these contrasting results, this subsection begins by ruling out three potential explanations for our findings: i) FTA tariff changes were too small to drive substantial effects, ii) U.S. and Canadian tariff changes offset within each industry, and iii) Canada's industrial geography facilitated transitions across industries. We then present three empirical results that, while not directly revealing what primitive features of the Canadian context facilitated worker adjustment, do explain how that adjustment occurred. First, Canadian workers moved quickly from industries facing large increases in competition to industries facing smaller shocks. Second, the CUSFTA tariff changes did not induce mass layoffs. Third, industry employment responded to the tariff cuts primarily by reducing the number of new hires.

Shock Size: Were the FTA tariff cuts too small to have substantial effects on Canadian workers? Figure 1 shows that U.S. import penetration in Canada grew by 40 percentage points during our outcome period of 1988-2004. This was more than 4 times larger than the growth in Chinese import penetration in Canadian during this period and the growth in Chinese import penetration in the U.S. during 1991-2011 (Autor et al., 2014, Table I). Moreover, Table 1 shows that the FTA tariff changes were in fact large enough to cause substantial displacement of workers. Table 4 (below)

\footnotetext{
${ }^{53}$ Our findings are more in line with a series of papers on the German labor market's response to increased trade with China and Eastern Europe, finding offsetting effects of import competition and export opportunities and relatively smooth transitions between sectors (Dauth et al., 2014, 2017, 2021). However, these papers study the effects of trade flows rather than changes in bilateral trade policy.
} 
shows that Canadian tariff cuts also reduced in overall industry employment growth. These findings together rule out the possibility that the FTA tariff cuts were too small to have meaningful labor market impacts.

Offsetting Canadian and U.S. Tariff Cuts Within Industries: Perhaps the negative effects of Canadian tariff cuts were exactly offset by favorable effects of U.S. tariff cuts within industries, so that minimal worker adjustment was required. Because we include both sets of tariff cuts in all of our analyses, if industries facing larger Canadian tariff cuts nearly always faced larger U.S. tariff cuts, there would be insufficient independent variation available to separately identify the effects of each set of cuts. This is not the case (see footnote 36). Also, sections 5.3 and 5.4 document substantial worker reallocation, which is inconsistent with perfectly offsetting shocks within industry. Finally, Appendix C.10 makes this variation explicit by showing nonzero net effects of Canadian and U.S. tariff cuts by industry. ${ }^{54}$ The wide variation in net effects across industries makes clear that while the bilateral tariff changes are correlated, they do not simply offset each other within industries.

Industrial Geography: When migration is costly, workers may be more likely to transition between industries if their local labor market is more industrially diverse. Because our longitudinal data do not include detailed geographic information, we cannot implement a standard local labor markets analysis as in Topalova (2010), Autor et al. (2013a), or Kovak (2013). Instead, Appendix C.11 uses data on the pre-FTA industrial composition of local employment to compare the industrial geography of Canada to that of the U.S. We find that i) Canadians do not live in systematically more industrially diverse labor markets, ii) Canadian workers are not systematically more likely to live in larger urban areas, and iii) locations of similar size have similar industry concentrations in the two countries. ${ }^{55}$ Moreover, Canadian industrial geography does not systematically lead

\footnotetext{
${ }^{54}$ Workers in industries like Fibre, Yarn, and Thread and Medical Equipment experience favorable net effects because they face relatively large U.S. tariff cuts and relatively small Canadian cuts, while workers in industries like Textile Furnishings and Household Appliances experience unfavorable net effects because they face relatively large Canadian tariff cuts and small U.S. cuts.

${ }^{55}$ Autor et al. (2021) find modestly larger effects of the China Shock in U.S. commuting zones with higher levels of industry employment concentration.
} 
to Canadian workers facing larger regional trade shocks when facing simulated industry-level tariff changes. While not definitive, these results suggest that industrial geography is not likely to explain the smoother cross-industry transitions that we observe in Canada relative to other contexts.

Having ruled out the preceding explanations for Canada's smooth labor market adjustment, we turn to three empirical results explaining how these relatively smooth adjustments occurred.

Speedy Transitions Away From Import Competition: Sections 5.3 and 5.4 have shown that Canadian workers whose initial industries faced larger increases in import competition shifted into other industries and sectors. Figure 5 shows that these transitions occurred quickly and that workers systematically shifted into industries facing smaller increases in import competition. The Figure divides low attachment workers into terciles based on the size of their initial industry's tariff cut and plots the average tariff cut for each group of workers in their current industry in each subsequent year. ${ }^{56}$ If workers had stayed in their initial industries, the profiles would have been flat. If cross-industry transitions were uncorrelated with industry tariff cuts, we would find evidence of mean reversion, in which the high tariff-cut tercile would decline while the low tariff-cut tercile would increase. Instead, the declining profiles for all three terciles indicate that workers systematically transitioned from relatively high-tariff industries to relatively low-tariff industries. ${ }^{57}$

Mass Layoffs: Mass layoffs lead to substantial and persistently negative labor market outcomes for affected workers (Jacobson et al., 1993; Couch and Placzek, 2010; Lachowska et al., 2020). ${ }^{58}$ In

\footnotetext{
${ }^{56}$ When calculating this average, we omit workers who are not employed in the relevant year and assign nontradable industries a tariff cut of zero. The results for high attachment workers are similar and appear in Appendix Figure A15. While the ideal approach would take into account local equilibrium spillovers from tradable to nontradable industries as in Kovak (2013), our lack of detailed geographic information precludes such an analysis.

${ }^{57}$ Autor et al. (2014) present a related analysis showing that although U.S. workers were likely to switch firms and industries in response to increased Chinese import competition, many workers moved into jobs facing similar import competition. We replicate their analysis in Appendix Figure A16 and confirm the conclusions of Figure 5: Canadian workers facing import competition due to the FTA quickly transitioned into industries facing substantially less import competition. In addition, their movements were close to what one might expect if workers moved exclusively into industries that saw no direct increase in import competition. In contrast to the U.S. experience, these relatively fast transitions help explain Canadian workers' ability to quickly recover from employment and earnings losses when their initial firms faced large Canadian tariff cuts.

${ }^{58}$ Although not focusing on mass layoffs, Morissette et al. (2013) and Stepner (2019) also find substantial income losses following general layoffs in the Canadian context.
} 
Figure 5: Average Tariff Cuts in Workers' Current Industries: Low Attachment Workers

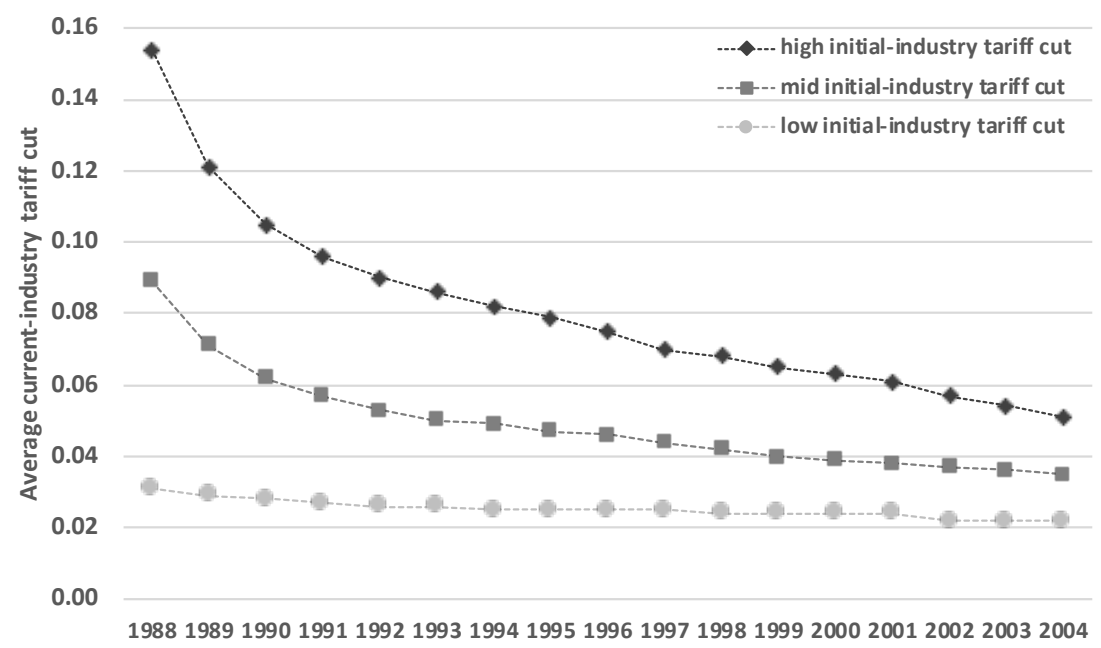

Notes: We divide manufacturing industries into terciles based on the size of the industry's Canadian tariff cut and assign workers to each tercile based on their initial industry of employment. The set of workers in each tercile bin remains fixed over time, and for each bin we plot the average total Canadian tariff cut faced by workers in their current industry of employment during the year listed on the x-axis. Non-employed individuals in a given year are omitted from that year's average, and we assign zero tariff cut to non-tradable industries. Declining profiles imply that, on average, workers transition into industries that faced smaller Canadian tariff cuts than their initial industry.

Table 3, we examine whether the CUSFTA tariff cuts altered the probability of a mass layoff at affected firms. Following Jacobson et al. (1993) we create a sample of manufacturing firms that employed at least fifty workers in 1988 and employed workers in our sample in each year between 1984 and 1988 (inclusive). ${ }^{59}$ A firm has a mass layoff if its employment fell below 70 percent of its pre-FTA (1984-88) peak in any year between 1989 and $2004 .{ }^{60}$ We then run a firm-level regression of the mass-layoff indicator on Canadian and U.S. tariff changes, their interactions with the initial firm size, and the full sets of firm and industry level controls described in Section 4. For comparison, we report the coefficient on the industry's change in Chinese import penetration in Canada (which was included as a control in all prior analyses).

Column (1) of Table 3 shows that larger Canadian tariff cuts did not increase the probability of a mass layoff, nor did larger U.S. tariff cuts reduce that probability. The point estimates have

\footnotetext{
${ }^{59}$ Again, we use the nalus definition of total firm employment.

${ }^{60}$ Results are similar using definitions based on firm exit or year-to-year employment declines.
} 
Table 3: Mass Layoffs (1989-2004)

\begin{tabular}{|c|c|c|}
\hline & $(1)$ & (2) \\
\hline$-\Delta \ln \left(1+\tau_{j}^{\mathrm{CAN}}\right)$ & $\begin{array}{l}-0.309 \\
(0.447)\end{array}$ & \\
\hline$-\Delta \ln \left(1+\tau_{j}^{\mathrm{CAN}}\right) * \mathbb{1}($ small firm $)$ & & $\begin{array}{l}-0.523 \\
(0.688)\end{array}$ \\
\hline$-\Delta \ln \left(1+\tau_{j}^{\text {CAN }}\right) * \mathbb{1}($ medium firm $)$ & & $\begin{array}{l}-0.165 \\
(0.493)\end{array}$ \\
\hline$-\Delta \ln \left(1+\tau_{j}^{\mathrm{CAN}}\right) * \mathbb{1}($ large firm $)$ & & $\begin{array}{l}-0.381 \\
(1.432)\end{array}$ \\
\hline$-\Delta \ln \left(1+\tau_{j}^{\mathrm{US}}\right)$ & $\begin{array}{l}0.0722 \\
(0.652)\end{array}$ & \\
\hline$-\Delta \ln \left(1+\tau_{j}^{\mathrm{US}}\right) * \mathbb{1}($ small firm $)$ & & $\begin{array}{l}0.876 \\
(1.025)\end{array}$ \\
\hline$-\Delta \ln \left(1+\tau_{j}^{\mathrm{US}}\right) * \mathbb{1}($ medium firm $)$ & & $\begin{array}{l}-0.239 \\
(0.619)\end{array}$ \\
\hline$-\Delta \ln \left(1+\tau_{j}^{\mathrm{US}}\right) * \mathbb{1}($ large firm $)$ & & $\begin{array}{l}-4.221 \\
(2.692)\end{array}$ \\
\hline$\Delta I P R_{j}^{\mathrm{CHN}}$ & $\begin{array}{l}0.193^{* *} \\
(0.0825)\end{array}$ & $\begin{array}{l}0.191^{* *} \\
(0.0859)\end{array}$ \\
\hline R-squared & 0.028 & 0.035 \\
\hline
\end{tabular}

Notes: These firm-level regressions examine the effects of Canadian and U.S. tariff cuts and increased Chinese import penetration on mass layoffs across 4,206 firms. The dependent variable is an indicator for having a mass layoff, defined as having at least one year in 1989-2004 in which employment falls below 70 percent of the firm's 1984-1988 peak employment (results robust to definitions based on year-to-year employment changes or firm exit). Column (1) examines overall effects, while column (2) presents the results of tariff cuts separately by firm size in 1988 (small=1-99, medium=100-999, large=1000+). All specifications include the full set of firm-level and industry-level controls described in Section 4 . Standard errors clustered by 4 -digit NAICS industry. $* * * \mathrm{p}<0.01,{ }^{* *} \mathrm{p}<0.05, * \mathrm{p}<0.1$.

the opposite sign of what one would expect, are statistically indistinguishable from zero, and have small magnitudes. For example, firms whose Canadian tariff cuts differed by the industry-level interquartile range of 0.043 have predicted mass layoff probabilities that differ by 1.3 percentage points. ${ }^{61}$ In contrast, increased Chinese import penetration drove a statistically significant increase in the probability of a mass layoff for firms in affected industries. The interquartile range for Chinese import penetration is 0.140 , implying a 2.7 percentage point larger mass layoff probability for firms facing larger China shocks. Column (2) shows that these results continue to hold when we allow the tariff-cut effects to vary by firm size. While the CUSFTA tariff changes did not induce mass layoffs, the substantial effect of the China Shock shows that Canadian labor markets were not invulnerable to trade shocks. Given how disruptive mass layoffs are to workers' employment outcomes, the lack

\footnotetext{
${ }^{61}$ This interquartile range weights industries equally, in contrast to the earlier values, which implicitly weight by employment in the worker sample.
} 
Table 4: Aggregate Industry Employment Growth (1988-2004)

\begin{tabular}{lccccc}
\hline \hline & $\begin{array}{c}(1) \\
\text { Industry } \\
\text { Employment } \\
\text { Growth }\end{array}$ & $\begin{array}{c}(2) \\
\text { Manufacturing } \\
\text { Workers }\end{array}$ & $\begin{array}{c}\text { Non-Manuf. } \\
\text { Workers }\end{array}$ & $\begin{array}{c}\text { Previously } \\
\text { Unemployed }\end{array}$ & $\begin{array}{c}\text { New } \\
\text { Entrants }\end{array}$ \\
\hline \multirow{2}{*}{$\Delta \ln \left(1+\tau_{j}^{\text {CAN }}\right)$} & $-3.816^{*}$ & -0.565 & -0.726 & $-0.285^{*}$ & $-2.241^{* *}$ \\
& $(2.131)$ & $(0.580)$ & $(0.589)$ & $(0.153)$ & $(1.112)$ \\
$-\Delta \ln \left(1+\tau_{j}^{\text {US }}\right)$ & -0.460 & -0.392 & 0.0271 & -0.0729 & -0.0225 \\
$\Delta I P R_{j}^{\text {CHN }}$ & $(3.460)$ & $(0.941)$ & $(0.956)$ & $(0.248)$ & $(1.805)$ \\
& $-0.700^{* *}$ & $-0.214^{* *}$ & -0.118 & $-0.0437^{*}$ & $-0.325^{*}$ \\
& $(0.333)$ & $(0.0906)$ & $(0.0921)$ & $(0.0239)$ & $(0.174)$ \\
\hline R-Squared & 0.404 & 0.403 & 0.299 & 0.384 & 0.469 \\
\hline \hline
\end{tabular}

Notes: These industry-level regressions examine the effects of Canadian and U.S. tariff cuts and increased Chinese import penetration on the proportional change in aggregate industry employment from 1989-2004, across 78 manufacturing industries (not restricting to workers initially in manufacturing as in earlier analyses). Column (1) examines overall industry employment growth, while columns (2)-(5) study the portion of industry employment growth accounted for by its additively separable components: (2): workers employed in manufacturing in 1988; (3): those employed outside manufacturing in 1988; (4): those employed between 1984 and 1987 , but not in 1988 ("unemployed"); and (5) those not employed between 1984 and 1988 ("new entrants"). All specifications include the dependent variable pre-trend, calculated for 1984-1987 (results are similar without this pre-trend control), and the full set of industry-level controls described in Section 4. Standard errors clustered by 4-digit NAICS industry which is equivalent to heteroskedasticity-robust for these industry-level regressions. ${ }^{* * *} \mathrm{p}<0.01,{ }^{* *} \mathrm{p}<0.05,{ }^{*} \mathrm{p}<0.1$.

of mass layoffs in response to the FTA helps explain its lack of substantial long-run effects. ${ }^{62}$

Industry Employment Growth: While the main analysis focused on workers initially employed in manufacturing, the Canadian labor market may also have adjusted through changes in employment among other workers. To examine that possibility, Table 4 studies the change in total industry employment and its components. The dependent variable in column (1) is the proportional change in total industry employment from 1988 to 2004. We then regress this growth on Canadian and U.S. tariff cuts and the full set of industry controls described in Section 4. We again report the coefficient on the industry's change in Chinese import penetration for comparison. Column (1) of Table 4 shows that both Canadian tariff cuts and increased import penetration from China substantially reduced industry-level employment growth: an interquartile increase in the Canadian tariff cut reduced employment growth by 16.4 percentage points. This is large relative to the effect of an interquartile difference in Chinese import penetration: a reduction of 9.8 percentage points.

\footnotetext{
${ }^{62}$ Unlike Head and Ries (1999) and Trefler (2004), we observe firms and not plants so that there may have still been mass layoff events at the plant level that were too small to register at the firm level.
} 
The remaining columns additively decompose overall industry growth into the portion accounted for by incumbent workers who were already employed in manufacturing in 1988 (column 2), those who were employed outside manufacturing in 1988 (column 3), those not employed in 1988 but who were observed working in previous years (column 4), and those who entered the labor force after 1988 (column 5). While the China shock affected employment growth across various margins, the effect of Canadian tariff cuts is strongly concentrated among new entrants. This adjustment among new entrants does not appear in our main analysis because of the latter's focus on individuals initially employed in manufacturing. However, this finding for entrants corroborates a pattern revealed in our main analysis: the negative effects of import competition resulting from Canadian tariff cuts are minimal among those with strong labor force attachment, and larger for low attachment workers.

Summary: The supplementary results presented here help explain the small effects of the FTA on Canadian manufacturing workers. Canadian tariff cuts did not lead to highly disruptive mass layoffs, and workers quickly transitioned from adversely affected industries to those facing smaller increases in import competition. Although Canadian tariff cuts did reduce industry employment growth, this occurred primarily among new entrants, while insulating incumbent manufacturing workers. In contrast, the China Shock in Canada increased the probability of a mass layoff and reduced employment among both incumbent workers and new entrants. This difference in effects across different shocks suggests that the Canadian labor market is not invulnerable to all trade shocks, and that labor market institutions alone are insufficient explain the relatively smooth adjustment to the FTA tariff changes documented in this paper.

\section{$6 \quad$ Firm Heterogeneity}

This section returns to the issues of firm heterogeneity raised in Section 5.2 by examining heterogeneous effects of the CUSFTA tariff cuts by initial firm size. We find evidence for within-industry reallocation of workers from small to large firms in industries with expanding export opportunities, consistent with the Melitz (2003) model and its asymmetric-country extension in Demidova and 
Rodríguez-Clare (2013). In contrast to the predictions of standard firm-heterogeneity models of trade, increased import competition drove separations primarily among workers initially at large firms, consistent with Head and Ries (1999) and Holmes and Stevens (2014). We also find that although the overall effects of the tariff cuts discussed in Section 5 are modest, one relatively small group of workers does experience substantial effects on cumulative earnings: low labor-force attachment workers initially employed at large firms. However, even for this group the adverse effects of Canadian tariff cuts and favorable effects of U.S. cuts largely offset, leading to very small net effects on average.

\subsection{Transitions}

Table 1 showed that bilateral tariff cuts affected the probability of a worker experiencing a permanent work-shorted related separation from their initial firm. Here, we additively decompose those separation results based on the worker's subsequent employment situation. We categorize workers based on their primary job in the year following displacement, so each separated worker falls in precisely one employment transition category or unemployment. ${ }^{63}$ The results of this decomposition appear in Figures 6 and 7. We present magnitude calculations comparing interquartile differences in tariff cuts, following the same procedure used in Figure 3, and the associated regression results appear in Appendix Tables A18 - A20. The first set of bars ("Total") is simply the change in layoff probability due to an interquartile comparison, while the remaining bars present the decomposition. ${ }^{64}$ Estimates suppressed by Statistics Canada due to confidentiality concerns appear with an "x".

Figure 6 shows the effects of Canadian tariff cuts. Results for workers initially at large firms (top panels) and those initially at small firms (bottom panels) tend to be mirror opposites. Canadian tariff concessions induce a higher separation probability at large firms, but a smaller probability at small firms. Separated workers at large firms did not stay in the same industry, but moved elsewhere

\footnotetext{
${ }^{63}$ Because we observe yearly earnings, we define unemployment as earning less than 1600 hours at the provincial minimum wage in the year following separation.

${ }^{64}$ The "Total" bars for 2003 correspond to the magnitude calculations for the regression estimates in Table 1. Results for workers at medium-sized firms appear in Appendix Tables A18 - A20.
} 
in manufacturing or into construction, consistent with movement into industries insulated from import competition, as documented in Figure 5. Low attachment workers at small firms (Panel c) benefit from Canadian tariff cuts through lower layoff probabilities and fewer transitions into unemployment, with similar though muted effects for high attachment workers (Panel d).

As mentioned in Section 5.2, displacement effects of import competition concentrated at large firms runs counter to standard firm heterogeneity models such as Melitz (2003) and Demidova and Rodríguez-Clare (2013), which predict employment losses at smaller firms. Our findings are more in line with empirical studies of the effects of increased import competition that find larger effects at large firms, perhaps justified by the niche market argument proposed by Head and Ries (1999) and formalized by Holmes and Stevens (2014) or the complementary product-cycle arguments of Eriksson et al. (2021). ${ }^{65}$ Yet, in spite of this increased probability of separation from their initial employers, workers at large firms reallocated relatively smoothly into other industries and did not see statistically significant increases in unemployment at the short one-year time horizon following separation.

Figure 7 examines reallocations in response to U.S. concessions. U.S. tariff cuts for low attachment workers at large Canadian firms reduced separations largely by reducing transitions into unemployment (Panel a). The opposite occurs for workers initially at small firms: there is a heightened probability of separation and transition to another firm in the same industry, into construction, or into unemployment (Panel c). This pattern is consistent with results in Trefler (2004) and Lileeva (2008) in which U.S. tariff cuts increase employment at exporters (large firms) but reduce it for non-exporters (small firms). Results for high attachment workers are similar but less precisely estimated: increased job stability at large firms is mirrored by increased transitions to other firms within the same industry for those initially employed at small firms (Panels b and d). The effects of U.S. tariff cuts therefore conform with the predictions of models of firm heterogeneity: increased access to export markets benefits larger firms able to bear the fixed costs of exporting while po-

\footnotetext{
${ }^{65}$ Examples of empirical papers finding larger effects of import competition at large firms include Head and Ries (1999), Baldwin et al. (2001), Baldwin and Gu (2004), and Lileeva (2008), for empirical analyses of the CUSFTA in Canada and Autor et al. (2013b) and Pierce et al. (2020) on Chinese import competition in the U.S.
} 


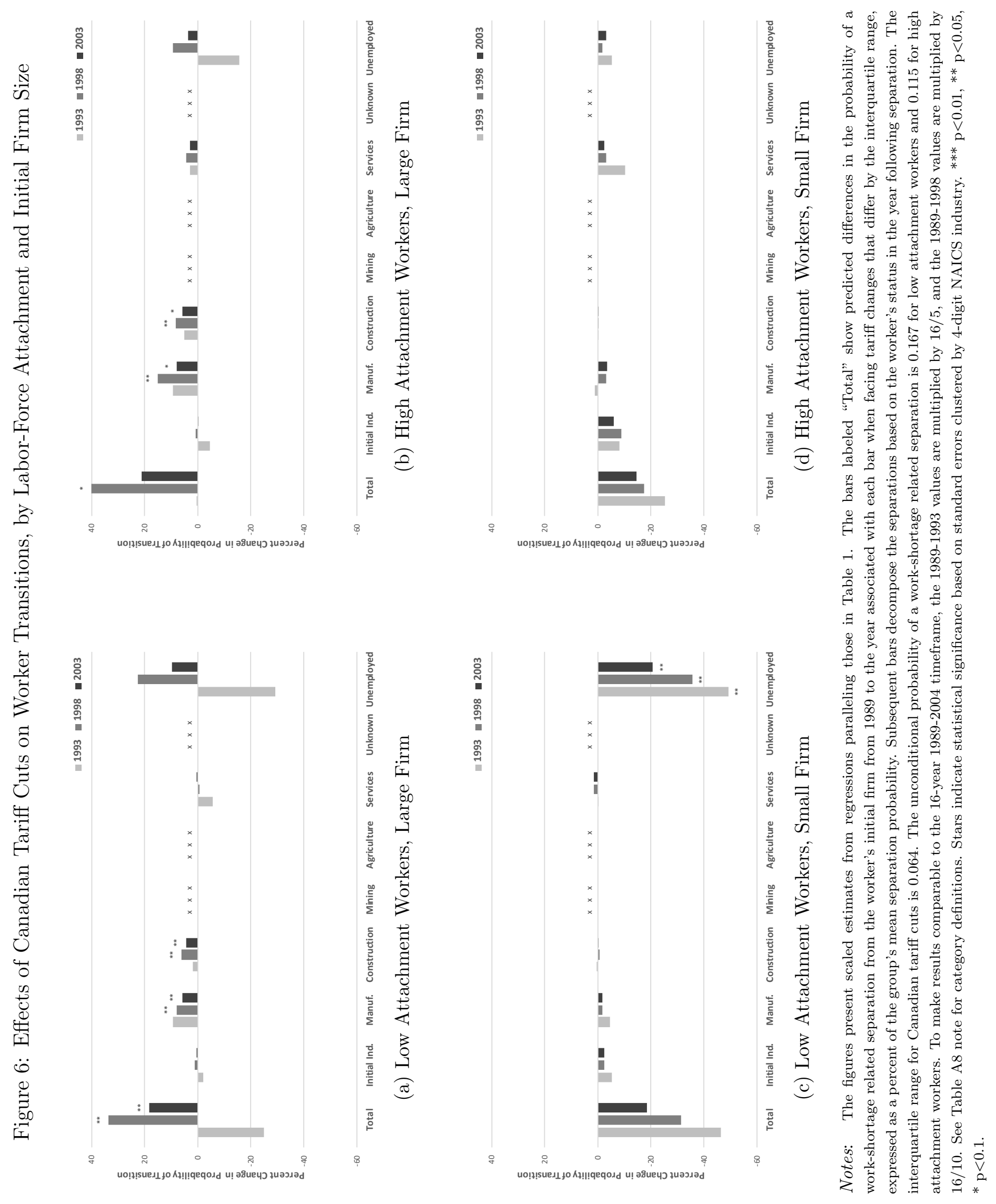




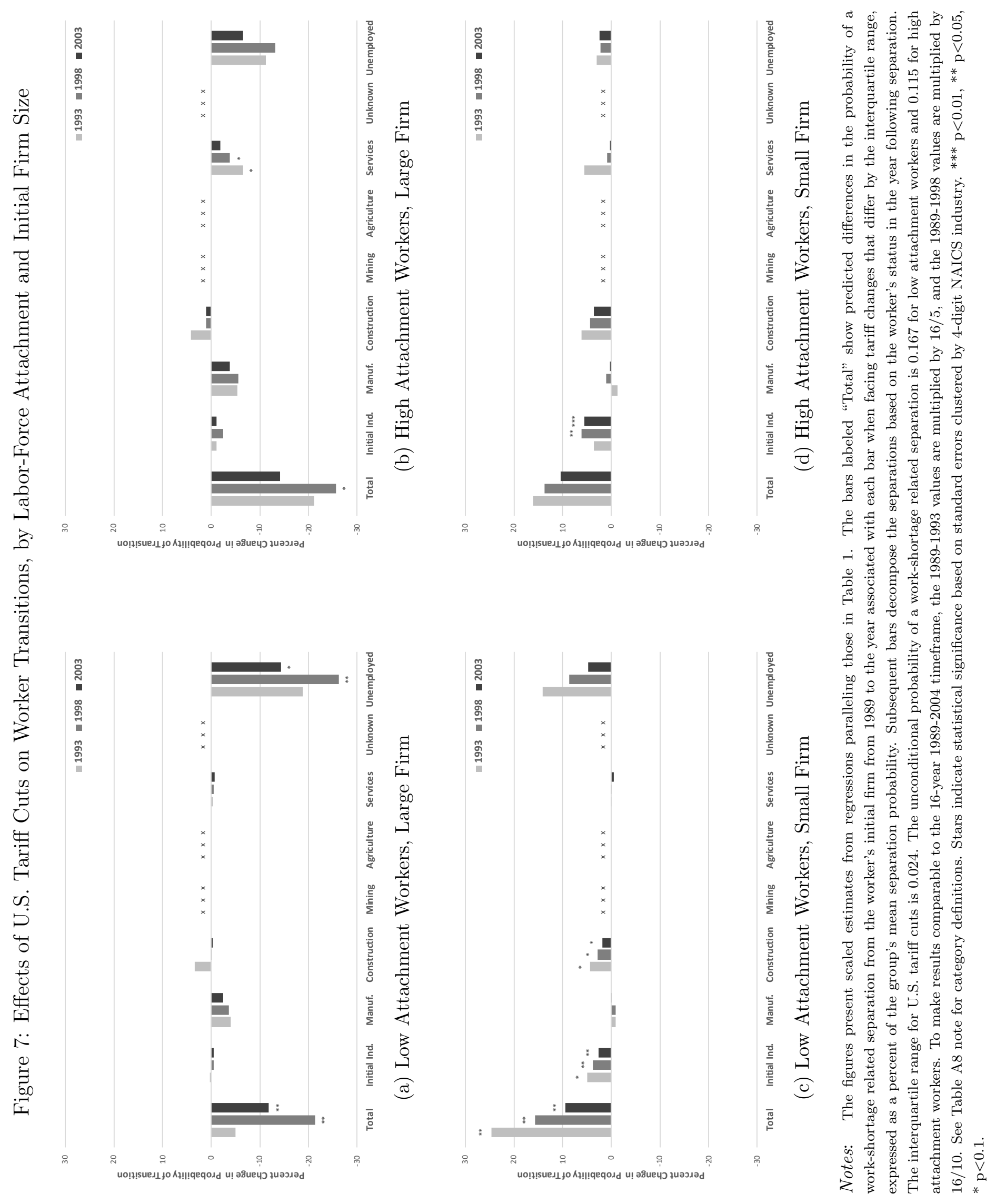


tentially heightening factor market competition that harms smaller non-exporting firms (Demidova and Rodríguez-Clare, 2013).

\subsection{Earnings}

Figures 8 and 9 examine effects on cumulative earnings for workers initially employed at large or small firms, using the same organization as Figures 6 and 7.66 Up to this point, we have emphasized the quantitatively small effects of the CUSFTA on worker outcomes. However, in Figures 8 and 9, we find meaningful effects of both Canadian and U.S. tariff cuts on the earnings of low attachment workers initially employed in large firms. Effects for these workers are substantial and grow over time in their intensity. However, income losses due to Canadian tariff cuts are still offset by gains due to U.S. tariff cuts on average, so the predicted net effects depend importantly upon the particular set of tariff cuts facing workers in each industry.

Figure 8, Panel (a) finds that an interquartile comparison of Canadian tariff concessions reduces long-run cumulative earnings by 5.3 percent for low-attachment workers initially employed at large firms. This effect is accounted for by earnings losses of 10.7 percent in the worker's initial firm and initial industry (combined), with 5.6 percent recovered through increased earnings in manufacturing, construction, and services. For low attachment workers at small firms and for high attachment workers (regardless of firm size), we find little long run effect of Canadian concessions on cumulative earnings.

Turning to the effect of U.S. concessions in Figure 9, there are larger gains (5.1 percent) for low attachment workers at large firms (Panel (a)), with the majority (3.3 percent) coming from increased initial-firm earnings. For high attachment workers at large firms (Panel (b)), we see higher initial-firm earnings offset by lower earnings at other firms in the industry. ${ }^{67}$ For workers at small firms (Panels (c) and (d)), we find little effect, irrespective of labor force attachment.

The overall earnings analysis in Figure 4 showed that, on average, Canadian workers with high

\footnotetext{
${ }^{66}$ Regression tables corresponding to these figures appear in the Appendix Tables A21-A23.

${ }^{67}$ These initial-firm earnings increases for workers at large firms gaining freer access to the U.S. market are consistent with Verhoogen's (2008) finding that more productive Mexican plants exhibited higher wage increases after an exchange rate devaluation.
} 


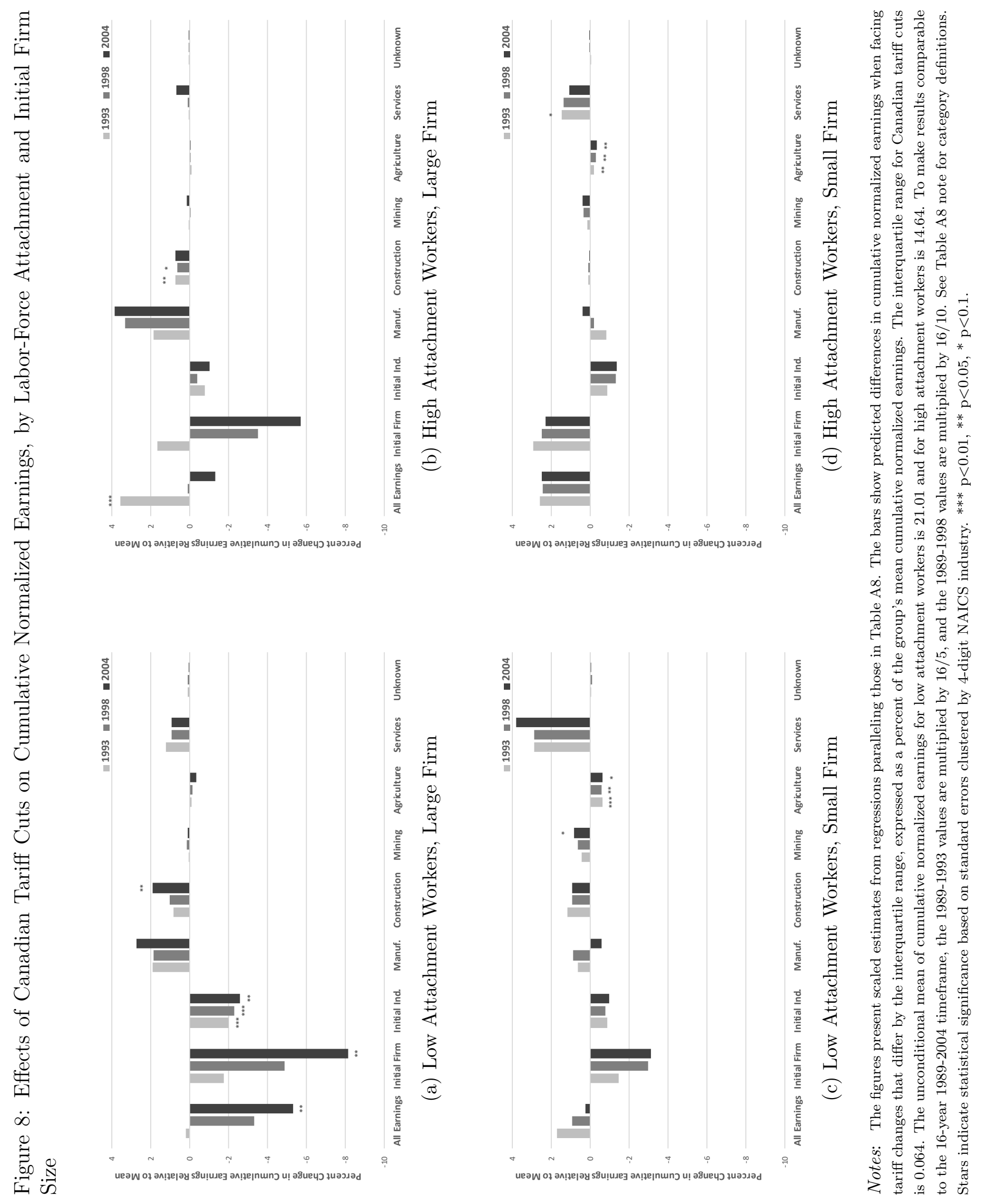




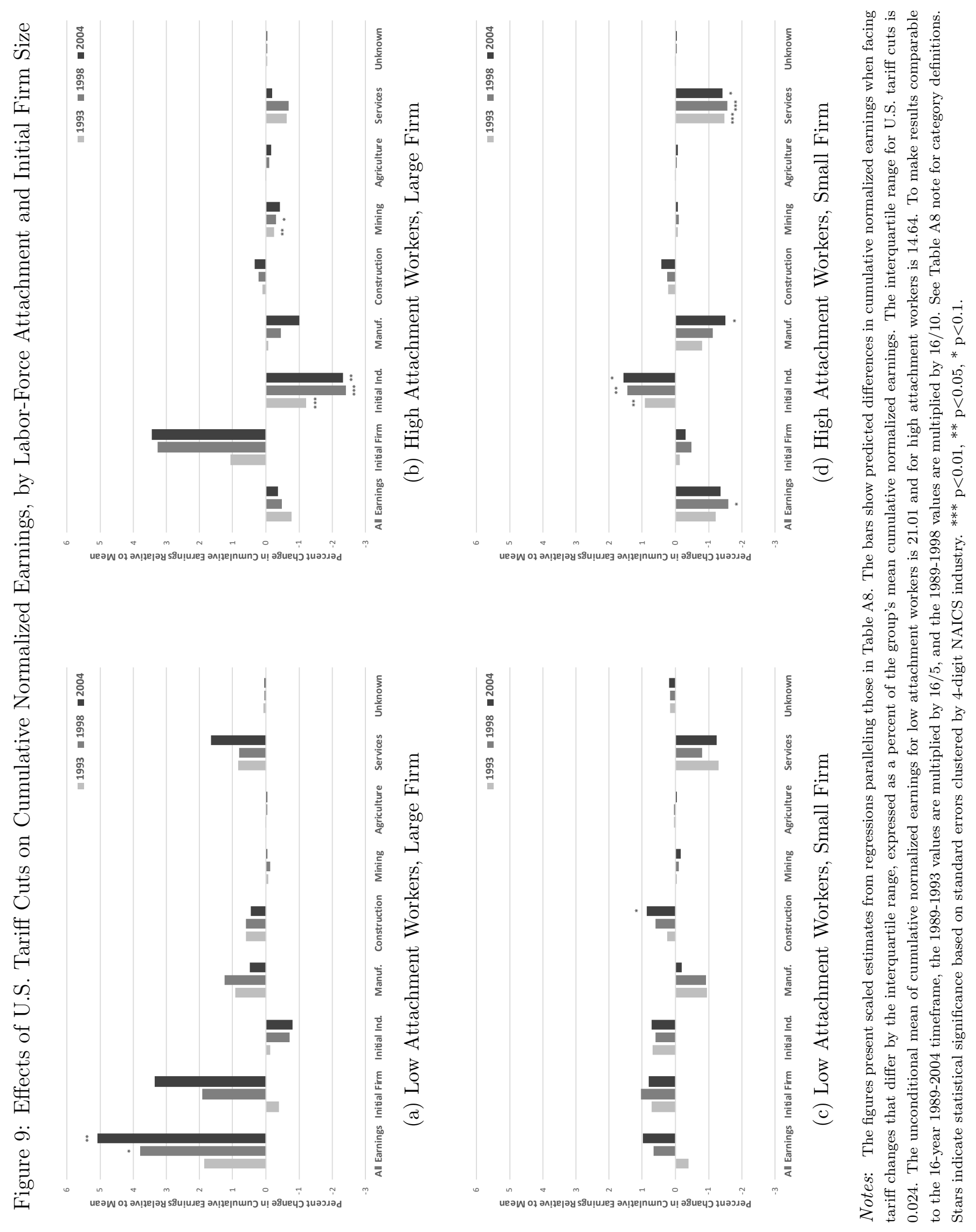


and low labor force attachment experienced relatively small effects of the CUSFTA tariff changes. The firm-size heterogenetiy analysis in Figures 8 and 9 confirms that this finding also holds for low attachment workers at small firms and for the roughly 75 percent of our sample with high labor force attachment. However, this subsection finds substantial earnings effects for the minority of our sample consisting of low attachment workers initially employed at large firms. While this nontrivial effect poses an important qualifier to our baseline analysis in Section 5, it is important to keep in mind that the effects of Canadian and U.S. tariff cuts offset each other on average, even for low attachment workers at large firms. When this group simultaneously faces interquartile differences in Canadian and U.S. tariff cuts, the predicted difference in net cumulative earnings is very close to zero: -0.2 percent $(=5.1-5.3) .{ }^{68}$

\section{Conclusion}

This paper uses 21 years of longitudinal worker-firm administrative data to examine how the bilateral tariff reductions legislated by the Canada-U.S. Free Trade Agreement affected Canadian workers. The bilateral tariff cuts had muted effects on worker outcomes. Substantial adverse effects of Canadian tariff concessions on employment and earnings at workers' initial firm of employment were generally offset by opposing effects elsewhere in the labor market, as workers transitioned into other manufacturing industries, construction, and services. Because Canadian and U.S. tariff reductions generally had opposite signs, the net effects had even smaller magnitudes on average. For example, although low attachment workers initially employed at large firms had larger magnitude effects of each country's tariff change than did other worker groups, the net effects of the FTA were still very small.

These relatively optimistic findings contrast strikingly with the prolonged effects of import

\footnotetext{
${ }^{68}$ As discussed in Section 5.6, the predicted net effect of Canadian and U.S. cuts differs by industry. Consider low attachment workers initially at large firms, as this group generally has the largest point estimates for each individual tariff change. For the separation probability and for cumulative earnings, we can only reject the null of zero net effect for 3 out of 78 industries, and the effects are generally small. However, for the net effect of tariff cuts on earnings at the worker's initial firm, we can reject the null of zero for 25 industries, all of which have negative point estimates. See Appendix Figures A5-A7.
} 
competition and mass layoffs documented in Jacobson et al. (1993), Autor et al. (2014), and DixCarneiro and Kovak (2017). To help reconcile this difference, we show that Canadian workers left affected industries quickly and that U.S. import competition did not induce mass layoffs. In addition, even though the Canadian tariff reductions and the China shock of Autor et al. (2014) in the Canadian context led to similar magnitude reductions in overall industry employment (Table 4), the tariff cuts primarily reduced the number of new hires in affected industries and had little effect on incumbent workers.

This collection of results allows us to reject certain explanations for the small effects of the CUSFTA. Figures 1 and 2 rule out the possibility that CUSFTA was simply too small to matter; if anything, it was larger than the China Shocks in Canada and the U.S. We also reject the possibility that Canadian labor markets simply respond more flexibly to all trade shocks. Tables 3 and 4 suggest this is not the case, as an interquartile difference in Chinese import penetration growth led to a 2.7 percentage point increase in the firm-level mass-layoff probability and a 9.8 percentage point slower growth in industry employment. Instead, our findings show that different trade shocks of similar magnitude can lead to quite distinct labor market outcomes, even within the same institutional context. 


\section{References}

Acemoglu, Daron, David Autor, David Dorn, Gordon H. Hanson, and Brendan Price, "Import Competition and the Great US Employment Sag of the 2000s," Journal of Labor Economics, 2016, 34 (S1), 141-198.

Autor, David, David Dorn, and Gordon H Hanson, "On the Persistence of the China Shock," Technical Report, National Bureau of Economic Research 2021.

Autor, David H., David Dorn, and Gordon H. Hanson, "The China Syndrome: Local Labor Market Effects of Import Competition in the United States," American Economic Review, October 2013, 103 (6), 2121-2168.

_ , _, and _ , "The China Shock: Learning from Labor-Market Adjustment to Large Changes in Trade," Annual Review of Economics, 2016, 8, 205-240.

_ , _ , , and Jae Song, "Trade Adjustment: Worker-Level Evidence," NBER Working Paper, 2013, (19226).

_ , _ , , and _, "Trade Adjustment: Worker-Level Evidence," The Quarterly Journal of Economics, 2014, 129 (4), 1799-1860.

Baldwin, John R and Wulong Gu, "Trade liberalization: Export-market participation, productivity growth, and innovation," Oxford Review of Economic Policy, 2004, 20 (3), 372-392.

_, Desmond Beckstead, and Richard E Caves, "Changes in the diversification of Canadian manufacturing firms (1973-1997): a move to specialization," Statistics Canada, Analytical Studies-Micro-Economic Analysis Div. Series 11F0019MIE, 2001, (179).

Baziki, Selva Bahar, Teodora Borota Milicevic, and Rita Ginja, "Import Competition and Labour Reallocation: Firm Level Evidence," working paper, 2021.

Beaulieu, Eugene, "The Canada-U.S. Free Trade Agreement and labour market adjustment in Canada," Canadian Journal of Economics/Revue canadienne economique, 2003, 33 (2), 540-563.

Besedes, Tibor, Tristan Kohl, and James Lake, "Phase out tariffs, phase in trade?," Journal of International Economics, 2020, 127, 103385.

Biscourp, Pierre and Francis Kramarz, "Employment, skill structure and international trade: Firm-level evidence for France," Journal of International Economics, 2007, 72 (1), 22-51.

Bloom, Nicholas, Kyle Handley, André Kurmann, and Philip Luck, "The impact of chinese trade on US employment: The good, the bad, and the apocryphal," in "American economic association annual meetings," Vol. 20192019.

Brambilla, Irene, Guido Porto, and Alessandro Tarozzi, "Adjusting to trade policy: evidence from US antidumping duties on Vietnamese catfish," Review of Economics and Statistics, 2012, 94 (1), 304-319. 
Breinlich, Holger, "Heterogeneous firm-level responses to trade liberalization: A test using stock price reactions," Journal of International Economics, 2014, 93, 270-285.

Chan, Jeff, "Tariffs and the composition of Employment: Evidence from the Canada-US free trade agreement," Canadian Public Policy, 2019, 45 (3), 342-365.

Chaney, Thomas, "Distorted gravity: the intensive and extensive margins of international trade," American Economic Review, 2008, 98 (4), 1707-21.

Chiquiar, Daniel, "Globalization, regional wage differentials and the Stolper-Samuelson Theorem: Evidence from Mexico," Journal of International Economics, January 2008, 74 (1), 70-93.

Copeland, Brian R, "Of Mice and Elephants: the Canada-US Free Trade Agreement," Contemporary Economic Policy, 1989, 7 (3), 42-60.

Costa, Francisco, Jason Garred, and Joao Paulo Pessoa, "Winners and losers from a commodities-for-manufactures trade boom," Journal of International Economics, 2016, 102, 5069.

Couch, Kenneth A. and Dana W. Placzek, "Earnings Losses of Displaced Workers Revisited," American Economic Review, 2010, 100 (1), 572-589.

Dauth, Wolfgang, Sebastian Findeisen, and Jens Suedekum, "The rise of the East and the Far East: German labor markets and trade integration," Journal of the European Economic Association, 2014, 12 (6), 1643-1675.

_ , _ , and _ , "Trade and Manufacturing Jobs in Germany," American Economic Review: Papers and Proceedings, 2017, 107 (5), 337-342.

_ , _ , and _ , "Adjusting to Globalization in Germany," Journal of Labor Economics, 2021, 1 (39), 263-302.

Demidova, Svetlana and Andrés Rodríguez-Clare, "The simple analytics of the Melitz model in a small economy," Journal of International Economics, 2013, 90, 266-272.

Dix-Carneiro, Rafael and Brian K. Kovak, "Trade Liberalization and Regional Dynamics,"

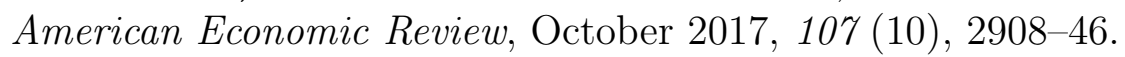

- and Brian K Kovak, "Margins of labor market adjustment to trade," Journal of International Economics, 2019, 117, 125-142.

Eckert, Fabian, Teresa C. Fort, Peter K. Schott, and Natalie J. Yang, "Imputing Missing Values in the US Census Bureau's County Business Patterns," NBER Working Paper, 2020, (26632).

Egger, Hartmut and Udo Kreickemeier, "Firm Heterogeneity And The Labor Market Effects Of Trade Liberalization," International Economic Review, February 2009, 50 (1), 187-216. 
Eriksson, Katherine, Katheryn N. Russ, Jay C. Shambaugh, and Minfei Xu, "Trade shocks and the shifting landscape of U.S. manufacturing," Journal of International Money and Finance, 2021, 114 .

Feenstra, Robert C, "U.S. Exports by TSUSA, HS, SITC, 1972-2001," Working Paper 5590, National Bureau of Economic Research March 1997.

_ , Hong Ma, and Yuan Xu, "US exports and employment," Journal of International Economics, 2019, 120, 46-58.

Felbermayr, Gabriel, Julien Prat, and Hans-Jorg Schmerer, "Globalization and labor market outcomes: Wage bargaining, search frictions, and firm heterogeneity," Journal of Economic Theory, January 2011, 146 (1), 39-73.

Flaaen, Aaron, Matthew D. Shapiro, and Isaac Sorkin, "Reconsidering the Consequences of Worker Displacements: Firm versus Worker Perspective," American Economic Journal: Macroeconomics, 2019, 11 (2), 193-227.

Forsey, Eugene A., How Canadians Govern Themselves, 10th edition ed., Library of Parliament, 2020.

Fort, Teresa C, Justin R Pierce, and Peter K Schott, "New perspectives on the decline of US manufacturing employment," Journal of Economic Perspectives, 2018, 32 (2), 47-72.

Gaston, Noel and Daniel Trefler, "The Labour Market Consequences of the Canada-U.S. Free Trade Agreement," The Canadian Journal of Economics / Revue canadienne d'Economique, 1997, 30 (1), 18-41.

Greenland, Andrew N., Mihai Ion, John W. Lopresti, and Peter K. Schott, "Using Equity Market Reactions to Infer Exposure to Trade Liberalization," NBER Working Paper, 2020, (27510).

Hakobyan, Shushanik and John McLaren, "Looking for Local Labor Market Effects of NAFTA," The Review of Economics and Statistics, October 2016, 98 (4), 728-741.

Hanson, Gordon H., "What Has Happened to Wages in Mexico since NAFTA?," NBER Working Papers 9563, National Bureau of Economic Research, Inc March 2003.

Harrigan, James and Geoffrey Barrows, "Testing the theory of trade policy: Evidence from the Abrupt End of the Multifiber Arrangement," The Review of Economics and Statistics, 2009, $91(2), 282-294$.

Harrison, Ann E., "The Changing Landscape of International Trade: Protectionism, Bashing China and the American Worker," in Federal Reserve Bank of Kansas City, ed., Fostering a Dynamic Global Economy: Jackson Hole Economic Policy Symposium, 2017, pp. 137-152.

Head, Keith and John Ries, "Rationalization effects of tariff reductions," Journal of International Economics, April 1999, 47 (2), 295-320. 
Helpman, Elhanan, Oleg Itskhoki, and Stephen Redding, "Inequality and unemployment in a global economy," Econometrica, 2010, 78 (4), 1239-1283.

Holmes, Thomas J and John J Stevens, "An alternative theory of the plant size distribution, with geography and intra-and international trade," Journal of Political Economy, 2014, 122 (2), 369-421.

Hsieh, Chang-Tai, Nicholas Li, Ralph Ossa, and Mu-Jeung Yang, "Gains from Trade with Flexible Extensive Margin Adjustment," NBER Working Papers 22069, National Bureau of Economic Research, Inc March 2016.

Hummels, David, Jakob R Munch, Lars Skipper, and Chong Xiang, "Offshoring, transition, and training: Evidence from Danish matched worker-firm data," American Economic Review, 2012, 102 (3), 424-28.

Jacobson, Louis S, Robert J LaLonde, and Daniel G Sullivan, "Earnings losses of displaced workers," The American economic review, 1993, pp. 685-709.

Kovak, Brian K, "Regional effects of trade reform: What is the correct measure of liberalization?," American Economic Review, 2013, 103 (5), 1960-76.

Lachowska, Marta, Alexandre Mas, and Stephen A. Woodbury, "Sources of Displaced Workers' Long-Term Earnings Losses," American Economic Review, 2020, 110 (10), 3231-3266.

Lemieux, Thomas, The "Mincer Equation" Thirty Years After Schooling, Experience, and Earnings, Boston, MA: Springer US,

Lester, John, Tony Morehen et al., "New estimates of Canadian tariff rates by industry and commodity," Technical Report, Department of Finance Canada 1988.

Lileeva, Alla, "Trade liberalization and productivity dynamics: evidence from Canada," Canadian Journal of Economics/Revue canadienne d'économique, 2008, 41 (2), 360-390.

- and Daniel Trefler, The Quarterly Journal of Economics, 2010, 125 (3), 1051-1099.

McCaig, Brian, "Exporting out of poverty: Provincial poverty in Vietnam and US market access," Journal of International Economics, 2011, 85 (1), 102-113.

- and Nina Pavcnik, "Export markets and labor allocation in a low-income country," American Economic Review, 2018, 108 (7), 1899-1941.

Melitz, Marc J., "The Impact of Trade on Intra-Industry Reallocations and Aggregate Industry Productivity," Econometrica, November 2003, 71 (6), 1695-1725.

Melitz, Marc J and Stephen J Redding, "Heterogeneous firms and trade," Handbook of international economics, 2014, 4, 1-54.

Mincer, Jacob, Schooling, Experience, and Earnings, Columbia University Press: New York, 1974. 
Morici, Peter, "The Environment for Free Trade," in Peter Morici, ed., Making Free Trade Work: The Canada-U.S. Agreement, New York: Council on Foreign Relations, 1990, chapter 1, pp. 1-26.

Morissette, Rene, Hanqing Qiu, and Ping Ching Winnie Chan, "The risk and cost of job loss in Canada, 1978-2008," Canadian Journal of Economics/Revue canadienne d'economique, 2013, 46 (4), 1480-1509.

Pierce, Justin R. and Peter K. Schott, "Concording U.S. Harmonized System Codes over Time," Journal of Official Statistics, 2012, 28 (1), 53-68.

_, , , and Cristina Tello-Trillo, "Trade Liberalization and Labor-Market Outcomes: Evidence from US Matched Employer-Employee Data," Unpublished manuscript, 2020.

Romalis, John, "NAFTA's and CUSFTA's Impact on International Trade," The Review of Economics and Statistics, August 2007, 89 (3), 416-435.

Sears, Robin, "The great free-trade election of 1988," Globe and Mail, October 12012.

Stepner, Michael, "The Insurance Value of Redistributive Taxes and Transfers," Unpublished manuscript, 2019.

Stolper, Wolfgang F. and Paul A. Samuelson, "Protection and Real Wages," Review of Economic Studies, 1941, 9 (1), 58-73.

Thompson, Aileen J., "The Anticipated Sectoral Adjustment to the Canada - United States Free Trade Agreement: An Event Study Analysis," Canadian Journal of Economics, 1993, 26 (2), 253-271.

Topalova, Petia, "Trade liberalization, poverty and inequality: Evidence from Indian districts," in "Globalization and poverty," University of Chicago Press, 2007, pp. 291-336.

_, "Factor immobility and regional impacts of trade liberalization: Evidence on poverty from India," American Economic Journal: Applied Economics, 2010, 2 (4), 1-41.

Trefler, Daniel, "The Long and Short of the Canada-U. S. Free Trade Agreement," American Economic Review, September 2004, 94 (4).

Utar, Hale, "When the floodgates open: Northern firms' response to removal of trade quotas on Chinese goods," American Economic Journal: Applied Economics, 2014, 6 (4), 226-50.

_ , "Workers beneath the Floodgates: Low-Wage Import Competition and Workers' Adjustment," Review of Economics and Statistics, 2018, 100 (4), 631-647.

Verhoogen, Eric A, "Trade, quality upgrading, and wage inequality in the Mexican manufacturing sector," The Quarterly Journal of Economics, 2008, 123 (2), 489-530. 


\section{Online Appendices}

(Not for publication)

$\begin{array}{ll}\text { A Tariff Data } & 54\end{array}$

B Administrative Data Construction $\quad 55$

B.1 Sample Selection . . . . . . . . . . . . . . . . . . . . . . 55

B.2 Worker Variables . . . . . . . . . . . . . . . . . . . . . . . 55

B.3 Firm Variables . . . . . . . . . . . . . . . . . . . . . . 56

B.4 Industry Variables . . . . . . . . . . . . . . . . . . . 57

$\begin{array}{ll}\text { C Additional Results } & 58\end{array}$

C.1 CUSFTA Tariff Cuts . . . . . . . . . . . . . . . . . . . . . 58

C.2 Change in Trade Flows by Tariff Change . . . . . . . . . . . . . . . . . . . . . . 59

C.3 Correlates of High Attachment Status . . . . . . . . . . . . . . . . . . . . . . 60

C.4 Exogeneity of Trade Policy . . . . . . . . . . . . . . . . . . . . . . 61

C.5 Probability of Non-Work-Shortage Related Separation . . . . . . . . . . . . . . . . 62

C.6 Years Worked Results Tables . . . . . . . . . . . . . . . . . . . . . 63

C.7 Cumulative Normalized Earnings Results Tables . . . . . . . . . . . . . . . . . . . 65

C.8 Results Controlling for NAFTA Tariff Cuts Facing Imports from Mexico . . . . . . 68

C.9 Effects by Income Level _. . . . . . . . . . . . . . . . . . . . . . . . . . . 71

C.10 Net Effects by Industry . . . . . . . . . . . . . . . . . . . . . . . . . 80

C.11 Regional Shocks and Industrial Geography . . . . . . . . . . . . . . . . . . . . 84

C.12 Evolution of Tariff-Cut Exposure . . . . . . . . . . . . . . . . . . . . . 95

C.13 Worker Transitions by Initial Firm Size Results Tables . . . . . . . . . . . . . . . . 98

C.14 Cumulative Normalized Earnings by Initial Firm Size Results Tables . . . . . . . . . 101 


\section{A Tariff Data}

Our measures of the CUSFTA bilateral tariff cuts come from the statutory phase-in from the published Canada-U.S. Free Trade Agreement. Data from it were generously provided in digitized form by by Emily Yu at Global Affairs Canada. Raw data are provided at the HS 8-digit level. We start by dropping 365 Canadian HS 8-digit codes that are specific tariffs, compound tariffs, or in which there are two entries for an 8-digit tariff with one of them being specific or compound. This reduces the number of codes from 7241 to 6876 . We then take the weighted average of these tariffs within a given HS 6-digit code where weights corresponding to Canadian imports from the U.S. in 1988. We retain the import value at the HS 6-digit level as we use it below. Independently, we use the concordance from Pierce and Schott (2012) to create a many to one crosswalk between 1992 HS 6-digit codes and 1997 6-digit NAICS codes. We then using a many to one merge to merge the latter crosswalk with the HS 6-digit tariffs.

We then take the 2002 to 2007 6-digit NAICS crosswalk from the U.S. census and reshape it so that there is exactly one observation per 2002 6-digit NAICS code. This is merged (one to many) with the 1997 to 2002 6-digit NAICS crosswalk from the same source. This creates a mapping of all the 2007 6-digit NAICS codes that a given 1997 6-digit NAICS code maps into. We then merge this with the 1997 6-digit NAICS tariff data and reshape it (long) so that for a given 20076 digit NAICS code, there are values for each of the 1992 HS 6-digit tariffs that map into it. Finally, we take the weighted average of these tariffs for a given year within a 4-digit 2007 NAICS code where weights correspond to values of imports from the U.S. in 1988 in a given 1988 6-digit HS code that maps into the 4-digit 2007 NAICS code. This is the level at which leapnaics is defined at in the primary data set.

For U.S. tariffs, the procedure is similar. We start with 8-digit HS codes and then drop those that contain specific or compound tariffs. The U.S. has far more of these than Canada (1171 vs. 365). Analogously to the Canadian tariffs, these are collapsed down to the 1988 HS 6-digit level using imports from Canada as weights and converted to the 4-digit 2007 NAICS code using the same procedure as above.

Canadian MFN rates are calculated as follows. All MFN rates that are not ad-valorem were converted to ad-valorem measures by Global Affairs Canada. HS 1988 8-digit MFN rates are converted to 6-digit rates using simple averages. We then use the crosswalks defined above to convert these to MFN rates at the 4-digit 2007 NAICS level using simple averages. The change in MFN rates is defined as the 1998 MFN rate minus the 1988 tariff on U.S. exports calculated above that the U.S. faced prior to CUSFTA. For this calculation the 1988 tariff in Auto Pact sectors is the statutory rate (before waivers are granted). We use actual MFN rates and not bound rates.

We calculate U.S. MFN tariffs as follows. For 1988, we rely on TS-USA imports. ${ }^{69}$ At the sevendigit TS level, we isolate total duties paid and total customs imports into from Austria, Denmark, Finland, France, Germany, Greece, Ireland, Italy, the Netherlands, Norway, Spain, Sweden, and the United Kingdom, divided by total customs value of imports from those same countries. We refer to the latter countries as MFN countries. We then use a crosswalk from the same resource to merge these into the 10-digit HS level. We then sum duties paid and customs value to the 10-digit HS level. The 1988 U.S. MFN tariff is equal to total duties paid on these MFN countries divided by the customs value of imports from these MFN countries. These are then aggregated to the NAICS level

\footnotetext{
${ }^{69}$ Available from https://cid.econ.ucdavis.edu/usixd/wp5515d.html
} 
using a crosswalk constructed from the 1989 U.S. import data from the same source where weights correspond to total import value at the HS level within NAICS codes. For the years 1989-1998, we calculate the 10-digit HS tariff at the HS-country-year level for the same countries. We then take the weighted average over the remaining countries with similar weights. Time varying NAICS codes are transformed into 2007 NAICS codes using crosswalks from the U.S. Census.

\section{B Administrative Data Construction}

\section{B.1 Sample Selection}

We start with the raw data set $L W F \_T 2 L E A P_{\_} w_{-} u i e a r n . d t a$ provided to us by the Economic Analysis Division at Statistics Canada. We keep workers born between 1940 and 1964 (inclusive) so that they were between 22 and 64 in all years from 1986 to 2004 . We consider these to be "prime age workers." When workers have multiple years of birth listed, we take the earliest year. We also drop workers who have an unknown province of residence in any year.

We also drop workers who worked for the first time after 1988 (exclusive). As we discuss below, these workers cannot be assigned to the "low attachment" or "high attachment" groups because we cannot see their 1984-1988 work histories. Using the Statistics Canada variable earnflag, we attribute all of a worker's earnings in a given year to their highest paying job for the years 19841988. We drop workers who did not work in any of the years 1986-1988 because we cannot assign them to an initial industry or firm. However, for the years 1989-2004, earnings are attributed to the industry or sector in which they were earned, not just to the primary job's sector. For example, if a worker separated from their initial manufacturing job in 1995, and then took a primary construction job and a side job in services, they would have earnings showing in both construction and services (e.g. Tables A6-A8). However, years worked are attributed to the primary sector of employment so that the maximum number of years worked between 1989 and 2004 (inclusive) is 16 .

For a large number of "initial" outcomes (e.g. initial industry, initial firm, etc.), we require a base year. For workers with positive earnings in 1988, we set their base year to 1988. This causes all high attachment workers to have 1988 as their base year. If the worker did not have positive earnings in 1988 but did have positive earnings in 1987, we set their base year to 1987. If they did not have positive earnings in 1988 nor 1987, we set their base year to 1986. All workers have positive earnings in at least one of these years. We then define the initial industry as the industry of primary employment in the base year. The initial firm and initial province are defined analogously. For a small number of workers that we see in both 1986 and 1988, we assign the initial industry and firm based on 1986 data if the 1988 industry code is missing.

\section{B.2 Worker Variables}

We start by describing our sample construction in detail. We define a minimum wage cutoff as total income a worker would have earned at a prevailing province-year nominal minimum wage if they worked 1600 hours a year, as in Autor et al. (2014). ${ }^{70}$ We define a "high attachment" worker as one who earned more than this cutoff for each of the years 1985-1988.

\footnotetext{
${ }^{70}$ These were retrieved from http://srv116.services.gc.ca/dimt-wid/sm-mw/rpt2.aspx?GoCTemplateCulture=en$C A$.
} 
We now have a potentially unbalanced panel with each worker having no more than one observation per year. We define the initial industry of employment as the industry of the highest paying job for a given worker in 1988. If there is not record for 1988 but a record with an industry code in 1987, we use 1987. If there are no records with industry codes for 1988 and, we use 1986. The initial firm is defined as the firm (lbid) of the firm at which the worker had primary employment in the year for which we assign the initial industry. Annual income is defined as total T4 earnings in a given year. Average worker earnings from 1986 to 1988 are the simple average of annual T4 total earnings during this period. Nominal values are deflated to 2002 real values using the Canadian CPI available as Statistics Canada table 18-10-0004-13. Cumulative earnings are total worker T4 income after and including 1989. We define a top earner as a worker with the 99th percentile of cumulative earnings for each final year of employment (e.g. the 99th percentile of cumulative earnings for workers who stopped working in 1989, 1990, 1991, and so on). We drop workers whose final year cumulative earnings are greater than the 99th percentile of all workers who have the same final year of work.

Normalized cumulative earnings are cumulative earnings in the final year of employment divided by the Average worker income for 1986-1988 only taking positive values of earnings in those years into account. Firm tenure at the initial firm is constructed as follows: create a dummy variable that takes a value of one for every year prior to the base year. If the sum of these dummy variables equals 0 or 1 , they are defined as "low tenure", if the sum is strictly greater than one and strictly less than four, they are defined as "medium tenure", if the sum is weakly greater than four, they are defined as "high tenure."

To create firm size bins, we start by taking the firm size (nalus) of the base firm. These are full time equivalent workers calculated by Statistics Canada as total payroll divided by average wages taking worker characteristics into account. Because we are using nalus from the LEAP portion of the data set, this counts all workers at the firm and not just those in the sample. If this average is strictly less than 100, then the firm is assigned to the "small" bin, if the average is strictly greater than 99 and strictly less than 1000, then the firm is assigned to the "medium" bin, and if the average is strictly greater than 999, then the firm is assigned to the "large" bin. The correlation between this variable and the number of workers we observe at the firm (multipled by 10) is high.

Experience captures the number of years the worker was employed from 1984 to 1988 (inclusive). The experience dummy takes a value of 1 if the worker worked strictly less than three years, a value of 2 if they worked between 2 and 5 years, a value of 3 if they worked strictly greater than four years. This differs from "high attachment" as it does not account for wages earned in these jobs. It differs from the tenure variable in that it does not distinguish the firm of employment.

A worker's average real initial income is calculated by taking the average real T4 earnings for a given worker in the years 1986-1988 for years in which they had positive earnings. The worker pre-trend is defined as the difference between a worker's log real 1986 T4 income and their log real 1988 T4 income. When this is included as a explanatory variable, it requires that even low attachment workers work in the years 1986 and 1988 (but not necessarily 1987).

\section{B.3 Firm Variables}

We now describe firm variables that we use as controls. We measure the average level of worker wages at firm level as a control variable. Starting with the raw data set $L W F \_T 2 L E A P \_w \_u i e a r n$.dta, we start by only keeping observations for the years 1988. We then take (unweighted) mean of log real 
worker earnings for workers employed at that firm in 1988. To create the firm pre-trend, we start with the raw data set LWF_T2LEAP_w_uiearn.dta, keep only observations for the years 1986 and 1988. We then calculate log real earnings for workers at the firm in those years, and the change in log real earnings for workers at the firm in 1986 and 1988. We then take the (unweighted) mean of that variable for the firm.

\section{B.4 Industry Variables}

We now describe industry variables that we use as controls. To measure the average worker wages in the initial industry in 1988, we starting with the raw data set LWF_T2LEAP_w_uiearn.dta, and keep observations for 1988. We then take the log of real t4 earnings in the industry in 1988 and take the mean of that variable for the initial industry of employment. To create the industry pre-trend, we start with the raw data set $L W F \_T 2 L E A P_{\_} w_{-} u i e a r n . d t a$, we take the change in the log of worker real income between 1986 and 1988 defined above and take the mean of that for the initial industry of employment.

The NAICS four-digit industry's log capital-labor ratio is calculated by starting with the raw data set LWF_T2LEAP_w_uiearn.dta, removing firm-year duplicates, and then summing both total_assets and nalus by industry, and then dividing the former by the latter. We measure the log share of workers (in our sample) at the NAICS four-digit level in 1988 who earn less than the aggregate median wage (also in 1988). Trends in the importance of the industry are captured by the trend in the log of the industry's share of aggregate employment. It takes the number of workers (in our sample) in the NAICS industry in 1984 and divides it by the total number of workers (in our sample) in 1984. It then takes the (log) difference in this between 1984 and 1988. The cyclicality measure is as discussed in the text. Finally, we also control for the China Shock in Canada between 1989 and 2004. The numerator of this is the change in real imports into Canada from China between these years in the industry of initial employment. The denominator is real absorption in Canada in 1992 as defined as real output plus real industry imports from the world from Canada minus real industry exports to the world from Canada. 1992 is the first year for which production data are available so we scale all industries by the change in nominal aggregate manufacturing production between 1988 and 1992 before converting from nominal to real values. This actually means scaling the nominal value up by approximately $4.5 \%$ consistent with the early 1990s recession in Canada. This scaling only scales the coefficient when this industry-level variable is included in regression but does affect the level when data is presented visually. 


\section{Additional Results}

\section{C.1 CUSFTA Tariff Cuts}

Figure A1: CUSFTA Tariff Cuts

Panel A: Canadian Tariffs Over Time

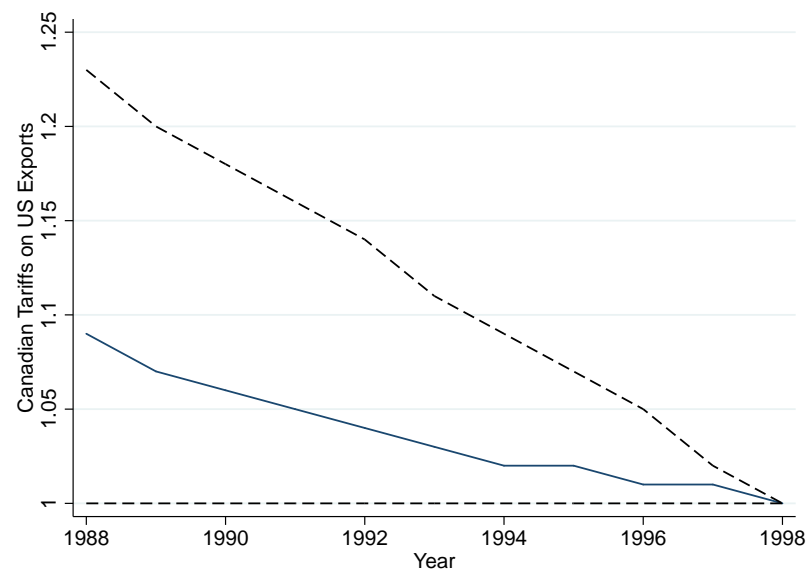

Panel C: U.S. Tariffs Over Time

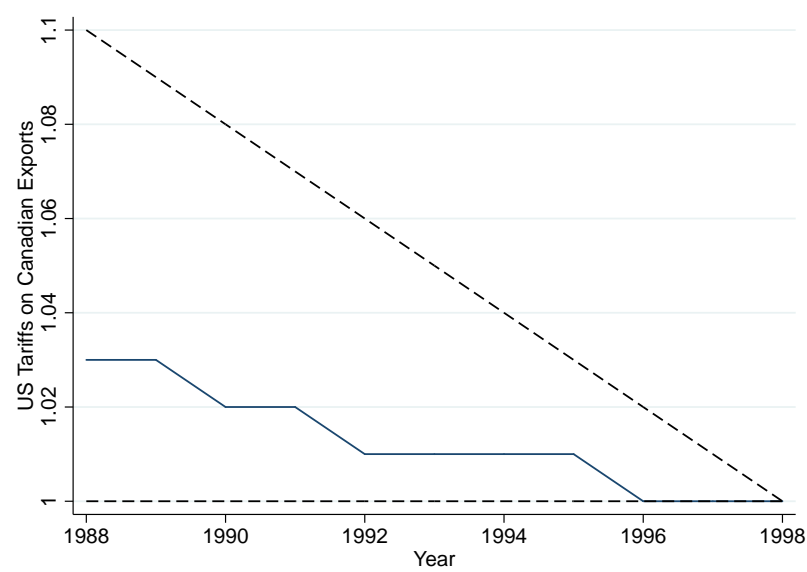

Panel B: Canadian Tariff Cuts Against Initial Level

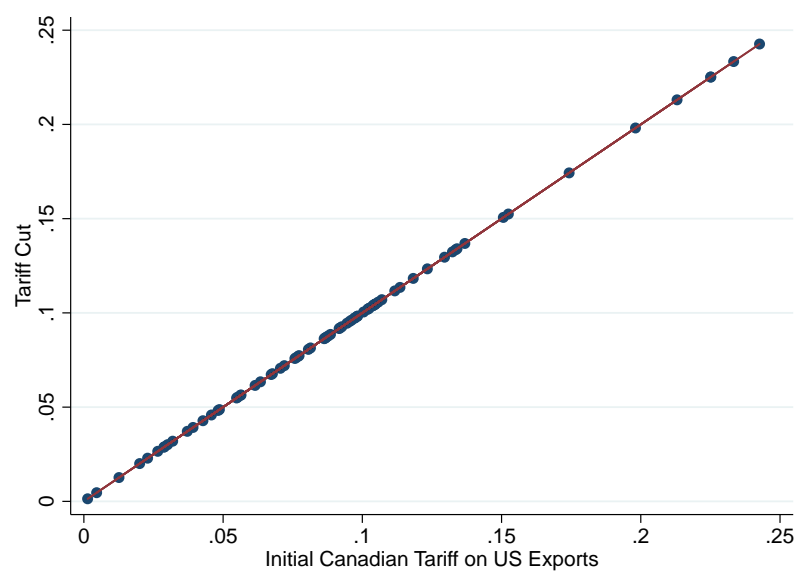

Panel D: U.S. Tariff Cuts Against Initial Level

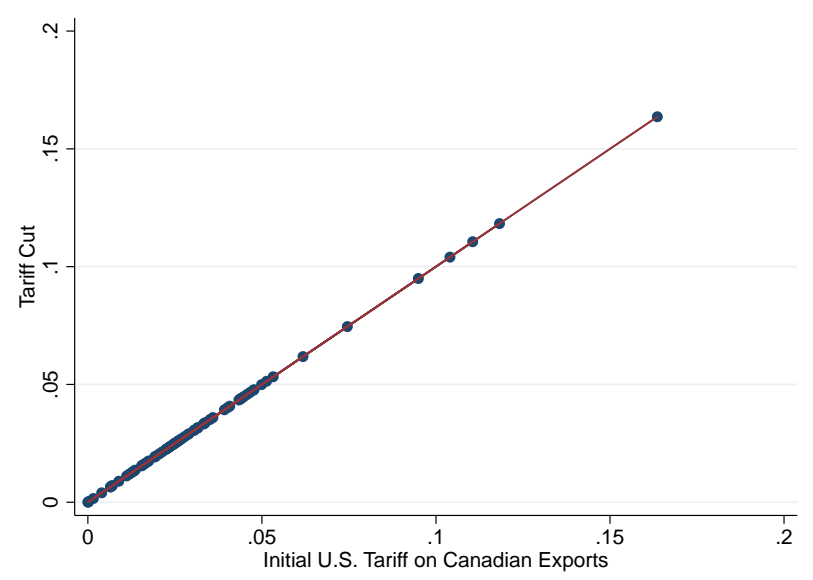

Notes: Panel A plots the unweighted average Canadian NAICS tariff plus one against U.S. exports from 1988 through 1998. Values of 1 represent no tariff. The dotted lines represent $5^{\text {th }}$ and $95^{\text {th }}$ percentiles. Panel B plots the initial 1988 tariff on the horizontal axis and the cut from 1988 to 1998 on the vertical axis. Each dot is an industry and the line is a 45 degree line. Values of zero on the horizontal axis represent no tariff. Panels C and D does the same for U.S. tariffs against Canadian exports. 


\section{C.2 Change in Trade Flows by Tariff Change}

Figure A2: Change in Trade Flows by Tariff change

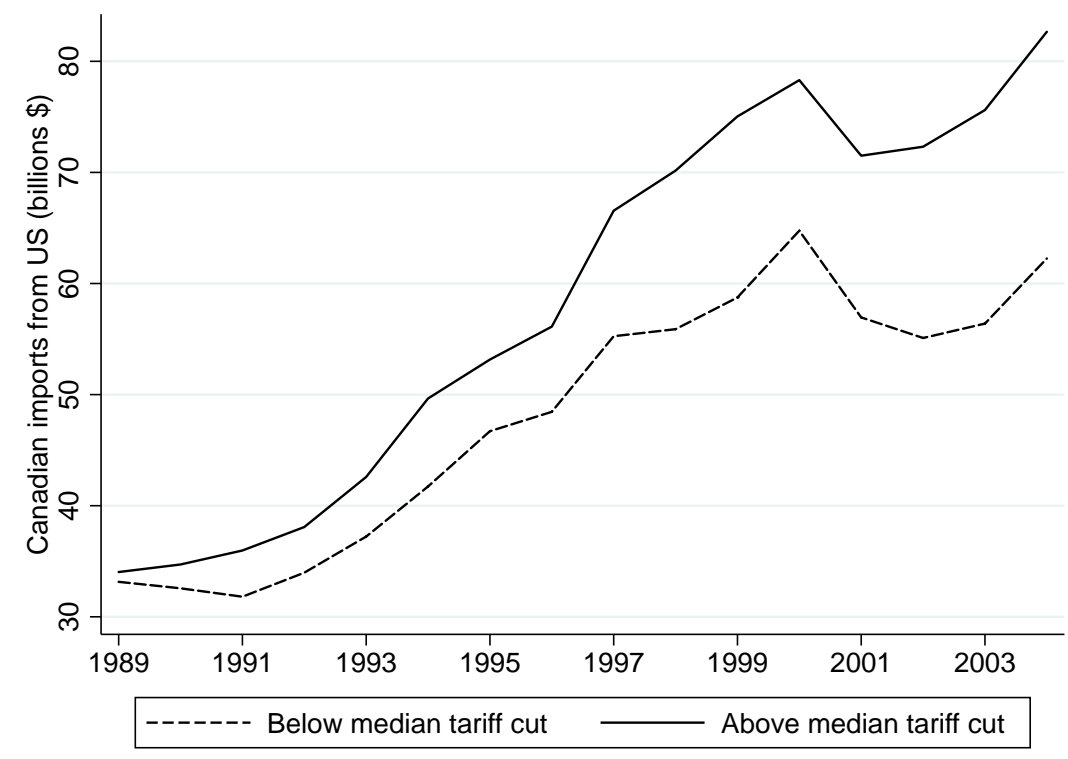

Notes: The y-axis plots the level of Canadian imports from the United States in billions of CAD for the years 1989-2004 (the x-axis). The solid line represents the level of imports in HS 6-digit codes whose 1988 tariff was above the median industry level. The dashed line represents imports in HS 6-digit codes whose 1988 tariff was below the median industry level.

Figure A2 shows that Canadian imports from the U.S. increased more quickly for 6-digit HS products that faced larger Canadian tariff cuts than for products facing smaller tariff cuts, and that the gap between these two sets of products grew steadily over time. The solid line shows Canadian imports from the U.S. in billions of CAD for products facing above-median Canadian tariff cuts, while the dashed line shows the same measure for products facing below-median tariff cuts. While both series start with quite similar trade values in 1989, at the start of the FTA, they steadily diverge throughout our sample period, with products experiencing larger tariff cuts exhibiting larger increases in trade values. We thank Teresa Fort for suggesting this figure. 


\section{C.3 Correlates of High Attachment Status}

Table A1: Correlates of High Attachment Status

\begin{tabular}{|c|c|c|c|}
\hline & $\overline{(1)}$ & $\overline{(2)}$ & $\overline{(3)}$ \\
\hline \multicolumn{4}{|l|}{ Worker Characteristics } \\
\hline Female $_{i}$ & $\begin{array}{c}-0.189^{* * *} \\
(0.0209)\end{array}$ & & $\begin{array}{r}0.0637^{* * *} \\
(0.00596)\end{array}$ \\
\hline $\operatorname{Age}_{i}$ & & $\begin{array}{r}0.0775^{* * *} \\
(0.00489)\end{array}$ & $\begin{array}{r}0.0607^{* * *} \\
(0.00751)\end{array}$ \\
\hline $\operatorname{Age}_{i}^{2}$ & & $\begin{array}{c}-0.000920^{* * *} \\
(6.56 \mathrm{e}-05)\end{array}$ & $\begin{array}{l}-4.20 \mathrm{e}-05 \\
(3.63 \mathrm{e}-05)\end{array}$ \\
\hline Age $_{i} \times \ln \left(\right.$ income $\left._{i, 1986-1988}\right)$ & & & $\begin{array}{r}-0.00558^{* * *} \\
(0.000822)\end{array}$ \\
\hline $\ln \left(\right.$ income $\left._{i, 1986-1988}\right)$ & & & $\begin{array}{c}0.636^{* * *} \\
(0.0286)\end{array}$ \\
\hline$\Delta_{1986-1988} \ln \left(\right.$ income $\left._{i}\right)$ & & & $\begin{array}{c}-0.0753^{* * *} \\
(0.00502)\end{array}$ \\
\hline \multicolumn{4}{|l|}{ Firm Characteristics } \\
\hline $\ln \left(\right.$ income $_{f, 1986-1988)}$ & & & $\begin{array}{c}0.0197 * * * \\
(0.00360)\end{array}$ \\
\hline$\Delta_{1986-1988} \ln \left(\right.$ income $\left._{f}\right)$ & & & $\begin{array}{c}-0.0230^{* * *} \\
(0.00550)\end{array}$ \\
\hline $\mathbb{1}($ medium firm $)$ & & & $\begin{array}{c}0.00336 \\
(0.00590)\end{array}$ \\
\hline $\mathbb{1}($ large firm $)$ & & & $\begin{array}{r}-0.0198^{* *} \\
(0.00813)\end{array}$ \\
\hline \multicolumn{4}{|l|}{ Industry Characteristics } \\
\hline$\overline{\ln \left(1+\tau_{j, 1988}^{\mathrm{CAN}}\right)}$ & & & $\begin{array}{r}-0.0699 \\
(0.117)\end{array}$ \\
\hline $\ln \left(1+\tau_{j, 1988}^{\mathrm{US}}\right)$ & & & $\begin{array}{l}-0.151 \\
(0.141)\end{array}$ \\
\hline$\Delta_{1988-1998} \ln \left(1+\tau_{j}^{\mathrm{CAN}, \mathrm{MFN}}\right)$ & & & $\begin{array}{l}0.243^{*} \\
(0.123)\end{array}$ \\
\hline$\Delta_{1988-1998} \ln \left(1+\tau_{j}^{\mathrm{US}, \mathrm{MFN}}\right)$ & & & $\begin{array}{l}0.0436 \\
(0.159)\end{array}$ \\
\hline$\Delta I P R_{j}^{\mathrm{CHN}}$ & & & $\begin{array}{l}-0.0108 \\
(0.0270)\end{array}$ \\
\hline Cyclicality $_{j}$ & & & $\begin{array}{c}8.10 \mathrm{e}-05 \\
(0.00237)\end{array}$ \\
\hline Share below median income $_{j, 1988}$ & & & $\begin{array}{l}-0.0227 \\
(0.0279)\end{array}$ \\
\hline Mean log earnings ${ }_{j, 1988}$ & & & $\begin{array}{l}-0.0529^{*} \\
(0.0296)\end{array}$ \\
\hline Log capital-labor $\operatorname{ratio}_{j, 1988}$ & & & $\begin{array}{c}-0.00618^{* *} \\
(0.00257)\end{array}$ \\
\hline$\Delta_{1984-1988} \ln \left(\frac{e m p_{j}}{\sum_{j^{\prime}} e m p_{j^{\prime}}}\right)$ & & & -0.0257 \\
\hline$\Delta_{1986-1988}$ Mean log earnings $s_{j}$ & & & $\begin{array}{c}(0.0249) \\
-0.227^{* *} \\
(0.0883)\end{array}$ \\
\hline Observations & 83,705 & 83,705 & 83,705 \\
\hline R-squared & 0.039 & 0.048 & 0.437 \\
\hline
\end{tabular}

Notes: ${ }^{* * *}: p<0.01,{ }^{* *}: 0.01 \leq p<0.05,{ }^{*}: 0.05 \leq p<0.1$. The dependent variable is an indicator for workers with high attachment status. Standard errors clustered at the 2007 NAICS-4 digit level are in parentheses. $a g e_{i}$ is the age of individual $i$ in the initial year. 


\section{C.4 Exogeneity of Trade Policy}

Table A2: Exogeneity of Trade Policy

\begin{tabular}{|c|c|c|c|c|}
\hline \multirow[t]{2}{*}{ Dependent variable: } & \multicolumn{2}{|c|}{$\ln \left(1+\tau_{j, 1988}^{\mathrm{CAN}}\right)$} & \multicolumn{2}{|c|}{$\ln \left(1+\tau_{j, 1988}^{\mathrm{US}}\right)$} \\
\hline & (1) & (2) & (3) & (4) \\
\hline $\ln \left(1+\tau_{j, 1988}^{\mathrm{US}}\right)$ & & $\begin{array}{c}0.965^{* * *} \\
(0.166)\end{array}$ & & \\
\hline $\ln \left(1+\tau_{j, 1988}^{\mathrm{CAN}}\right)$ & & & & $\begin{array}{c}0.351^{* * *} \\
(0.060)\end{array}$ \\
\hline$\Delta_{1988-1998} \ln \left(1+\tau_{j}^{\mathrm{CAN}, \mathrm{MFN}}\right)$ & & $\begin{array}{c}0.644^{* * *} \\
(0.010)\end{array}$ & & $\begin{array}{c}-0.186^{* *} \\
(0.073)\end{array}$ \\
\hline$\Delta_{1988-1998} \ln \left(1+\tau_{j}^{\mathrm{US}, \mathrm{MFN}}\right)$ & & $\begin{array}{c}0.007 \\
(0.202)\end{array}$ & & $\begin{array}{l}-0.028 \\
(0.122)\end{array}$ \\
\hline$\Delta I P R_{j}^{\mathrm{CHN}}$ & $\begin{array}{c}0.015 \\
(0.029)\end{array}$ & $\begin{array}{l}0.040^{* *} \\
(0.020)\end{array}$ & $\begin{array}{l}-0.012 \\
(0.014)\end{array}$ & $\begin{array}{l}-0.022^{*} \\
(0.012)\end{array}$ \\
\hline Separation prob. $1985-1988, j$ & $\begin{array}{l}-0.143 \\
(0.200)\end{array}$ & $\begin{array}{c}0.042 \\
(0.137)\end{array}$ & $\begin{array}{l}-0.054 \\
(0.098)\end{array}$ & $\begin{array}{l}-0.042 \\
(0.082)\end{array}$ \\
\hline Cyclicality $_{j}$ & $\begin{array}{l}0.008^{*} \\
(0.004)\end{array}$ & $\begin{array}{l}-0.003 \\
(0.003)\end{array}$ & $\begin{array}{c}0.008^{* * *} \\
(0.002)\end{array}$ & $\begin{array}{c}0.006^{* * *} \\
(0.002)\end{array}$ \\
\hline Share below median income $_{j, 1988}$ & $\begin{array}{l}-0.043 \\
(0.057)\end{array}$ & $\begin{array}{l}-0.006 \\
(0.039)\end{array}$ & $\begin{array}{l}-0.014 \\
(0.028)\end{array}$ & $\begin{array}{l}-0.006 \\
(0.023)\end{array}$ \\
\hline Mean log earnings $_{j, 1988}$ & $\begin{array}{l}-0.075 \\
(0.047)\end{array}$ & $\begin{array}{l}-0.023 \\
(0.032)\end{array}$ & $\begin{array}{l}-0.036 \\
(0.023)\end{array}$ & $\begin{array}{l}-0.015 \\
(0.020)\end{array}$ \\
\hline Log capital-labor ratio $_{j, 1988}$ & $\begin{array}{l}-0.005 \\
(0.005)\end{array}$ & $\begin{array}{c}0.002 \\
(0.004)\end{array}$ & $\begin{array}{l}-0.003 \\
(0.003)\end{array}$ & $\begin{array}{l}-0.003 \\
(0.002)\end{array}$ \\
\hline$\Delta_{1984-1988} \ln \left(\frac{e m p_{j}}{\sum_{j^{\prime}} e m p_{j^{\prime}}}\right)$ & $\begin{array}{l}-0.012 \\
(0.037)\end{array}$ & $\begin{array}{c}0.033 \\
(0.027)\end{array}$ & $\begin{array}{c}-0.053^{* * *} \\
(0.018)\end{array}$ & $\begin{array}{c}-0.048^{* * *} \\
(0.015)\end{array}$ \\
\hline$\Delta_{1986-1988}$ Mean log earnings ${ }_{j}$ & $\begin{array}{l}-0.186 \\
(0.147)\end{array}$ & $\begin{array}{l}-0.137 \\
(0.103)\end{array}$ & $\begin{array}{l}-0.114 \\
(0.072)\end{array}$ & $\begin{array}{l}-0.029 \\
(0.063)\end{array}$ \\
\hline Observations & 78 & 78 & 78 & 78 \\
\hline R-squared & 0.323 & 0.706 & 0.417 & 0.618 \\
\hline
\end{tabular}

Notes: ${ }^{* * *}: p<0.01,{ }^{* *}: 0.01 \leq p<0.05,{ }^{*}: 0.05 \leq p<0.1$. Standard errors clustered at the 2007 NAICS-4 digit level are in parentheses. All columns estimate versions of equation (3). All variables are as described in the text. Estimation is OLS. 


\section{C.5 Probability of Non-Work-Shortage Related Separation}

Table A3: Probability of Non-Work-Shortage Related Separation from Initial Firm (1989-2003)

\begin{tabular}{|c|c|c|c|c|}
\hline & \multicolumn{2}{|c|}{ Low Attachment } & \multicolumn{2}{|c|}{ High Attachment } \\
\hline & (1) & (2) & $(3)$ & $(4)$ \\
\hline$-\Delta_{k} \ln \left(1+\tau_{j}^{\mathrm{CAN}}\right)$ & $\begin{array}{l}0.0404 \\
(0.163)\end{array}$ & & $\begin{array}{l}0.0262 \\
(0.171)\end{array}$ & \\
\hline$-\Delta_{k} \ln \left(1+\tau_{j}^{\mathrm{CAN}}\right) * \mathbb{1}($ small firm $)$ & & $\begin{array}{c}0.207 \\
(0.200)\end{array}$ & & $\begin{array}{r}-0.0546 \\
(0.226)\end{array}$ \\
\hline$-\Delta_{k} \ln \left(1+\tau_{j}^{\mathrm{CAN}}\right) * \mathbb{1}($ medium firm $)$ & & $\begin{array}{l}0.0402 \\
(0.221)\end{array}$ & & $\begin{array}{c}0.189 \\
(0.250)\end{array}$ \\
\hline$-\Delta_{k} \ln \left(1+\tau_{j}^{\mathrm{CAN}}\right) * \mathbb{1}$ (large firm $)$ & & $\begin{array}{l}-0.181 \\
(0.249)\end{array}$ & & $\begin{array}{l}0.0312 \\
(0.231)\end{array}$ \\
\hline$-\Delta_{k} \ln \left(1+\tau_{j}^{\mathrm{US}}\right)$ & $\begin{array}{c}0.331 \\
(0.302)\end{array}$ & & $\begin{array}{c}0.864^{* * *} \\
(0.304)\end{array}$ & \\
\hline$-\Delta_{k} \ln \left(1+\tau_{j}^{\mathrm{US}}\right) * \mathbb{1}$ (small firm) & & $\begin{array}{c}0.230 \\
(0.349)\end{array}$ & & $\begin{array}{c}0.452 \\
(0.324)\end{array}$ \\
\hline$-\Delta_{k} \ln \left(1+\tau_{j}^{\mathrm{US}}\right) * \mathbb{1}($ medium firm $)$ & & $\begin{array}{c}0.388 \\
(0.362)\end{array}$ & & $\begin{array}{c}0.527 \\
(0.365)\end{array}$ \\
\hline$-\Delta_{k} \ln \left(1+\tau_{j}^{\mathrm{US}}\right) * \mathbb{1}$ (large firm) & & $\begin{array}{c}0.245 \\
(0.439) \\
\end{array}$ & & $\begin{array}{r}1.595^{* * *} \\
(0.476)\end{array}$ \\
\hline Observations & 20,577 & 20,577 & 63,128 & 63,128 \\
\hline R-Squared & 0.057 & 0.058 & 0.034 & 0.035 \\
\hline
\end{tabular}

Notes: Dependent variable is an indicator for experiencing a permanent non-work-shortage based separation from the worker's initial firm during 1989-2003. These separations include firing, quits, returning to school, seasonal work ending, etc., but omit layoffs, which are the focus of Table 1 . The independent variables of interest are the 1988-1998 tariff cuts facing U.S. exports to Canada $\left(-\Delta \ln \left(1+\tau_{j}^{\text {CAN }}\right)\right)$ or facing Canadian exports to the U.S. $\left(-\Delta \ln \left(1+\tau_{j}^{\mathrm{US}}\right)\right)$ in the worker's initial industry. A positive (negative) coefficient means that larger tariff cuts in the worker's initial industry lead to increased (reduced) probability of separation. Columns (1) and (3) present results of estimating equation (1) for low and high labor force attachment workers, respectively. Columns (2) and (4) present analogous regressions interacting the tariff cuts with initial firm size (small=1-99, medium=100-999, large=1000+). All specifications include extensive worker, initial firm, and initial industry controls, described in Section 4. Standard errors clustered by 4-digit NAICS industry. $* * * \mathrm{p}<0.01, * *$ $\mathrm{p}<0.05,{ }^{*} \mathrm{p}<0.1$. 


\section{C.6 Years Worked Results Tables}

Table A4: Years Worked (1989-1993)

\begin{tabular}{|c|c|c|c|c|c|c|c|c|c|}
\hline & $\begin{array}{c}(1) \\
\text { Total }\end{array}$ & $\begin{array}{c}(2) \\
\text { Initial Firm }\end{array}$ & $\begin{array}{c}(3) \\
\text { Initial Ind. }\end{array}$ & $\begin{array}{c}(4) \\
\text { Manuf. }\end{array}$ & $\begin{array}{c}(5) \\
\text { Constr. }\end{array}$ & $\begin{array}{c}(6) \\
\text { Mining }\end{array}$ & $\begin{array}{c}(7) \\
\text { Agric. }\end{array}$ & $\begin{array}{c}(8) \\
\text { Services }\end{array}$ & $\begin{array}{c}(9) \\
\text { Unknown }\end{array}$ \\
\hline \multicolumn{10}{|c|}{ Panel A: Low Attachment $(\mathrm{n}=20,577)$} \\
\hline$-\Delta \ln \left(1+\tau_{j}^{\mathrm{CAN}}\right)$ & $\begin{array}{c}-0.819^{* * *} \\
(0.299)\end{array}$ & $\begin{array}{c}-1.268 \\
(0.772)\end{array}$ & $\begin{array}{l}-0.732 \\
(0.443)\end{array}$ & $\begin{array}{c}0.240 \\
(0.446)\end{array}$ & $\begin{array}{c}0.199 \\
(0.245)\end{array}$ & $\begin{array}{c}0.0479 \\
(0.0804)\end{array}$ & $\begin{array}{l}-0.227 \\
(0.162)\end{array}$ & $\begin{array}{l}0.841^{*} \\
(0.471)\end{array}$ & $\begin{array}{c}0.0804^{* *} \\
(0.0305)\end{array}$ \\
\hline$-\Delta \ln \left(1+\tau_{j}^{\mathrm{US}}\right)$ & $\begin{array}{c}0.319 \\
(0.519)\end{array}$ & $\begin{array}{c}0.933 \\
(1.204)\end{array}$ & $\begin{array}{c}1.890^{* * * *} \\
(0.688)\end{array}$ & $\begin{array}{c}-1.950^{* *} \\
(0.839)\end{array}$ & $\begin{array}{c}0.430 \\
(0.514)\end{array}$ & $\begin{array}{l}0.0248 \\
(0.120)\end{array}$ & $\begin{array}{l}0.0554 \\
(0.297)\end{array}$ & $\begin{array}{l}-1.017 \\
(0.905)\end{array}$ & $\begin{array}{l}-0.0481 \\
(0.0498)\end{array}$ \\
\hline R-squared & 0.115 & 0.175 & 0.034 & 0.035 & 0.037 & 0.013 & 0.020 & 0.056 & 0.009 \\
\hline \multicolumn{10}{|c|}{ Panel B: High Attachment $(\mathrm{n}=63,128)$} \\
\hline$\overline{-\Delta \ln \left(1+\tau_{j}^{\mathrm{CAN}}\right)}$ & $\begin{array}{c}0.935^{* *} \\
(0.389)\end{array}$ & $\begin{array}{c}0.575 \\
(0.922)\end{array}$ & $\begin{array}{c}-0.441 \\
(0.366)\end{array}$ & $\begin{array}{c}0.475 \\
(0.764)\end{array}$ & $\begin{array}{c}0.227 \\
(0.165)\end{array}$ & $\begin{array}{c}0.0679 \\
(0.0682)\end{array}$ & $\begin{array}{l}-0.126^{*} \\
(0.0746)\end{array}$ & $\begin{array}{c}0.142 \\
(0.260)\end{array}$ & $\begin{array}{c}0.0144 \\
(0.0258)\end{array}$ \\
\hline$-\Delta \ln \left(1+\tau_{j}^{\mathrm{US}}\right)$ & $\begin{array}{l}-0.685 \\
(0.577)\end{array}$ & $\begin{array}{c}2.377 \\
(1.901)\end{array}$ & $\begin{array}{c}0.723 \\
(0.762)\end{array}$ & $\begin{array}{l}-1.717 \\
(1.334)\end{array}$ & $\begin{array}{l}-0.0353 \\
(0.364)\end{array}$ & $\begin{array}{c}-0.115 \\
(0.0907)\end{array}$ & $\begin{array}{c}-0.0682 \\
(0.114)\end{array}$ & $\begin{array}{c}-1.813^{* * *} \\
(0.466)\end{array}$ & $\begin{array}{l}-0.0370 \\
(0.0504)\end{array}$ \\
\hline R-squared & 0.037 & 0.111 & 0.017 & 0.039 & 0.020 & 0.012 & 0.009 & 0.054 & 0.004 \\
\hline
\end{tabular}

Notes: Dependent variable is the number of years worked (with nonzero earnings) during 1989-1993. The independent variables of interest are the 1988-1998 tariff cuts facing U.S. exports to Canada $\left(-\Delta \ln \left(1+\tau_{j}^{\mathrm{CAN}}\right)\right)$ or facing Canadian exports to the U.S. $\left(-\Delta \ln \left(1+\tau_{j}^{\mathrm{US}}\right)\right)$ in the worker's initial industry. A positive (negative) coefficient means that larger tariff cuts in the worker's initial industry lead to increased (decreased) years worked. Column (1) examines total years worked, (2) years worked at the initial firm, (3) at firms other than the initial firm, but in the same initial 4-digit industry, (4) in manufacturing industries (NAICS=3xxx) other than the initial industry, (5) in construction and utilities (NAICS $=22 \mathrm{xx}, 23 \mathrm{xx}),(6)$ in mining (NAICS $=21 \mathrm{xx}$ ), (7) in agriculture (NAICS $=1 \mathrm{xxx}),(8)$ in services (NAICS $\geq 4 \mathrm{xxx}$ ), or (9) in a firm with unknown industry code. Each worker-year is assigned to only one category in columns (2) through (9) based on the primary (highest-earning) job, so the coefficients in columns (2) through (9) sum to the overall effect in column (1). All specifications include extensive worker, initial firm, and initial industry controls, described in Section 4 . Standard errors clustered by 4-digit NAICS industry. ${ }^{* * *} \mathrm{p}<0.01,{ }^{* *} \mathrm{p}<0.05,{ }^{*} \mathrm{p}<0.1$. 
Table A5: Years Worked (1989-1998)

\begin{tabular}{|c|c|c|c|c|c|c|c|c|c|}
\hline & $\begin{array}{c}(1) \\
\text { Total }\end{array}$ & $\begin{array}{c}(2) \\
\text { Initial Firm }\end{array}$ & $\begin{array}{c}(3) \\
\text { Initial Ind. }\end{array}$ & $\begin{array}{c}(4) \\
\text { Manuf. }\end{array}$ & $\begin{array}{c}(5) \\
\text { Constr. }\end{array}$ & $\begin{array}{c}(6) \\
\text { Mining }\end{array}$ & $\begin{array}{c}(7) \\
\text { Agric. }\end{array}$ & $\begin{array}{c}(8) \\
\text { Services }\end{array}$ & $\begin{array}{c}(9) \\
\text { Unknown }\end{array}$ \\
\hline \multicolumn{10}{|c|}{ Panel A: Low Attachment $(\mathrm{n}=20,577)$} \\
\hline$-\Delta \ln \left(1+\tau_{j}^{\mathrm{CAN}}\right)$ & $\begin{array}{l}-1.015 \\
(0.773)\end{array}$ & $\begin{array}{c}-3.360^{* *} \\
(1.678)\end{array}$ & $\begin{array}{l}-1.479 \\
(1.001)\end{array}$ & $\begin{array}{c}1.299 \\
(1.100)\end{array}$ & $\begin{array}{l}0.688^{*} \\
(0.411)\end{array}$ & $\begin{array}{c}0.215 \\
(0.205)\end{array}$ & $\begin{array}{l}-0.416 \\
(0.368)\end{array}$ & $\begin{array}{l}1.964^{* *} \\
(0.977)\end{array}$ & $\begin{array}{c}0.0728^{* *} \\
(0.0356)\end{array}$ \\
\hline$-\Delta \ln \left(1+\tau_{j}^{\mathrm{US}}\right)$ & $\begin{array}{c}-0.996 \\
(1.393)\end{array}$ & $\begin{array}{c}2.565 \\
(2.373)\end{array}$ & $\begin{array}{c}4.038 * * \\
(1.695)\end{array}$ & $\begin{array}{c}-5.127^{* * *} \\
(1.852)\end{array}$ & $\begin{array}{c}0.719 \\
(0.980)\end{array}$ & $\begin{array}{c}-0.0664 \\
(0.293)\end{array}$ & $\begin{array}{c}0.154 \\
(0.689)\end{array}$ & $\begin{array}{c}-3.254^{*} \\
(1.899)\end{array}$ & $\begin{array}{l}-0.0266 \\
(0.0471)\end{array}$ \\
\hline R-squared & 0.103 & 0.150 & 0.044 & 0.041 & 0.041 & 0.017 & 0.023 & 0.056 & 0.010 \\
\hline \multicolumn{10}{|c|}{ Panel B: High Attachment $(\mathrm{n}=63,128)$} \\
\hline$-\Delta \ln \left(1+\tau_{j}^{\mathrm{CAN}}\right)$ & $\begin{array}{c}1.627^{* *} \\
(0.657)\end{array}$ & $\begin{array}{c}-0.536 \\
(2.260)\end{array}$ & $\begin{array}{c}-1.122 \\
(0.901)\end{array}$ & $\begin{array}{c}2.553 \\
(1.799)\end{array}$ & $\begin{array}{c}0.532 \\
(0.381)\end{array}$ & $\begin{array}{c}0.190 \\
(0.207)\end{array}$ & $\begin{array}{r}-0.349^{*} \\
(0.194)\end{array}$ & $\begin{array}{c}0.326 \\
(0.732)\end{array}$ & $\begin{array}{c}0.0335 \\
(0.0272)\end{array}$ \\
\hline$-\Delta \ln \left(1+\tau_{j}^{\mathrm{US}}\right)$ & $\begin{array}{l}-1.468 \\
(0.915)\end{array}$ & $\begin{array}{c}5.841 \\
(4.557)\end{array}$ & $\begin{array}{c}2.086 \\
(2.535)\end{array}$ & $\begin{array}{l}-4.836 \\
(3.189)\end{array}$ & $\begin{array}{c}0.00433 \\
(0.829)\end{array}$ & $\begin{array}{l}-0.139 \\
(0.251)\end{array}$ & $\begin{array}{l}-0.311 \\
(0.320)\end{array}$ & $\begin{array}{c}-4.071^{* * *} \\
(1.290)\end{array}$ & $\begin{array}{l}-0.0422 \\
(0.0528)\end{array}$ \\
\hline R-squared & 0.041 & 0.107 & 0.032 & 0.042 & 0.020 & 0.021 & 0.012 & 0.057 & 0.004 \\
\hline
\end{tabular}

Notes: Dependent variable is the number of years worked (with nonzero earnings) during 1989-1998. The independent variables of interest are the 1988-1998 tariff cuts facing U.S. exports to Canada $\left(-\Delta \ln \left(1+\tau_{j}^{\mathrm{CAN}}\right)\right)$ or facing Canadian exports to the U.S. $\left(-\Delta \ln \left(1+\tau_{j}^{\mathrm{US}}\right)\right)$ in the worker's initial industry. A positive (negative) coefficient means that larger tariff cuts in the worker's initial industry lead to increased (decreased) years worked. Column (1) examines total years worked, (2) years worked at the initial firm, (3) at firms other than the initial firm, but in the same initial 4-digit industry, (4) in manufacturing industries (NAICS=3xxx) other than the initial industry, (5) in construction and utilities (NAICS $=22 x x, 23 x x),(6)$ in mining (NAICS $=21 x x),(7)$ in agriculture (NAICS $=1 \mathrm{xxx}),(8)$ in services (NAICS $\geq 4 \mathrm{xxx}$ ), or (9) in a firm with unknown industry code. Each worker-year is assigned to only one category in columns (2) through (9) based on the primary (highest-earning) job, so the coefficients in columns (2) through (9) sum to the overall effect in column (1). All specifications include extensive worker, initial firm, and initial industry controls, described in Section 4 . Standard errors clustered by 4-digit NAICS industry. ${ }^{* * *} \mathrm{p}<0.01,{ }^{* *} \mathrm{p}<0.05,{ }^{*} \mathrm{p}<0.1$. 


\section{C.7 Cumulative Normalized Earnings Results Tables}

Table A6: Cumulative Normalized Earnings (1989-1993)

\begin{tabular}{lccccccccc}
\hline \hline & $(1)$ & $(2)$ & $(3)$ & $(4)$ & $(5)$ & $(6)$ & $(7)$ & $(8)$ & $(9)$ \\
& Total & Initial Firm & Initial Ind. & Manuf. & $\begin{array}{c}(7) \\
\text { Constr. }\end{array}$ & Mining & Agric. & Services & Unknown \\
\hline \multicolumn{2}{l}{ Panel A: Low Attachment } & $(\mathrm{n}=20,577)$ & & & & & & & \\
$-\Delta \ln \left(1+\tau_{j}^{\text {CAN }}\right)$ & 0.683 & -0.796 & $-1.292^{*}$ & 1.302 & $0.799^{* *}$ & 0.175 & $-0.353^{* *}$ & 1.009 & 0.0136 \\
& $(1.205)$ & $(1.284)$ & $(0.773)$ & $(1.215)$ & $(0.362)$ & $(0.196)$ & $(0.174)$ & $(0.914)$ & $(0.0804)$ \\
$-\Delta \ln \left(1+\tau_{j}^{\text {US }}\right)$ & 2.385 & 1.388 & 1.364 & -1.909 & 0.875 & 0.0686 & 0.0922 & 0.329 & 0.245 \\
& $(1.811)$ & $(2.207)$ & $(1.111)$ & $(2.073)$ & $(0.753)$ & $(0.412)$ & $(0.318)$ & $(1.723)$ & $(0.201)$ \\
\hline R-squared & 0.110 & 0.065 & 0.013 & 0.035 & 0.024 & 0.011 & 0.020 & 0.087 & 0.012 \\
\hline \multicolumn{2}{l}{ Panel B: High Attachment } & $(\mathrm{n}=63,128)$ & & & & & & & \\
$-\Delta \ln \left(1+\tau_{j}^{\text {CAN }}\right)$ & $1.349^{*}$ & 1.161 & -0.373 & 0.372 & 0.220 & 0.0743 & -0.0799 & 0.0444 & 0.00394 \\
$-\Delta \ln \left(1+\tau_{j}^{\text {US }}\right)$ & $(0.792)$ & $(1.091)$ & $(0.451)$ & $(0.806)$ & $(0.174)$ & $(0.0802)$ & $(0.0659)$ & $(0.350)$ & $(0.0257)$ \\
& -0.0916 & 2.413 & -0.0705 & -1.191 & 0.104 & -0.212 & -0.0520 & $-1.269^{* * *}$ & -0.0254 \\
& $0.936)$ & $(1.790)$ & $(0.788)$ & $(1.237)$ & $(0.362)$ & $(0.130)$ & $(0.0913)$ & $(0.476)$ & $(0.0402)$ \\
\hline R-squared & 0.076 & 0.077 & 0.016 & 0.039 & 0.019 & 0.009 & 0.008 & 0.055 & 0.005 \\
\hline \hline
\end{tabular}

Notes: Dependent variable is the sum of a worker's earnings during 1989-1993, divided by the worker's average yearly earnings in 1986-1988 (omitting years with zero earnings), defined in equation (2). The independent variables of interest are the 1988-1998 tariff cuts facing U.S. exports to Canada $\left(-\Delta \ln \left(1+\tau_{j}^{\text {CAN }}\right)\right)$ or facing Canadian exports to the U.S. $\left(-\Delta \ln \left(1+\tau_{j}^{\text {US }}\right)\right)$ in the worker's initial industry. A positive (negative) coefficient means that larger tariff cuts in the worker's initial industry lead to increased (decreased) cumulative earnings. Column (1) examines total earnings from all sources, (2) earnings from the initial firm, (3) from firms other than the initial firm, but in the same initial 4-digit industry, (4) in manufacturing industries (NAICS=3xxx) other than the initial industry, (5) in construction and utilities (NAICS $=22 \mathrm{xx}, 23 \mathrm{xx}$ ), (6) in mining (NAICS=21xx), (7) in agriculture (NAICS=1xxx), (8) in services (NAICS $\geq 4 \mathrm{xxx}$ ), or (9) from a firm with unknown industry code. Because earnings in columns (2) through (9) additively decompose total earnings, the coefficients in columns (2) through (9) sum to the overall effect in column (1). All specifications include extensive worker, initial firm, and initial industry controls, described in Section 4. Standard errors clustered by 4-digit NAICS industry. $* * * \mathrm{p}<0.01, * *$ $\mathrm{p}<0.05,{ }^{*} \mathrm{p}<0.1$. 
Table A7: Cumulative Normalized Earnings (1989-1998)

\begin{tabular}{lccccccccc}
\hline \hline & $(1)$ & $(2)$ & $(3)$ & $(4)$ & $(5)$ & $(6)$ & $(7)$ & $(8)$ & $(9)$ \\
& Total & Initial Firm & Initial Ind. & Manuf. & Constr. & Mining & Agric. & Services & Unknown \\
\hline \multicolumn{2}{l}{ Panel A: Low Attachment } & $(\mathrm{n}=20,577)$ & & & & & & & \\
$-\Delta \ln \left(1+\tau_{j}^{\text {CAN }}\right)$ & -1.198 & $-5.336^{*}$ & -2.418 & 3.229 & $1.688^{* *}$ & 0.679 & -0.706 & 1.710 & -0.0436 \\
& $(3.309)$ & $(2.780)$ & $(2.040)$ & $(2.973)$ & $(0.815)$ & $(0.578)$ & $(0.497)$ & $(2.308)$ & $(0.111)$ \\
$-\Delta \ln \left(1+\tau_{j}^{\text {US }}\right)$ & 7.251 & 5.960 & 1.616 & -4.862 & 2.479 & 0.0354 & 0.0979 & 1.318 & $0.606^{* *}$ \\
& $(5.808)$ & $(4.770)$ & $(3.199)$ & $(5.378)$ & $(1.590)$ & $(1.028)$ & $(0.908)$ & $(5.314)$ & $(0.289)$ \\
\hline R-squared & 0.115 & 0.059 & 0.014 & 0.030 & 0.025 & 0.016 & 0.019 & 0.105 & 0.010 \\
\hline \multicolumn{2}{l}{ Panel B: High Attachment } & $(\mathrm{n}=63,128)$ & & & & & & & \\
\hline$-\Delta \ln \left(1+\tau_{j}^{\text {CAN }}\right)$ & 0.993 & -0.821 & -0.688 & 2.283 & 0.467 & 0.200 & -0.206 & -0.270 & 0.0260 \\
& $(2.009)$ & $(2.926)$ & $(1.196)$ & $(1.964)$ & $(0.396)$ & $(0.243)$ & $(0.176)$ & $(0.968)$ & $(0.0350)$ \\
$-\Delta \ln \left(1+\tau_{j}^{\text {US }}\right)$ & 0.00475 & 7.419 & -0.659 & -3.909 & 0.325 & -0.343 & -0.328 & $-2.461^{*}$ & -0.0379 \\
& $(2.446)$ & $(5.236)$ & $(2.832)$ & $(3.263)$ & $(0.856)$ & $(0.390)$ & $(0.259)$ & $(1.302)$ & $(0.0440)$ \\
\hline R-squared & 0.087 & 0.072 & 0.026 & 0.046 & 0.021 & 0.016 & 0.011 & 0.066 & 0.004 \\
\hline \hline
\end{tabular}

Notes: Dependent variable is the sum of a worker's earnings during 1989-1998, divided by the worker's average yearly earnings in 1986-1988 (omitting years with zero earnings), defined in equation (2). The independent variables of interest are the 1988-1998 tariff cuts facing U.S. exports to Canada $\left(-\Delta \ln \left(1+\tau_{j}^{\text {CAN }}\right)\right)$ or facing Canadian exports to the U.S. $\left(-\Delta \ln \left(1+\tau_{j}^{\text {US }}\right)\right)$ in the worker's initial industry. A positive (negative) coefficient means that larger tariff cuts in the worker's initial industry lead to increased (decreased) cumulative earnings. Column (1) examines total earnings from all sources, (2) earnings from the initial firm, (3) from firms other than the initial firm, but in the same initial 4-digit industry, (4) in manufacturing industries (NAICS=3xxx) other than the initial industry, (5) in construction and utilities (NAICS $=22 \mathrm{xx}, 23 \mathrm{xx}),(6)$ in mining (NAICS $=21 \mathrm{xx}$ ), (7) in agriculture (NAICS=1xxx), (8) in services (NAICS $\geq 4 \mathrm{xxx}$ ), or (9) from a firm with unknown industry code. Because earnings in columns (2) through (9) additively decompose total earnings, the coefficients in columns (2) through (9) sum to the overall effect in column (1). All specifications include extensive worker, initial firm, and initial industry controls, described in Section 4. Standard errors clustered by 4-digit NAICS industry. $* * * p<0.01, * *$ $\mathrm{p}<0.05,{ }^{*} \mathrm{p}<0.1$. 
Table A8: Cumulative Normalized Earnings (1989-2004)

\begin{tabular}{|c|c|c|c|c|c|c|c|c|c|}
\hline & $\begin{array}{c}(1) \\
\text { Total }\end{array}$ & $\begin{array}{c}(2) \\
\text { Initial Firm }\end{array}$ & $\begin{array}{c}(3) \\
\text { Initial Ind. }\end{array}$ & $\begin{array}{c}(4) \\
\text { Manuf. }\end{array}$ & $\begin{array}{c}(5) \\
\text { Constr. }\end{array}$ & $\begin{array}{c}(6) \\
\text { Mining }\end{array}$ & $\begin{array}{c}(7) \\
\text { Agric. }\end{array}$ & $\begin{array}{c}(8) \\
\text { Services }\end{array}$ & $\begin{array}{c}(9) \\
\text { Unknown }\end{array}$ \\
\hline \multicolumn{10}{|c|}{ Panel A: Low Attachment $(\mathrm{n}=20,577)$} \\
\hline$-\Delta \ln \left(1+\tau_{j}^{\mathrm{CAN}}\right)$ & $\begin{array}{l}-6.142 \\
(6.742)\end{array}$ & $\begin{array}{c}-13.21^{* * *} \\
(4.853)\end{array}$ & $\begin{array}{l}-4.455 \\
(3.802)\end{array}$ & $\begin{array}{c}4.314 \\
(5.614)\end{array}$ & $\begin{array}{l}4.311^{* *} \\
(1.742)\end{array}$ & $\begin{array}{c}1.446 \\
(1.117)\end{array}$ & $\begin{array}{l}-1.203 \\
(0.839)\end{array}$ & $\begin{array}{c}2.614 \\
(4.619)\end{array}$ & $\begin{array}{l}0.0449 \\
(0.224)\end{array}$ \\
\hline$-\Delta \ln \left(1+\tau_{j}^{\mathrm{US}}\right)$ & $\begin{array}{c}14.74 \\
(12.67)\end{array}$ & $\begin{array}{c}12.34 \\
(9.066)\end{array}$ & $\begin{array}{c}3.107 \\
(6.182)\end{array}$ & $\begin{array}{l}-7.687 \\
(10.52)\end{array}$ & $\begin{array}{c}3.783 \\
(2.811)\end{array}$ & $\begin{array}{c}0.263 \\
(2.028)\end{array}$ & $\begin{array}{l}-0.858 \\
(1.424)\end{array}$ & $\begin{array}{c}2.800 \\
(10.66)\end{array}$ & $\begin{array}{c}0.988 \\
(0.722)\end{array}$ \\
\hline R-squared & 0.141 & 0.048 & 0.017 & 0.038 & 0.030 & 0.021 & 0.017 & 0.123 & 0.005 \\
\hline \multicolumn{10}{|c|}{ Panel B: High Attachment $(\mathrm{n}=63,128)$} \\
\hline$-\Delta \ln \left(1+\tau_{j}^{\mathrm{CAN}}\right)$ & $\begin{array}{c}0.542 \\
(3.295)\end{array}$ & $\begin{array}{c}-3.007 \\
(5.698)\end{array}$ & $\begin{array}{l}-2.101 \\
(2.263)\end{array}$ & $\begin{array}{c}4.822 \\
(3.649)\end{array}$ & $\begin{array}{c}0.794 \\
(0.817)\end{array}$ & $\begin{array}{c}0.570 \\
(0.591)\end{array}$ & $\begin{array}{l}-0.385 \\
(0.307)\end{array}$ & $\begin{array}{l}-0.195 \\
(2.108)\end{array}$ & $\begin{array}{c}0.0435 \\
(0.0437)\end{array}$ \\
\hline$-\Delta \ln \left(1+\tau_{j}^{\mathrm{US}}\right)$ & $\begin{array}{c}0.627 \\
(4.197)\end{array}$ & $\begin{array}{c}11.69 \\
(9.409)\end{array}$ & $\begin{array}{c}0.285 \\
(5.188)\end{array}$ & $\begin{array}{l}-8.773 \\
(5.849)\end{array}$ & $\begin{array}{c}1.216 \\
(1.700)\end{array}$ & $\begin{array}{l}-0.554 \\
(0.847)\end{array}$ & $\begin{array}{c}-0.803^{*} \\
(0.435)\end{array}$ & $\begin{array}{l}-2.417 \\
(3.020)\end{array}$ & $\begin{array}{l}-0.0213 \\
(0.0592)\end{array}$ \\
\hline R-squared & 0.121 & 0.070 & 0.029 & 0.052 & 0.023 & 0.024 & 0.014 & 0.077 & 0.004 \\
\hline
\end{tabular}

Notes: Dependent variable is the sum of a worker's earnings during 1989-2004, divided by the worker's average yearly earnings in 1986-1988 (omitting years with zero earnings), defined in equation (2). The independent variables of interest are the 1988-1998 tariff cuts facing U.S. exports to Canada $\left(-\Delta \ln \left(1+\tau_{j}^{\mathrm{CAN}}\right)\right)$ or facing Canadian exports to the U.S. $\left(-\Delta \ln \left(1+\tau_{j}^{\mathrm{US}}\right)\right)$ in the worker's initial industry. A positive (negative) coefficient means that larger tariff cuts in the worker's initial industry lead to increased (decreased) cumulative earnings. Column (1) examines total earnings from all sources, (2) earnings from the initial firm, (3) from firms other than the initial firm, but in the same initial 4-digit industry, (4) in manufacturing industries (NAICS=3xxx) other than the initial industry, (5) in construction (NAICS $=22 x x, 23 x x),(6)$ in mining (NAICS=21xx), (7) in agriculture (NAICS=1xxx), (8) in services $(\mathrm{NAICS} \geq 4 \mathrm{xxx})$, or (9) from a firm with unknown industry code. Because earnings in columns (2) through (9) additively decompose total earnings, the coefficients in columns (2) through (9) sum to the overall effect in column (1). All specifications include extensive worker, initial firm, and initial industry controls, described in Section 4. Standard errors clustered by 4-digit NAICS industry. $* * * \mathrm{p}<0.01, * * \mathrm{p}<0.05, *$ $\mathrm{p}<0.1$. 


\section{C.8 Results Controlling for NAFTA Tariff Cuts Facing Imports from Mexico}

Table A9: Probability of Separation from Initial Firm (1989-2003), Controlling for NAFTA Tariff Cuts Facing Imports from Mexico

\begin{tabular}{|c|c|c|c|c|}
\hline & \multicolumn{2}{|c|}{ Low Attachment } & \multicolumn{2}{|c|}{ High Attachment } \\
\hline & (1) & (2) & (3) & (4) \\
\hline$-\Delta \ln \left(1+\tau_{j}^{\mathrm{CAN}}\right)$ & $\begin{array}{l}0.0695 \\
(0.206)\end{array}$ & & $\begin{array}{c}0.129 \\
(0.221)\end{array}$ & \\
\hline$-\Delta \ln \left(1+\tau_{j}^{\mathrm{CAN}}\right) * \mathbb{1}($ small firm $)$ & & $\begin{array}{l}-0.729 \\
(0.477)\end{array}$ & & $\begin{array}{l}-0.369 \\
(0.401)\end{array}$ \\
\hline$-\Delta \ln \left(1+\tau_{j}^{\mathrm{CAN}}\right) * \mathbb{1}($ medium firm $)$ & & $\begin{array}{c}0.228 \\
(0.254)\end{array}$ & & $\begin{array}{l}-0.184 \\
(0.249)\end{array}$ \\
\hline$-\Delta \ln \left(1+\tau_{j}^{\mathrm{CAN}}\right) * \mathbb{1}($ large firm $)$ & & $\begin{array}{c}0.693^{* * *} \\
(0.230)\end{array}$ & & $\begin{array}{l}0.503^{* *} \\
(0.247)\end{array}$ \\
\hline$-\Delta \ln \left(1+\tau_{j}^{\mathrm{US}}\right)$ & $\begin{array}{l}-0.159 \\
(0.196)\end{array}$ & & $\begin{array}{r}-0.0219 \\
(0.291)\end{array}$ & \\
\hline$-\Delta \ln \left(1+\tau_{j}^{\mathrm{US}}\right) * \mathbb{1}($ small firm $)$ & & $\begin{array}{c}0.394 \\
(0.343)\end{array}$ & & $\begin{array}{c}0.402 \\
(0.336)\end{array}$ \\
\hline$-\Delta \ln \left(1+\tau_{j}^{\mathrm{US}}\right) * \mathbb{1}($ medium firm $)$ & & $\begin{array}{l}-0.430 \\
(0.329)\end{array}$ & & $\begin{array}{r}-0.0764 \\
(0.387)\end{array}$ \\
\hline$-\Delta \ln \left(1+\tau_{j}^{\mathrm{US}}\right) * \mathbb{1}($ large firm $)$ & & $\begin{array}{l}-0.400 \\
(0.415)\end{array}$ & & $\begin{array}{l}-0.389 \\
(0.499) \\
\end{array}$ \\
\hline Observations & 20,577 & 20,577 & 63,128 & 63,128 \\
\hline R-Squared & 0.067 & 0.069 & 0.037 & 0.038 \\
\hline
\end{tabular}

Notes: Dependent variable is an indicator for experiencing a permanent work-shortage based separation from the worker's initial firm during 1989-2003. The independent variables of interest are the 1988-1998 tariff cuts facing U.S. exports to Canada $\left(-\Delta \ln \left(1+\tau_{j}^{\text {CAN }}\right)\right)$ or facing Canadian exports to the U.S. $\left(-\Delta \ln \left(1+\tau_{j}^{\mathrm{US}}\right)\right)$ in the worker's initial industry. A positive (negative) coefficient means that larger tariff cuts in the worker's initial industry lead to increased (reduced) probability of separation. Columns (1) and (3) present results of estimating equation (1) for low and high labor force attachment workers, respectively. Columns (2) and (4) present analogous regressions interacting the tariff cuts with initial firm size (small=1-99, medium=100-999, large=1000+). All specifications include extensive worker, initial firm, and initial industry controls, described in Section 4, along with controls for the tariff cuts facing Canadian imports from Mexico under NAFTA. Standard errors clustered by 4-digit NAICS industry. ${ }^{* * *} \mathrm{p}<0.01,{ }^{* *} \mathrm{p}<0.05,{ }^{*} \mathrm{p}<0.1$. 
Table A10: Years Worked (1989-2004), Controlling for NAFTA Tariff Cuts Facing Imports from Mexico

\begin{tabular}{|c|c|c|c|c|c|c|c|c|c|}
\hline & $\begin{array}{c}(1) \\
\text { Total }\end{array}$ & $\begin{array}{c}(2) \\
\text { Initial Firm }\end{array}$ & $\begin{array}{c}(3) \\
\text { Initial Ind. }\end{array}$ & $\begin{array}{c}\text { (4) } \\
\text { Manuf. }\end{array}$ & $\begin{array}{c}(5) \\
\text { Constr. }\end{array}$ & $\begin{array}{c}\text { (6) } \\
\text { Mining }\end{array}$ & $\begin{array}{c}(7) \\
\text { Agric. }\end{array}$ & $\begin{array}{c}(8) \\
\text { Services }\end{array}$ & $\begin{array}{c}(9) \\
\text { Unknown }\end{array}$ \\
\hline \multicolumn{10}{|c|}{ Panel A: Low Attachment $(\mathrm{n}=20,577)$} \\
\hline$-\Delta \ln \left(1+\tau_{j}^{\mathrm{CAN}}\right)$ & $\begin{array}{l}-0.263 \\
(1.402)\end{array}$ & $\begin{array}{c}-6.908^{* *} \\
(3.028)\end{array}$ & $\begin{array}{c}-4.721^{* * *} \\
(1.636)\end{array}$ & $\begin{array}{l}4.122^{* *} \\
(1.831)\end{array}$ & $\begin{array}{l}1.365^{*} \\
(0.782)\end{array}$ & $\begin{array}{c}0.303 \\
(0.345)\end{array}$ & $\begin{array}{l}-0.522 \\
(0.551)\end{array}$ & $\begin{array}{c}5.967^{* * *} \\
(1.845)\end{array}$ & $\begin{array}{c}0.131^{* * *} \\
(0.0413)\end{array}$ \\
\hline$-\Delta \ln \left(1+\tau_{j}^{\mathrm{US}}\right)$ & $\begin{array}{l}-2.161 \\
(2.554)\end{array}$ & $\begin{array}{c}4.053 \\
(4.242)\end{array}$ & $\begin{array}{c}4.424 \\
(3.072)\end{array}$ & $\begin{array}{c}-7.721^{* * *} \\
(2.842)\end{array}$ & $\begin{array}{c}0.528 \\
(1.835)\end{array}$ & $\begin{array}{c}-0.370 \\
(0.600)\end{array}$ & $\begin{array}{c}0.0903 \\
(1.076)\end{array}$ & $\begin{array}{l}-3.166 \\
(3.059)\end{array}$ & $\begin{array}{c}-0.000191 \\
(0.0892)\end{array}$ \\
\hline R-squared & 0.096 & 0.132 & 0.050 & 0.048 & 0.046 & 0.023 & 0.027 & 0.062 & 0.008 \\
\hline \multicolumn{10}{|c|}{ Panel B: High Attachment $(\mathrm{n}=63,128)$} \\
\hline$-\Delta \ln \left(1+\tau_{j}^{\mathrm{CAN}}\right)$ & $\begin{array}{l}2.794^{*} \\
(1.548)\end{array}$ & $\begin{array}{l}-2.773 \\
(4.755)\end{array}$ & $\begin{array}{c}-4.490^{* *} \\
(1.739)\end{array}$ & $\begin{array}{l}7.632^{* *} \\
(2.957)\end{array}$ & $\begin{array}{c}1.060 \\
(0.760)\end{array}$ & $\begin{array}{c}0.241 \\
(0.406)\end{array}$ & $\begin{array}{c}-0.582^{*} \\
(0.313)\end{array}$ & $\begin{array}{c}1.680 \\
(1.570)\end{array}$ & $\begin{array}{c}0.0257 \\
(0.0366)\end{array}$ \\
\hline$-\Delta \ln \left(1+\tau_{j}^{\mathrm{US}}\right)$ & $\begin{array}{l}-2.398 \\
(2.037)\end{array}$ & $\begin{array}{c}6.800 \\
(8.017)\end{array}$ & $\begin{array}{c}2.743 \\
(4.392)\end{array}$ & $\begin{array}{l}-5.878 \\
(5.347)\end{array}$ & $\begin{array}{c}0.540 \\
(1.589)\end{array}$ & $\begin{array}{l}-0.615 \\
(0.520)\end{array}$ & $\begin{array}{l}-0.725 \\
(0.581)\end{array}$ & $\begin{array}{c}-5.205^{* *} \\
(2.303)\end{array}$ & $\begin{array}{l}-0.0577 \\
(0.0591)\end{array}$ \\
\hline R-squared & 0.058 & 0.102 & 0.036 & 0.044 & 0.022 & 0.028 & 0.015 & 0.061 & 0.004 \\
\hline
\end{tabular}

Notes: Dependent variable is the number of years worked (with nonzero earnings) during 1989-2004. The independent variables of interest are the 1988-1998 tariff cuts facing U.S. exports to Canada $\left(-\Delta \ln \left(1+\tau_{j}^{\mathrm{CAN}}\right)\right)$ or facing Canadian exports to the U.S. $\left(-\Delta \ln \left(1+\tau_{j}^{\mathrm{US}}\right)\right)$ in the worker's initial industry. A positive (negative) coefficient means that larger tariff cuts in the worker's initial industry lead to increased (decreased) years worked. Column (1) examines total years worked, (2) years worked at the initial firm, (3) at firms other than the initial firm, but in the same initial 4-digit industry, (4) in manufacturing industries (NAICS=3xxx) other than the initial industry, (5) in construction (NAICS $=22 \mathrm{xx}$ ), (6) in mining (NAICS $=21 \mathrm{xx}),(7)$ in agriculture (NAICS $=1 \mathrm{xxx}),(8)$ in services (NAICS $\geq 4 \mathrm{xxx}$ ), or (9) in a firm with unknown industry code. Each worker-year is assigned to only one category in columns (2) through (9) based on the primary (highest-earning) job, so the coefficients in columns (2) through (9) sum to the overall effect in column (1). All specifications include extensive worker, initial firm, and initial industry controls, described in Section 4, along with controls for the tariff cuts facing Canadian imports from Mexico under NAFTA. Standard errors clustered by 4-digit NAICS industry. ${ }^{* * *} \mathrm{p}<0.01,{ }^{* *} \mathrm{p}<0.05,{ }^{*} \mathrm{p}<0.1$. 
Table A11: Cumulative Normalized Earnings (1989-2004), Controlling for NAFTA Tariff Cuts Facing Imports from Mexico

\begin{tabular}{lccccccccc}
\hline \hline & $(1)$ & $(2)$ & $(3)$ & $(4)$ & $(5)$ & $(6)$ & $(7)$ & $(8)$ & $(9)$ \\
& Total & Initial Firm & Initial Ind. & Manuf. & $\begin{array}{c}(9) \\
\text { Constr. }\end{array}$ & Mining & Agric. & $\begin{array}{c}\text { Services } \\
\text { Unknown }\end{array}$ \\
\hline \multicolumn{2}{l}{ Panel A: Low Attachment } & $(\mathrm{n}=20,577)$ & & & & & & & \\
$-\Delta \ln \left(1+\tau_{j}^{\text {CAN }}\right)$ & 0.316 & $-12.78^{* *}$ & $-9.092^{* *}$ & $11.96^{* *}$ & $4.204^{* *}$ & 0.988 & -1.059 & 5.903 & 0.199 \\
& $(7.776)$ & $(5.442)$ & $(3.570)$ & $(5.403)$ & $(1.818)$ & $(1.267)$ & $(0.917)$ & $(5.160)$ & $(0.192)$ \\
$-\Delta \ln \left(1+\tau_{j}^{\text {US }}\right)$ & 21.90 & 12.82 & -2.033 & 0.786 & 3.665 & -0.245 & -0.698 & 6.447 & 1.159 \\
& $(13.52)$ & $(10.50)$ & $(6.512)$ & $(10.30)$ & $(3.112)$ & $(1.898)$ & $(1.477)$ & $(10.97)$ & $(0.736)$ \\
\hline R-squared & 0.141 & 0.048 & 0.019 & 0.038 & 0.030 & 0.021 & 0.017 & 0.123 & 0.005 \\
\hline \multicolumn{2}{l}{ Panel B: High Attachment } & $(\mathrm{n}=63,128)$ & & & & & & & \\
\hline$-\Delta \ln \left(1+\tau_{j}^{\text {CAN }}\right)$ & 2.617 & -2.593 & $-4.840^{* *}$ & $8.196^{* *}$ & 1.088 & 0.256 & -0.373 & 0.846 & 0.0366 \\
& $(3.392)$ & $(6.056)$ & $(2.193)$ & $(3.353)$ & $(0.829)$ & $(0.579)$ & $(0.301)$ & $(2.263)$ & $(0.0495)$ \\
$-\Delta \ln \left(1+\tau_{j}^{\text {US }}\right)$ & 3.694 & 12.31 & -3.764 & -3.786 & 1.651 & -1.018 & -0.785 & -0.878 & -0.0315 \\
& $(4.709)$ & $(10.26)$ & $(4.986)$ & $(5.767)$ & $(1.826)$ & $(0.984)$ & $(0.491)$ & $(2.409)$ & $(0.0564)$ \\
\hline R-squared & 0.121 & 0.070 & 0.031 & 0.053 & 0.023 & 0.024 & 0.014 & 0.077 & 0.004 \\
\hline \hline
\end{tabular}

Notes: Dependent variable is the sum of a worker's earnings during 1989-2004, divided by the worker's average yearly earnings in 1986-1988 (omitting years with zero earnings), defined in equation (2). The independent variables of interest are the 1988-1998 tariff cuts facing U.S. exports to Canada $\left(-\Delta \ln \left(1+\tau_{j}^{\mathrm{CAN}}\right)\right)$ or facing Canadian exports to the U.S. $\left(-\Delta \ln \left(1+\tau_{j}^{\mathrm{US}}\right)\right)$ in the worker's initial industry. A positive (negative) coefficient means that larger tariff cuts in the worker's initial industry lead to increased (decreased) cumulative earnings. Column (1) examines total earnings from all sources, (2) earnings from the initial firm, (3) from firms other than the initial firm, but in the same initial 4-digit industry, (4) in manufacturing industries (NAICS=3xxx) other than the initial industry, (5) in construction (NAICS $=22 x x, 23 x x),(6)$ in mining (NAICS=21xx), (7) in agriculture (NAICS=1xxx), (8) in services (NAICS $\geq 4 \mathrm{xxx}$ ), or (9) from a firm with unknown industry code. Because earnings in columns (2) through (9) additively decompose total earnings, the coefficients in columns (2) through (9) sum to the overall effect in column (1). All specifications include extensive worker, initial firm, and initial industry controls, described in Section 4, along with controls for the tariff cuts facing Canadian imports from Mexico under NAFTA. Standard errors clustered by 4-digit NAICS industry. ${ }^{* * *} \mathrm{p}<0.01,{ }^{* *} \mathrm{p}<0.05,{ }^{*} \mathrm{p}<0.1$. 
C.9 Effects by Income Level 

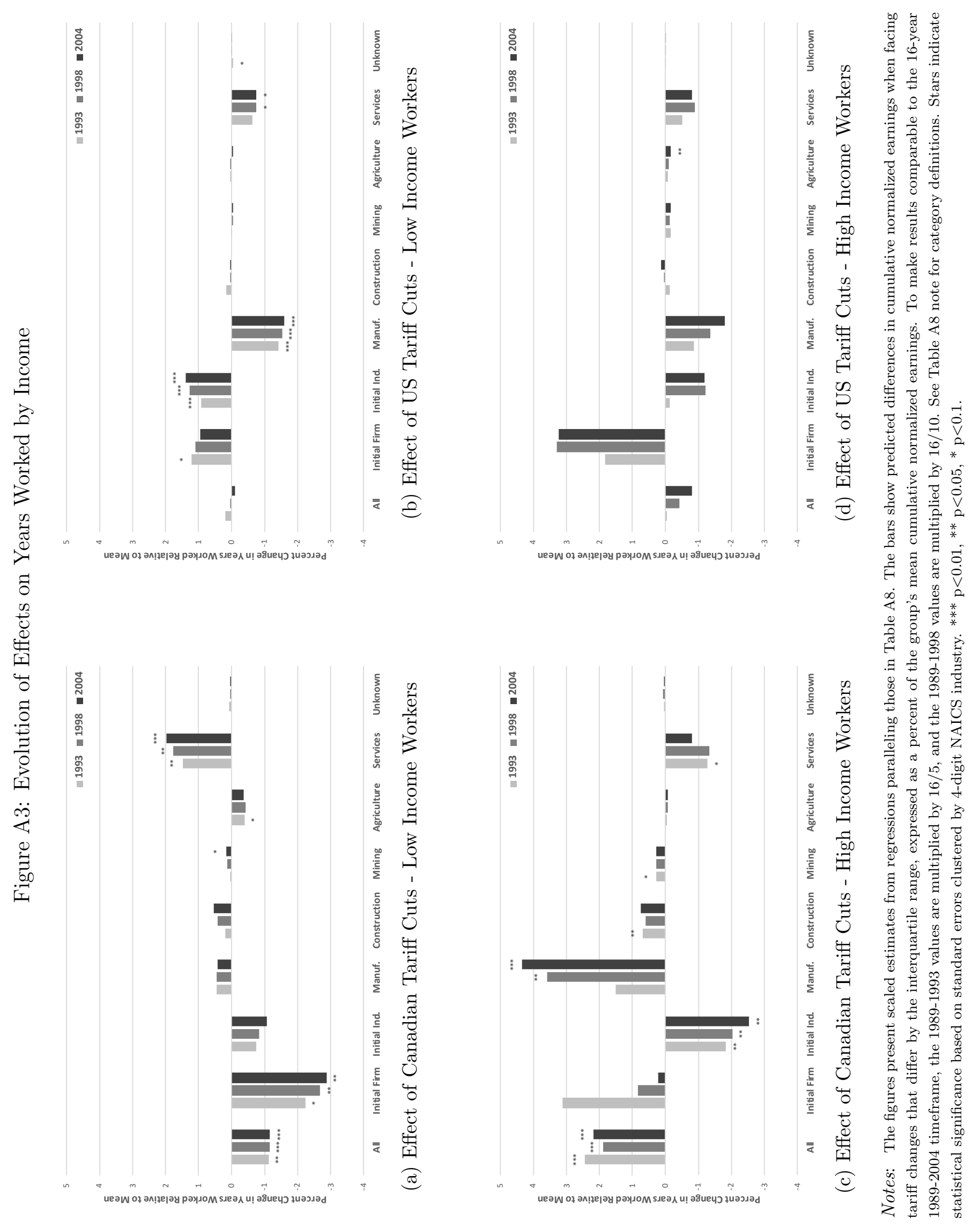
Table A12: Years Worked, by Income Group (1989-1993)

\begin{tabular}{|c|c|c|c|c|c|c|c|c|c|}
\hline & $\begin{array}{c}(1) \\
\text { Total }\end{array}$ & $\begin{array}{c}(2) \\
\text { Initial Firm }\end{array}$ & $\begin{array}{c}(3) \\
\text { Initial Ind. }\end{array}$ & $\begin{array}{c}\text { (4) } \\
\text { Manuf. }\end{array}$ & $\begin{array}{c}(5) \\
\text { Constr. }\end{array}$ & $\begin{array}{c}(6) \\
\text { Mining }\end{array}$ & $\begin{array}{c}(7) \\
\text { Agric. }\end{array}$ & $\begin{array}{c}(8) \\
\text { Services }\end{array}$ & $\begin{array}{c}(9) \\
\text { Unknown }\end{array}$ \\
\hline \multicolumn{10}{|c|}{ Panel A: Low Income $(\mathrm{n}=27,902)$} \\
\hline$-\Delta \ln \left(1+\tau_{j}^{\mathrm{CAN}}\right)$ & $\begin{array}{c}-0.709^{* *} \\
(0.294)\end{array}$ & $\begin{array}{r}-1.414^{*} \\
(0.788)\end{array}$ & $\begin{array}{l}-0.474 \\
(0.341)\end{array}$ & $\begin{array}{c}0.292 \\
(0.566)\end{array}$ & $\begin{array}{c}0.127 \\
(0.201)\end{array}$ & $\begin{array}{c}0.0205 \\
(0.0455)\end{array}$ & $\begin{array}{l}-0.248^{*} \\
(0.146)\end{array}$ & $\begin{array}{c}0.938^{* *} \\
(0.450)\end{array}$ & $\begin{array}{c}0.0496 \\
(0.0301)\end{array}$ \\
\hline$-\Delta \ln \left(1+\tau_{j}^{\mathrm{US}}\right)$ & $\begin{array}{c}0.326 \\
(0.433)\end{array}$ & $\begin{array}{l}1.949^{*} \\
(1.170)\end{array}$ & $\begin{array}{c}1.500 * * * \\
(0.561)\end{array}$ & $\begin{array}{c}-2.311^{* * *} \\
(0.783)\end{array}$ & $\begin{array}{c}0.253 \\
(0.358)\end{array}$ & $\begin{array}{l}-0.0185 \\
(0.0698)\end{array}$ & $\begin{array}{c}0.0693 \\
(0.273)\end{array}$ & $\begin{array}{l}-1.037 \\
(0.644)\end{array}$ & $\begin{array}{c}-0.0798^{*} \\
(0.0442)\end{array}$ \\
\hline R-squared & 0.105 & 0.182 & 0.031 & 0.041 & 0.036 & 0.010 & 0.020 & 0.064 & 0.008 \\
\hline \multicolumn{10}{|c|}{ Panel B: High Income $(\mathrm{n}=27,901)$} \\
\hline$-\Delta \ln \left(1+\tau_{j}^{\mathrm{CAN}}\right)$ & $\begin{array}{c}1.539 * * * \\
(0.496)\end{array}$ & $\begin{array}{c}1.978 \\
(1.233)\end{array}$ & $\begin{array}{c}-1.161^{* *} \\
(0.556)\end{array}$ & $\begin{array}{c}0.944 \\
(0.801)\end{array}$ & $\begin{array}{c}0.432^{* *} \\
(0.216)\end{array}$ & $\begin{array}{l}0.169^{*} \\
(0.100)\end{array}$ & $\begin{array}{l}-0.0286 \\
(0.0456)\end{array}$ & $\begin{array}{l}-0.810^{*} \\
(0.476)\end{array}$ & $\begin{array}{c}0.0152 \\
(0.0285)\end{array}$ \\
\hline$-\Delta \ln \left(1+\tau_{j}^{\mathrm{US}}\right)$ & $\begin{array}{c}-0.0978 \\
(0.914)\end{array}$ & $\begin{array}{c}2.948 \\
(2.988)\end{array}$ & $\begin{array}{l}-0.207 \\
(1.052)\end{array}$ & $\begin{array}{l}-1.389 \\
(2.553)\end{array}$ & $\begin{array}{l}-0.201 \\
(0.441)\end{array}$ & $\begin{array}{l}-0.262 \\
(0.159)\end{array}$ & $\begin{array}{c}-0.118 \\
(0.0851)\end{array}$ & $\begin{array}{c}-0.851 \\
(0.873)\end{array}$ & $\begin{array}{l}-0.0167 \\
(0.0535)\end{array}$ \\
\hline R-squared & 0.040 & 0.086 & 0.025 & 0.038 & 0.021 & 0.015 & 0.006 & 0.037 & 0.005 \\
\hline
\end{tabular}

Notes: Dependent variable is the number of years worked (with nonzero earnings) during 1989-1993. The independent variables of interest are the 1988-1998 tariff cuts facing U.S. exports to Canada $\left(-\Delta \ln \left(1+\tau_{j}^{\mathrm{CAN}}\right)\right)$ or facing Canadian exports to the U.S. $\left(-\Delta \ln \left(1+\tau_{j}^{\mathrm{US}}\right)\right)$ in the worker's initial industry. A positive (negative) coefficient means that larger tariff cuts in the worker's initial industry lead to increased (decreased) years worked. Column (1) examines total years worked, (2) years worked at the initial firm, (3) at firms other than the initial firm, but in the same initial 4-digit industry, (4) in manufacturing industries (NAICS=3xxx) other than the initial industry, (5) in construction and utilities (NAICS $=22 \mathrm{xx}, 23 \mathrm{xx}),(6)$ in mining (NAICS $=21 \mathrm{xx}),(7)$ in agriculture (NAICS $=1 \mathrm{xxx}),(8)$ in services (NAICS $\geq 4 \mathrm{xxx}$ ), or (9) in a firm with unknown industry code. Each worker-year is assigned to only one category in columns (2) through (9) based on the primary (highest-earning) job, so the coefficients in columns (2) through (9) sum to the overall effect in column (1). All specifications include extensive worker, initial firm, and initial industry controls, described in Section 4 . Standard errors clustered by 4-digit NAICS industry. ${ }^{* * *} \mathrm{p}<0.01,{ }^{* *} \mathrm{p}<0.05,{ }^{*} \mathrm{p}<0.1$. 
Table A13: Years Worked, by Income Group (1989-1998)

\begin{tabular}{|c|c|c|c|c|c|c|c|c|c|}
\hline & $\begin{array}{c}(1) \\
\text { Total }\end{array}$ & $\begin{array}{c}(2) \\
\text { Initial Firm }\end{array}$ & $\begin{array}{c}(3) \\
\text { Initial Ind. }\end{array}$ & $\begin{array}{c}(4) \\
\text { Manuf. }\end{array}$ & $\begin{array}{c}(5) \\
\text { Constr. }\end{array}$ & $\begin{array}{c}(6) \\
\text { Mining }\end{array}$ & $\begin{array}{c}(7) \\
\text { Agric. }\end{array}$ & $\begin{array}{c}(8) \\
\text { Services }\end{array}$ & $\begin{array}{c}(9) \\
\text { Unknown }\end{array}$ \\
\hline \multicolumn{10}{|c|}{ Panel A: Low Income $(\mathrm{n}=27,902)$} \\
\hline$-\Delta \ln \left(1+\tau_{j}^{\mathrm{CAN}}\right)$ & $\begin{array}{c}-1.449^{* * *} \\
(0.447)\end{array}$ & $\begin{array}{c}-3.394^{* *} \\
(1.600)\end{array}$ & $\begin{array}{l}-1.066 \\
(0.841)\end{array}$ & $\begin{array}{c}0.564 \\
(1.290)\end{array}$ & $\begin{array}{c}0.548 \\
(0.387)\end{array}$ & $\begin{array}{c}0.157 \\
(0.113)\end{array}$ & $\begin{array}{l}-0.524 \\
(0.325)\end{array}$ & $\begin{array}{c}2.221^{* *} \\
(0.938)\end{array}$ & $\begin{array}{c}0.0461 \\
(0.0365)\end{array}$ \\
\hline$-\Delta \ln \left(1+\tau_{j}^{\mathrm{US}}\right)$ & $\begin{array}{c}0.150 \\
(0.905)\end{array}$ & $\begin{array}{c}3.535 \\
(2.273)\end{array}$ & $\begin{array}{c}4.082^{* * *} \\
(1.370)\end{array}$ & $\begin{array}{c}-4.986^{* * *} \\
(1.680)\end{array}$ & $\begin{array}{l}0.0654 \\
(0.708)\end{array}$ & $\begin{array}{l}-0.133 \\
(0.162)\end{array}$ & $\begin{array}{l}0.0838 \\
(0.628)\end{array}$ & $\begin{array}{l}-2.443^{*} \\
(1.364)\end{array}$ & $\begin{array}{l}-0.0544 \\
(0.0457)\end{array}$ \\
\hline R-squared & 0.092 & 0.154 & 0.049 & 0.047 & 0.041 & 0.014 & 0.024 & 0.063 & 0.008 \\
\hline \multicolumn{10}{|c|}{ Panel B: High Income $(\mathrm{n}=27,901)$} \\
\hline$\overline{-\Delta \ln \left(1+\tau_{j}^{\mathrm{CAN}}\right)}$ & $\begin{array}{c}2.390 * * * \\
(0.711)\end{array}$ & $\begin{array}{c}1.034 \\
(2.784)\end{array}$ & $\begin{array}{c}-2.564^{* *} \\
(1.179)\end{array}$ & $\begin{array}{l}4.540^{* *} \\
(1.925)\end{array}$ & $\begin{array}{c}0.756 \\
(0.479)\end{array}$ & $\begin{array}{c}0.363 \\
(0.376)\end{array}$ & $\begin{array}{l}-0.114 \\
(0.152)\end{array}$ & $\begin{array}{l}-1.696 \\
(1.305)\end{array}$ & $\begin{array}{c}0.0712 \\
(0.0454)\end{array}$ \\
\hline$-\Delta \ln \left(1+\tau_{j}^{\mathrm{US}}\right)$ & $\begin{array}{l}-1.394 \\
(1.551)\end{array}$ & $\begin{array}{c}10.67 \\
(7.429)\end{array}$ & $\begin{array}{l}-3.933 \\
(3.468)\end{array}$ & $\begin{array}{l}-4.379 \\
(6.008)\end{array}$ & $\begin{array}{l}0.0255 \\
(1.014)\end{array}$ & $\begin{array}{l}-0.412 \\
(0.442)\end{array}$ & $\begin{array}{l}-0.381 \\
(0.264)\end{array}$ & $\begin{array}{l}-2.938 \\
(2.433)\end{array}$ & $\begin{array}{l}-0.0471 \\
(0.0666)\end{array}$ \\
\hline R-squared & 0.053 & 0.101 & 0.049 & 0.044 & 0.020 & 0.028 & 0.008 & 0.043 & 0.006 \\
\hline
\end{tabular}

Notes: Dependent variable is the number of years worked (with nonzero earnings) during 1989-1998. The independent variables of interest are the 1988-1998 tariff cuts facing U.S. exports to Canada $\left(-\Delta \ln \left(1+\tau_{j}^{\mathrm{CAN}}\right)\right)$ or facing Canadian exports to the U.S. $\left(-\Delta \ln \left(1+\tau_{j}^{\mathrm{US}}\right)\right)$ in the worker's initial industry. A positive (negative) coefficient means that larger tariff cuts in the worker's initial industry lead to increased (decreased) years worked. Column (1) examines total years worked, (2) years worked at the initial firm, (3) at firms other than the initial firm, but in the same initial 4-digit industry, (4) in manufacturing industries (NAICS=3xxx) other than the initial industry, (5) in construction and utilities (NAICS $=22 \mathrm{xx}, 23 \mathrm{xx}),(6)$ in mining (NAICS $=21 \mathrm{xx}$ ), (7) in agriculture (NAICS=1xxx), (8) in services (NAICS $\geq 4 \mathrm{xxx}$ ), or (9) in a firm with unknown industry code. Each worker-year is assigned to only one category in columns (2) through (9) based on the primary (highest-earning) job, so the coefficients in columns (2) through (9) sum to the overall effect in column (1). All specifications include extensive worker, initial firm, and initial industry controls, described in Section 4 . Standard errors clustered by 4-digit NAICS industry. ${ }^{* * *} \mathrm{p}<0.01,{ }^{* *} \mathrm{p}<0.05,{ }^{*} \mathrm{p}<0.1$. 
Table A14: Years Worked, by Income Group (1989-2004)

\begin{tabular}{|c|c|c|c|c|c|c|c|c|c|}
\hline & $\begin{array}{c}(1) \\
\text { Total }\end{array}$ & $\begin{array}{c}(2) \\
\text { Initial Firm }\end{array}$ & $\begin{array}{c}(3) \\
\text { Initial Ind. }\end{array}$ & $\begin{array}{c}\text { (4) } \\
\text { Manuf. }\end{array}$ & $\begin{array}{c}(5) \\
\text { Constr. }\end{array}$ & $\begin{array}{c}(6) \\
\text { Mining }\end{array}$ & $\begin{array}{c}(7) \\
\text { Agric. }\end{array}$ & $\begin{array}{c}(8) \\
\text { Services }\end{array}$ & $\begin{array}{c}(9) \\
\text { Unknown }\end{array}$ \\
\hline \multicolumn{10}{|c|}{ Panel A: Low Income $(n=27,902)$} \\
\hline$-\Delta \ln \left(1+\tau_{j}^{\mathrm{CAN}}\right)$ & $\begin{array}{c}-2.351^{* * *} \\
(0.803)\end{array}$ & $\begin{array}{c}-5.834^{* *} \\
(2.808)\end{array}$ & $\begin{array}{l}-2.182 \\
(1.508)\end{array}$ & $\begin{array}{c}0.866 \\
(2.109)\end{array}$ & $\begin{array}{c}1.110 \\
(0.698)\end{array}$ & $\begin{array}{l}0.345^{*} \\
(0.202)\end{array}$ & $\begin{array}{l}-0.734 \\
(0.496)\end{array}$ & $\begin{array}{c}4.015^{* * *} \\
(1.422)\end{array}$ & $\begin{array}{c}0.0641 \\
(0.0462)\end{array}$ \\
\hline$-\Delta \ln \left(1+\tau_{j}^{\mathrm{US}}\right)$ & $\begin{array}{c}-0.596 \\
(1.787)\end{array}$ & $\begin{array}{c}4.887 \\
(3.991)\end{array}$ & $\begin{array}{c}7.261^{* * *} \\
(2.578)\end{array}$ & $\begin{array}{c}-8.287^{* * *} \\
(2.590)\end{array}$ & $\begin{array}{l}0.0845 \\
(1.271)\end{array}$ & $\begin{array}{c}-0.254 \\
(0.300)\end{array}$ & $\begin{array}{c}-0.291 \\
(0.950)\end{array}$ & $\begin{array}{c}-3.919^{*} \\
(2.169)\end{array}$ & $\begin{array}{l}-0.0781 \\
(0.0604)\end{array}$ \\
\hline R-squared & 0.091 & 0.134 & 0.056 & 0.051 & 0.046 & 0.019 & 0.027 & 0.066 & 0.006 \\
\hline \multicolumn{10}{|c|}{ Panel B: High Income $(n=27,901)$} \\
\hline$\overline{-\Delta \ln \left(1+\tau_{j}^{\mathrm{CAN}}\right)}$ & $\begin{array}{c}4.409^{* * *} \\
(1.414)\end{array}$ & $\begin{array}{c}0.448 \\
(4.649)\end{array}$ & $\begin{array}{c}-5.150^{* *} \\
(2.129)\end{array}$ & $\begin{array}{c}8.765^{* * *} \\
(2.912)\end{array}$ & $\begin{array}{c}1.508 \\
(1.004)\end{array}$ & $\begin{array}{c}0.567 \\
(0.853)\end{array}$ & $\begin{array}{c}-0.182 \\
(0.285)\end{array}$ & $\begin{array}{l}-1.640 \\
(2.394)\end{array}$ & $\begin{array}{c}0.0920 \\
(0.0699)\end{array}$ \\
\hline$-\Delta \ln \left(1+\tau_{j}^{\mathrm{US}}\right)$ & $\begin{array}{l}-4.159 \\
(3.009)\end{array}$ & $\begin{array}{c}16.68 \\
(12.15)\end{array}$ & $\begin{array}{l}-6.198 \\
(6.297)\end{array}$ & $\begin{array}{l}-9.408 \\
(9.316)\end{array}$ & $\begin{array}{c}0.699 \\
(2.023)\end{array}$ & $\begin{array}{l}-0.847 \\
(0.903)\end{array}$ & $\begin{array}{c}-0.892^{* *} \\
(0.377)\end{array}$ & $\begin{array}{l}-4.165 \\
(4.635)\end{array}$ & $\begin{array}{l}-0.0264 \\
(0.0898)\end{array}$ \\
\hline R-squared & 0.083 & 0.108 & 0.055 & 0.046 & 0.020 & 0.039 & 0.011 & 0.049 & 0.005 \\
\hline
\end{tabular}

Notes: Dependent variable is the number of years worked (with nonzero earnings) during 1989-2004. The independent variables of interest are the 1988-1998 tariff cuts facing U.S. exports to Canada $\left(-\Delta \ln \left(1+\tau_{j}^{\mathrm{CAN}}\right)\right)$ or facing Canadian exports to the U.S. $\left(-\Delta \ln \left(1+\tau_{j}^{\mathrm{US}}\right)\right)$ in the worker's initial industry. A positive (negative) coefficient means that larger tariff cuts in the worker's initial industry lead to increased (decreased) years worked. Column (1) examines total years worked, (2) years worked at the initial firm, (3) at firms other than the initial firm, but in the same initial 4-digit industry, (4) in manufacturing industries (NAICS=3xxx) other than the initial industry, (5) in construction and utilities (NAICS $=22 \mathrm{xx}, 23 \mathrm{xx}),(6)$ in mining (NAICS $=21 \mathrm{xx}),(7)$ in agriculture (NAICS $=1 \mathrm{xxx}),(8)$ in services (NAICS $\geq 4 \mathrm{xxx}$ ), or (9) in a firm with unknown industry code. Each worker-year is assigned to only one category in columns (2) through (9) based on the primary (highest-earning) job, so the coefficients in columns (2) through (9) sum to the overall effect in column (1). All specifications include extensive worker, initial firm, and initial industry controls, described in Section 4 . Standard errors clustered by 4-digit NAICS industry. ${ }^{* * *} \mathrm{p}<0.01,{ }^{* *} \mathrm{p}<0.05,{ }^{*} \mathrm{p}<0.1$. 

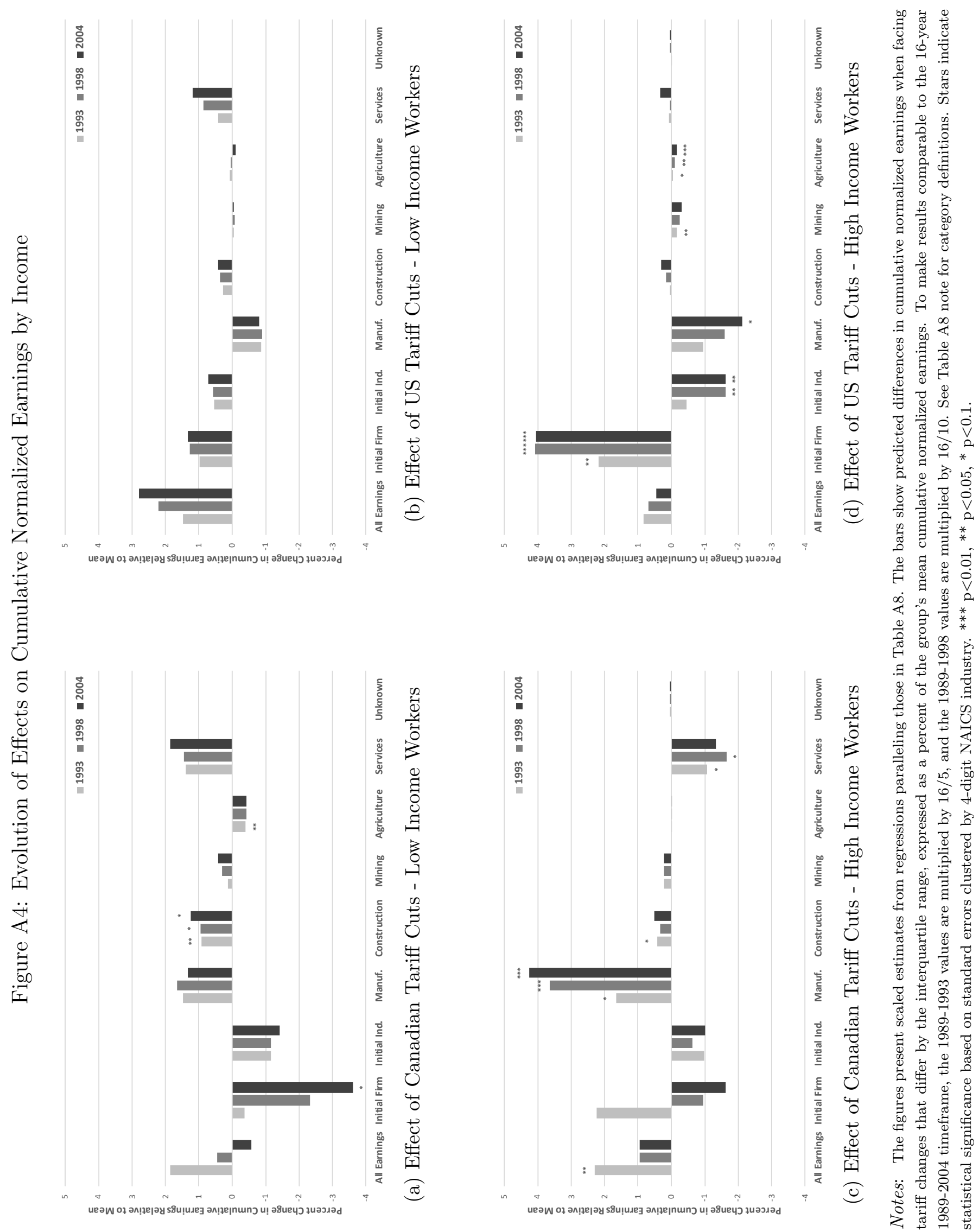
Table A15: Cumulative Normalized Earnings, by Income Group (1989-1993)

\begin{tabular}{|c|c|c|c|c|c|c|c|c|c|}
\hline & $\begin{array}{c}(1) \\
\text { Total }\end{array}$ & $\begin{array}{c}(2) \\
\text { Initial Firm }\end{array}$ & $\begin{array}{c}(3) \\
\text { Initial Ind. }\end{array}$ & $\begin{array}{c}\text { (4) } \\
\text { Manuf. }\end{array}$ & $\begin{array}{c}(5) \\
\text { Constr. }\end{array}$ & $\begin{array}{c}(6) \\
\text { Mining }\end{array}$ & $\begin{array}{c}(7) \\
\text { Agric. }\end{array}$ & $\begin{array}{c}(8) \\
\text { Services }\end{array}$ & $\begin{array}{c}(9) \\
\text { Unknown }\end{array}$ \\
\hline \multicolumn{10}{|c|}{ Panel A: Low Income $(n=27,902)$} \\
\hline$-\Delta \ln \left(1+\tau_{j}^{\mathrm{CAN}}\right)$ & $\begin{array}{c}1.469 \\
(1.412)\end{array}$ & $\begin{array}{c}-0.293 \\
(1.377)\end{array}$ & $\begin{array}{l}-0.919 \\
(0.605)\end{array}$ & $\begin{array}{c}1.172 \\
(1.234)\end{array}$ & $\begin{array}{c}0.735^{* *} \\
(0.352)\end{array}$ & $\begin{array}{c}0.100 \\
(0.119)\end{array}$ & $\begin{array}{c}-0.326^{* *} \\
(0.153)\end{array}$ & $\begin{array}{c}1.086 \\
(0.822)\end{array}$ & - \\
\hline$-\Delta \ln \left(1+\tau_{j}^{\mathrm{US}}\right)$ & $\begin{array}{c}2.992 \\
(1.971)\end{array}$ & $\begin{array}{c}1.953 \\
(2.111)\end{array}$ & $\begin{array}{c}1.118 \\
(0.911)\end{array}$ & $\begin{array}{l}-1.735 \\
(1.760)\end{array}$ & $\begin{array}{c}0.585 \\
(0.629)\end{array}$ & $\begin{array}{l}-0.110 \\
(0.283)\end{array}$ & $\begin{array}{c}0.115 \\
(0.284)\end{array}$ & $\begin{array}{c}0.830 \\
(1.300)\end{array}$ & - \\
\hline R-squared & 0.118 & 0.061 & 0.012 & 0.038 & 0.024 & 0.008 & 0.019 & 0.095 & 0.011 \\
\hline \multicolumn{10}{|c|}{ Panel B: High Income $(n=27,901)$} \\
\hline$\overline{-\Delta \ln \left(1+\tau_{j}^{\mathrm{CAN}}\right)}$ & $\begin{array}{l}1.809^{* *} \\
(0.832)\end{array}$ & $\begin{array}{c}1.775 \\
(1.288)\end{array}$ & $\begin{array}{l}-0.780 \\
(0.590)\end{array}$ & $\begin{array}{l}1.316^{*} \\
(0.753)\end{array}$ & $\begin{array}{l}0.332^{*} \\
(0.194)\end{array}$ & $\begin{array}{c}0.162 \\
(0.0991)\end{array}$ & $\begin{array}{l}-0.00131 \\
(0.0316)\end{array}$ & $\begin{array}{c}-0.855^{*} \\
(0.502)\end{array}$ & $\begin{array}{c}0.0217 \\
(0.0262)\end{array}$ \\
\hline$-\Delta \ln \left(1+\tau_{j}^{\mathrm{US}}\right)$ & $\begin{array}{c}1.670 \\
(1.305)\end{array}$ & $\begin{array}{c}4.418^{* *} \\
(1.909)\end{array}$ & $\begin{array}{l}-0.899 \\
(0.890)\end{array}$ & $\begin{array}{c}-1.950 \\
(1.685)\end{array}$ & $\begin{array}{l}0.0844 \\
(0.336)\end{array}$ & $\begin{array}{c}-0.354^{* *} \\
(0.176)\end{array}$ & $\begin{array}{l}-0.115^{*} \\
(0.0635)\end{array}$ & $\begin{array}{c}0.142 \\
(0.530)\end{array}$ & $\begin{array}{l}-0.0115 \\
(0.0341)\end{array}$ \\
\hline R-squared & 0.069 & 0.076 & 0.027 & 0.038 & 0.020 & 0.013 & 0.006 & 0.035 & 0.005 \\
\hline
\end{tabular}

Notes: Dependent variable is the sum of a worker's earnings during 1989-1993, divided by the worker's average yearly earnings in 1986-1988 (omitting years with zero earnings), defined in equation (2). The independent variables of interest are the 1988-1998 tariff cuts facing U.S. exports to Canada $\left(-\Delta \ln \left(1+\tau_{j}^{\mathrm{CAN}}\right)\right)$ or facing Canadian exports to the U.S. $\left(-\Delta \ln \left(1+\tau_{j}^{\mathrm{US}}\right)\right)$ in the worker's initial industry. A positive (negative) coefficient means that larger tariff cuts in the worker's initial industry lead to increased (decreased) cumulative earnings. Column (1) examines total earnings from all sources, (2) earnings from the initial firm, (3) from firms other than the initial firm, but in the same initial 4-digit industry, (4) in manufacturing industries (NAICS=3xxx) other than the initial industry, (5) in construction and utilities (NAICS=22xx, 23xx), (6) in mining (NAICS=21xx), (7) in agriculture (NAICS=1xxx), (8) in services (NAICS $\geq 4 \mathrm{xxx}$ ), or (9) from a firm with unknown industry code. Because earnings in columns (2) through (9) additively decompose total earnings, the coefficients in columns (2) through (9) sum to the overall effect in column (1). All specifications include extensive worker, initial firm, and initial industry controls, described in Section 4. Estimates suppressed due to data confidentiality concerns are shown as -. Standard errors clustered by 4-digit NAICS industry. ${ }^{* * *} \mathrm{p}<0.01,{ }^{* *} \mathrm{p}<0.05,{ }^{*} \mathrm{p}<0.1$. 
Table A16: Cumulative Normalized Earnings, by Income Group (1989-1998)

\begin{tabular}{|c|c|c|c|c|c|c|c|c|c|}
\hline & $\begin{array}{c}(1) \\
\text { Total }\end{array}$ & $\begin{array}{c}(2) \\
\text { Initial Firm }\end{array}$ & $\begin{array}{c}(3) \\
\text { Initial Ind. }\end{array}$ & $\begin{array}{c}(4) \\
\text { Manuf. }\end{array}$ & $\begin{array}{c}(5) \\
\text { Constr. }\end{array}$ & $\begin{array}{c}(6) \\
\text { Mining }\end{array}$ & $\begin{array}{c}(7) \\
\text { Agric. }\end{array}$ & $\begin{array}{c}(8) \\
\text { Services }\end{array}$ & $\begin{array}{c}(9) \\
\text { Unknown }\end{array}$ \\
\hline \multicolumn{10}{|c|}{ Panel A: Low Income $(n=27,902)$} \\
\hline$-\Delta \ln \left(1+\tau_{j}^{\mathrm{CAN}}\right)$ & $\begin{array}{c}0.719 \\
(3.532)\end{array}$ & $\begin{array}{l}-3.682 \\
(2.997)\end{array}$ & $\begin{array}{l}-1.834 \\
(1.653)\end{array}$ & $\begin{array}{c}2.626 \\
(3.052)\end{array}$ & $\begin{array}{l}1.504^{*} \\
(0.759)\end{array}$ & $\begin{array}{c}0.492 \\
(0.353)\end{array}$ & $\begin{array}{l}-0.675 \\
(0.437)\end{array}$ & $\begin{array}{c}2.277 \\
(2.079)\end{array}$ & - \\
\hline$-\Delta \ln \left(1+\tau_{j}^{\mathrm{US}}\right)$ & $\begin{array}{c}8.985 \\
(5.790)\end{array}$ & $\begin{array}{c}5.094 \\
(4.677)\end{array}$ & $\begin{array}{c}2.342 \\
(2.513)\end{array}$ & $\begin{array}{l}-3.652 \\
(4.587)\end{array}$ & $\begin{array}{c}1.477 \\
(1.376)\end{array}$ & $\begin{array}{l}-0.328 \\
(0.710)\end{array}$ & $\begin{array}{c}0.135 \\
(0.818)\end{array}$ & $\begin{array}{c}3.541 \\
(4.079)\end{array}$ & - \\
\hline R-squared & 0.124 & 0.053 & 0.014 & 0.033 & 0.025 & 0.013 & 0.019 & 0.114 & 0.009 \\
\hline \multicolumn{10}{|c|}{ Panel B: High Income $(n=27,901)$} \\
\hline$\overline{-\Delta \ln \left(1+\tau_{j}^{\mathrm{CAN}}\right)}$ & $\begin{array}{c}1.482 \\
(1.714)\end{array}$ & $\begin{array}{l}-1.514 \\
(2.965)\end{array}$ & $\begin{array}{c}-1.010 \\
(1.191)\end{array}$ & $\begin{array}{c}5.752^{* * *} \\
(2.015)\end{array}$ & $\begin{array}{c}0.532 \\
(0.475)\end{array}$ & $\begin{array}{c}0.326 \\
(0.354)\end{array}$ & $\begin{array}{c}-0.0307 \\
(0.111)\end{array}$ & $\begin{array}{c}-2.611^{*} \\
(1.426)\end{array}$ & $\begin{array}{c}0.0382 \\
(0.0283)\end{array}$ \\
\hline$-\Delta \ln \left(1+\tau_{j}^{\mathrm{US}}\right)$ & $\begin{array}{c}2.808 \\
(2.728)\end{array}$ & $\begin{array}{c}16.47^{* * *} \\
(5.686)\end{array}$ & $\begin{array}{c}-6.550 * * \\
(2.790)\end{array}$ & $\begin{array}{l}-6.498 \\
(4.444)\end{array}$ & $\begin{array}{c}0.655 \\
(0.849)\end{array}$ & $\begin{array}{l}-0.976 \\
(0.654)\end{array}$ & $\begin{array}{c}-0.448^{* *} \\
(0.197)\end{array}$ & $\begin{array}{c}0.154 \\
(1.644)\end{array}$ & $\begin{array}{l}0.00419 \\
(0.0409)\end{array}$ \\
\hline R-squared & 0.081 & 0.087 & 0.057 & 0.044 & 0.017 & 0.026 & 0.008 & 0.044 & 0.005 \\
\hline
\end{tabular}

Notes: Dependent variable is the sum of a worker's earnings during 1989-1998, divided by the worker's average yearly earnings in 1986-1988 (omitting years with zero earnings), defined in equation (2). The independent variables of interest are the 1988-1998 tariff cuts facing U.S. exports to Canada $\left(-\Delta \ln \left(1+\tau_{j}^{\mathrm{CAN}}\right)\right)$ or facing Canadian exports to the U.S. $\left(-\Delta \ln \left(1+\tau_{j}^{\mathrm{US}}\right)\right)$ in the worker's initial industry. A positive (negative) coefficient means that larger tariff cuts in the worker's initial industry lead to increased (decreased) cumulative earnings. Column (1) examines total earnings from all sources, (2) earnings from the initial firm, (3) from firms other than the initial firm, but in the same initial 4-digit industry, (4) in manufacturing industries (NAICS=3xxx) other than the initial industry, (5) in construction and utilities (NAICS $=22 \mathrm{xx}, 23 \mathrm{xx}),(6)$ in mining (NAICS $=21 \mathrm{xx}),(7)$ in agriculture (NAICS $=1 \mathrm{xxx}),(8)$ in services (NAICS $\geq 4 \mathrm{xxx}$ ), or (9) from a firm with unknown industry code. Because earnings in columns (2) through (9) additively decompose total earnings, the coefficients in columns (2) through (9) sum to the overall effect in column (1). All specifications include extensive worker, initial firm, and initial industry controls, described in Section 4. Estimates suppressed due to data confidentiality concerns are shown as -. Standard errors clustered by 4-digit NAICS industry. ${ }^{* * *} \mathrm{p}<0.01,{ }^{* *} \mathrm{p}<0.05,{ }^{*} \mathrm{p}<0.1$. 
Table A17: Cumulative Normalized Earnings, by Income Group (1989-2004)

\begin{tabular}{|c|c|c|c|c|c|c|c|c|c|}
\hline & $\begin{array}{c}(1) \\
\text { Total }\end{array}$ & $\begin{array}{c}(2) \\
\text { Initial Firm }\end{array}$ & $\begin{array}{c}(3) \\
\text { Initial Ind. }\end{array}$ & $\begin{array}{c}(4) \\
\text { Manuf. }\end{array}$ & $\begin{array}{c}(5) \\
\text { Constr. }\end{array}$ & $\begin{array}{c}(6) \\
\text { Mining }\end{array}$ & $\begin{array}{c}(7) \\
\text { Agric. }\end{array}$ & $\begin{array}{c}(8) \\
\text { Services }\end{array}$ & $\begin{array}{c}(9) \\
\text { Unknown }\end{array}$ \\
\hline \multicolumn{10}{|c|}{ Panel A: Low Income $(n=27,902)$} \\
\hline$-\Delta \ln \left(1+\tau_{j}^{\mathrm{CAN}}\right)$ & $\begin{array}{c}0.719 \\
(3.532)\end{array}$ & $\begin{array}{l}-3.682 \\
(2.997)\end{array}$ & $\begin{array}{l}-1.834 \\
(1.653)\end{array}$ & $\begin{array}{c}2.626 \\
(3.052)\end{array}$ & $\begin{array}{l}1.504^{*} \\
(0.759)\end{array}$ & $\begin{array}{c}0.492 \\
(0.353)\end{array}$ & $\begin{array}{l}-0.675 \\
(0.437)\end{array}$ & $\begin{array}{c}2.277 \\
(2.079)\end{array}$ & - \\
\hline$-\Delta \ln \left(1+\tau_{j}^{\mathrm{US}}\right)$ & $\begin{array}{c}8.985 \\
(5.790)\end{array}$ & $\begin{array}{c}5.094 \\
(4.677)\end{array}$ & $\begin{array}{c}2.342 \\
(2.513)\end{array}$ & $\begin{array}{l}-3.652 \\
(4.587)\end{array}$ & $\begin{array}{c}1.477 \\
(1.376)\end{array}$ & $\begin{array}{l}-0.328 \\
(0.710)\end{array}$ & $\begin{array}{c}0.135 \\
(0.818)\end{array}$ & $\begin{array}{c}3.541 \\
(4.079)\end{array}$ & - \\
\hline R-squared & 0.124 & 0.053 & 0.014 & 0.033 & 0.025 & 0.013 & 0.019 & 0.114 & 0.009 \\
\hline \multicolumn{10}{|c|}{ Panel B: High Income $(n=27,901)$} \\
\hline$\overline{-\Delta \ln \left(1+\tau_{j}^{\mathrm{CAN}}\right)}$ & $\begin{array}{c}1.482 \\
(1.714)\end{array}$ & $\begin{array}{l}-1.514 \\
(2.965)\end{array}$ & $\begin{array}{c}-1.010 \\
(1.191)\end{array}$ & $\begin{array}{c}5.752^{* * *} \\
(2.015)\end{array}$ & $\begin{array}{c}0.532 \\
(0.475)\end{array}$ & $\begin{array}{c}0.326 \\
(0.354)\end{array}$ & $\begin{array}{c}-0.0307 \\
(0.111)\end{array}$ & $\begin{array}{c}-2.611^{*} \\
(1.426)\end{array}$ & $\begin{array}{c}0.0382 \\
(0.0283)\end{array}$ \\
\hline$-\Delta \ln \left(1+\tau_{j}^{\mathrm{US}}\right)$ & $\begin{array}{c}2.808 \\
(2.728)\end{array}$ & $\begin{array}{c}16.47^{* * *} \\
(5.686)\end{array}$ & $\begin{array}{c}-6.550 * * \\
(2.790)\end{array}$ & $\begin{array}{l}-6.498 \\
(4.444)\end{array}$ & $\begin{array}{c}0.655 \\
(0.849)\end{array}$ & $\begin{array}{l}-0.976 \\
(0.654)\end{array}$ & $\begin{array}{c}-0.448^{* *} \\
(0.197)\end{array}$ & $\begin{array}{c}0.154 \\
(1.644)\end{array}$ & $\begin{array}{l}0.00419 \\
(0.0409)\end{array}$ \\
\hline R-squared & 0.081 & 0.087 & 0.057 & 0.044 & 0.017 & 0.026 & 0.008 & 0.044 & 0.005 \\
\hline
\end{tabular}

Notes: Dependent variable is the sum of a worker's earnings during 1989-2004, divided by the worker's average yearly earnings in 1986-1988 (omitting years with zero earnings), defined in equation (2). The independent variables of interest are the 1988-1998 tariff cuts facing U.S. exports to Canada $\left(-\Delta \ln \left(1+\tau_{j}^{\mathrm{CAN}}\right)\right)$ or facing Canadian exports to the U.S. $\left(-\Delta \ln \left(1+\tau_{j}^{\mathrm{US}}\right)\right)$ in the worker's initial industry. A positive (negative) coefficient means that larger tariff cuts in the worker's initial industry lead to increased (decreased) cumulative earnings. Column (1) examines total earnings from all sources, (2) earnings from the initial firm, (3) from firms other than the initial firm, but in the same initial 4-digit industry, (4) in manufacturing industries (NAICS=3xxx) other than the initial industry, (5) in construction and utilities (NAICS $=22 \mathrm{xx}, 23 \mathrm{xx}),(6)$ in mining (NAICS $=21 \mathrm{xx}),(7)$ in agriculture (NAICS $=1 \mathrm{xxx}),(8)$ in services (NAICS $\geq 4 \mathrm{xxx}$ ), or (9) from a firm with unknown industry code. Because earnings in columns (2) through (9) additively decompose total earnings, the coefficients in columns (2) through (9) sum to the overall effect in column (1). All specifications include extensive worker, initial firm, and initial industry controls, described in Section 4. Estimates suppressed due to data confidentiality concerns are shown as -. Standard errors clustered by 4-digit NAICS industry. ${ }^{* * *} \mathrm{p}<0.01,{ }^{* *} \mathrm{p}<0.05,{ }^{*} \mathrm{p}<0.1$. 


\section{C.10 Net Effects by Industry}

In Figures A5-A7, we present the net effects of Canadian and U.S. tariff cuts on the probability of experiencing a work-shortage related separation (layoff), on overall cumulative earnings, and on cumulative earnings from the initial firm. We present results for low attachment workers initially at large firms because this worker group generally exhibits the largest point estimates. The predicted effects are evaluated at the particular Canadian and U.S. tariff cuts facing each industry and divided by the average outcome for low attachment workers initially at large firms, so the predicted values are expressed as proportional differences from the average outcome. Each figure sorts industries on the $\mathrm{x}$-axis from most negative to most positive net effect.

Figure A5 shows the net effects for permanent work-shortage related separations. In spite of focusing on the worker group with the largest point estimates, the majority of predicted net effects are small, with magnitudes less than 20 percent, and only 3 out of 78 manufacturing industries exhibit effects that are statistically different from zero at the 5 percent level. The results for cumulative earnings in Figure A6 are similar. Only 4 industries exhibit point estimates with magnitudes above 10 percent, and again only 3 are statistically different from zero. These findings make clear that even though low attachment workers at large firms have nontrivial predicted effects of each individual tariff change, the net effects are relatively small because the effects of Canadian and U.S. tariff cuts generally offset each other.

Figure A7 shows the net effects on cumulative earnings from the worker's initial firm. Consistent with the overall estimates shown in the main text, these effects are substantially larger than the overall earnings estimates, reflecting Canadian workers' ability to recover lost earnings at the initial firm by transitioning into other positions. In this case 25 industries exhibit net effects that are distinguishable from zero, all of them with negative point estimates. 


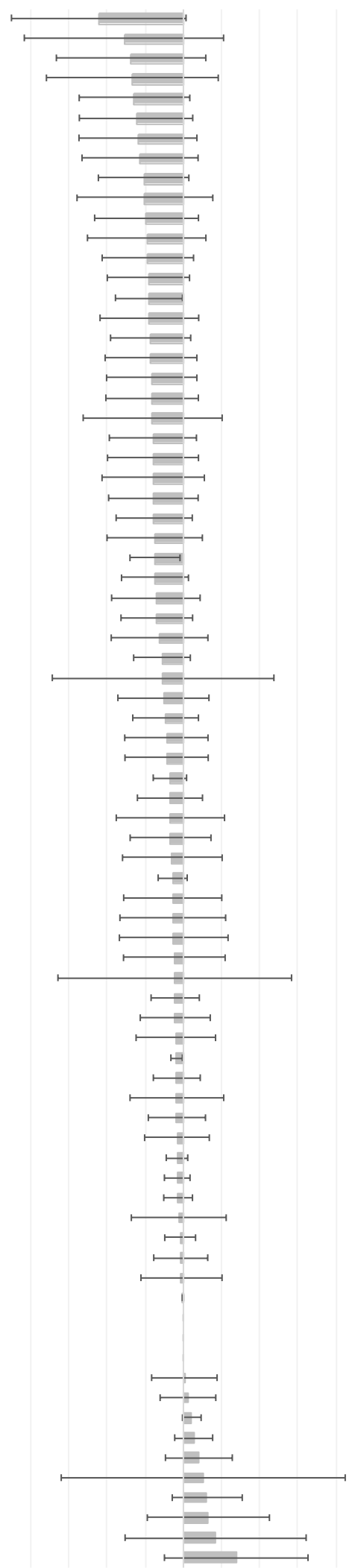

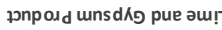

Su! पs!

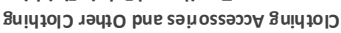

s8u!ys!uanf

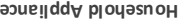

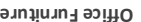

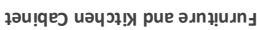

sulp!!ng zeog pue d!

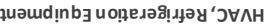

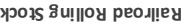

дәчцеә дачио

zon pord כopseld

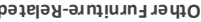

7uamd!nb

səạp uno-

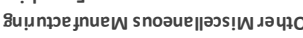

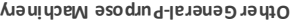

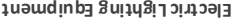

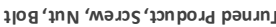

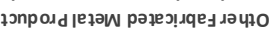

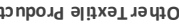

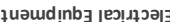

zonpord dəqqny

วэnpodd 2 ม!M pue Su!dds

роол дәчто

zэn родd dәdе d рәдәлио

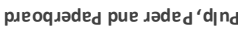

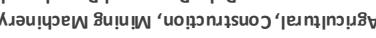

zиәші!n b

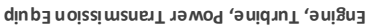

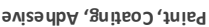

zon podd poo $M$ ләчто

ouquey

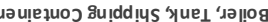

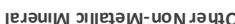

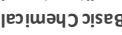

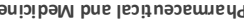

unu!man| pue eu!man|

zonpodd ןəozs

Su!dmets pue sulgos

sse.j

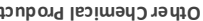

pood ןemin

әр!н рие дәчұеәา

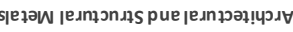

deos

јооц риен рие мәрпз

деамұоо-

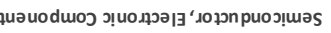

роoмk|d pue дәәиә

S|!!W |әәнs pue uod

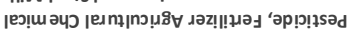

รุนว

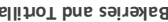

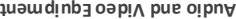

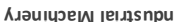

|eqaW snoגaz-UoN

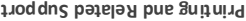

zиәшd!nb

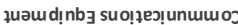

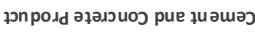

poojeas

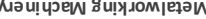

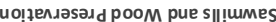

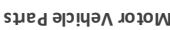

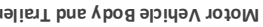

әрगччәА

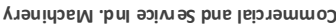

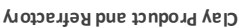

әэеdsonəy

zon pord $\mathrm{d}$ eо

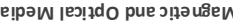

8u! чрор Mәs pue znว

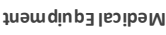

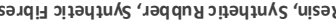

реәдप 1 pue uлe八 'әлq!

po어 사티라요 
poot ᄉiejoads

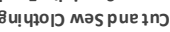

реәдчц рue ихек 'әхq!

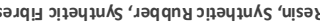

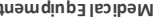

деәмұо0-

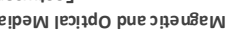

ग!qqe

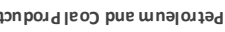

Moljexjay pue zonpodd Kep

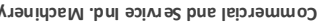

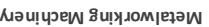

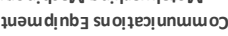

әэеdsoдән

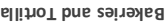

deos

10о1 риен рие Кәрп

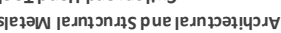

poojeas

әр!н рие дәчұеәт

S|!!W |әәэs pue uod|

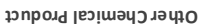

Suld duets pue su!gso-

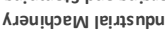

poomk Id pue дәәиә

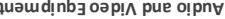

ұэnролd әұәлиоо рие ұиәшәว

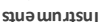

sseje

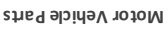

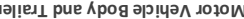

әр!ч๖ә

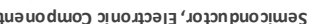

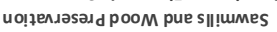

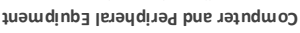

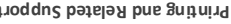

zonpodd jəכis

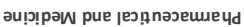

ןę⿰丨丨 snodxay-uon

ןอगุщәчว ग!ฺseg

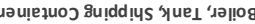

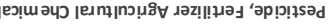

pood ןew!iu

|едәи!

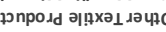

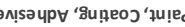

unu!̣un| pue eu!̣un|

zวnролd роом дачғо

ᄀนวш d!̣nb

zonposd dəded рәдәлио

วonpodd dəqqny

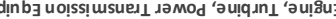

ponpodd a!!M pue su! sds

₹uәud!nb

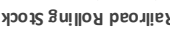

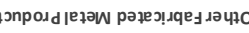

әемрден

poog дәчто

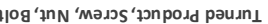

zonposd כịseld

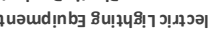

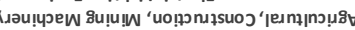

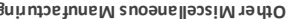

дәчұеә дация

Mәиічәеw әsodin d-ןедәиәэ дәчзо

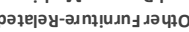

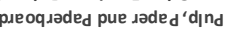

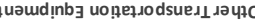

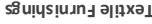

sə!.punot

Suip!ng łeog pue d! $!$ S

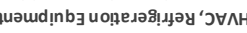

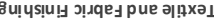

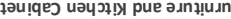

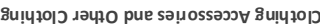

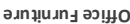

әэие!|ddy ріочәsno

วonposd uns $\mathrm{d} /{ }_{\mathrm{g}}$ pue əu!?
द્व

$\infty$ ర)

తై

\&

글

节

की

त

iั

$\stackrel{20}{\Xi}$

हี

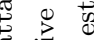

霖

3

잉 छ

$\begin{array}{lll}00 & 0 & 0\end{array}$

ヨ

ฮี

ठ

శึ.

4 ○

○

in 0

焉

50

武.

足范

ช ฮ

ฮี

$\dot{2} \stackrel{\square}{ }$

$\triangleright$ 票

¿

च 20

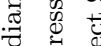

范

(ั)

8 \%

范

苍苛

娄

苞

를

范

可

$\ddot{2} . \dot{3}$

空

$x>$

击贾

ర్

D

สี

$\therefore$ 욜

西苟莺

$\therefore .980$

iी 0 ल

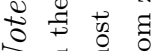




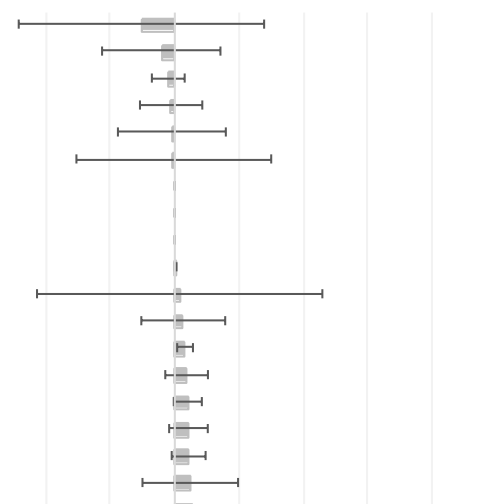

poof $\Lambda$ 기 ẹpads

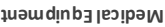

әэedsodər

วən pord

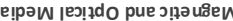

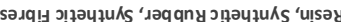

sนed әр!чәл

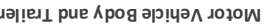

әрग़чә

uоाтелдәsаd d poom pue s!l!umes

реәлчп рие илек 'әлq!

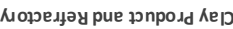

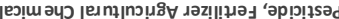

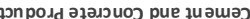

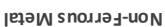

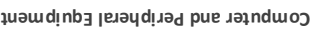

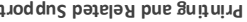

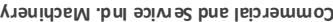

poojeas

poof ןeu!

słuəundzsu|

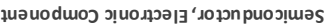

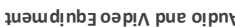

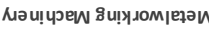

unu!̣un|

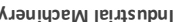

роомК Id pue дәәиә

S|!!W |әәtS pue uod!

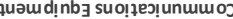

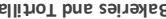

zonpodd ןəətS

ssej

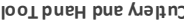

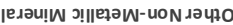

әр!н рие дәчдеәт

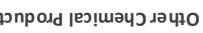

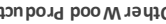

deos

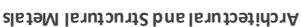

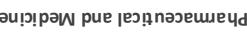

ןеग!шәчว गุseg

su!̣duets pue su!̣ి.ం-

pגeoquaded pue גəde $\mathrm{d}$ 'd $\mid \mathrm{n}_{d}$

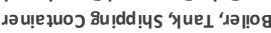

8u! पұo Mas pue zno

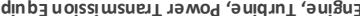

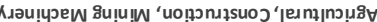

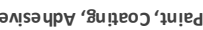

роО- дәчто

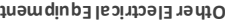

sə̣!puno-

алемрден

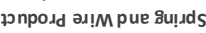

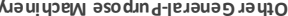

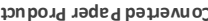

zuәud Inb

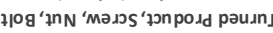

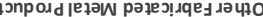

zuәud Inb

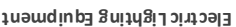

zonpodd dəqqny

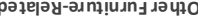

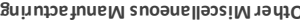

zuәud In b

Аәчреә дачро

деәмา00-

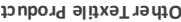

zon posd כịse |d

su!p!!ng teog pue d! !

yวots 8 8u!॥оy peod!!ey

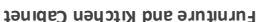

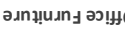

әэuе !dd $\forall$ рाочәsn он

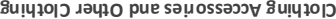

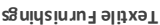

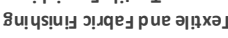

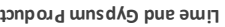




\section{C.11 Regional Shocks and Industrial Geography}

This Appendix explores what role geography plays in generating the results in this paper. Because the T2-LEAP-LWF data set from Statistics Canada includes only very coarse province-level geographic information, we are unable to observe worker outcomes by Canadian local labor market. This data limitation precludes the implementation of a local-labor-markets analysis along the lines of Topalova (2010), Kovak (2013), or Autor et al. (2013a). However, using data in the public domain, we can construct regional tariff shocks paralleling those used in these local-markets analyses in an effort to understand whether features of Canadian industrial geography may have facilitated Canadian worker adjustment to its CUSFTA tariff concessions. For example, if a large share of the Canadian population lives in cities or otherwise industrially diverse regions, then workers facing unfavorable shocks may be able to find employment in favorably affected industries without having to relocate.

In order to assess if Canadian geography is special in some way, we require a benchmark for comparison. We choose the US as a natural comparison. Our strategy is to calculate actual regional shocks associated with the Canadian CUSFTA tariff cuts using Canadian industrial geography, and then to calculate a hypothetical set of regional shocks using the same industry tariff cuts but US industrial geography. We emphasize that this is not a counterfactual experiment but rather an attempt to examine whether and how Canadian industrial geography might have affected regional shocks.

We emphasize three findings. First, using the same set of industrial shocks, fewer Canadian regions than US regions would face large shocks. Second, we find no evidence that this is because Canadian regions are more industrially diversified. Third, we show that randomly generated industry-level shocks do not generate systematically different regional shocks in Canada and the US. Together, these findings provide little evidence in support of observable differences in industrial geography as a main driver of the relatively smooth and speedy reallocation of Canadian workers away from industries facing large increases in import competition. Rather, this particular set of tariff changes would have generated more large-shock regions in the US than it did in Canada, but a similar comparison should not be expected for other arbitrary industry shocks.

\section{C.11.1 Local Labor Markets}

We define Canadian local labor markets based on the Census Division classification from Statistics Canada. This definition allows us to use a custom tabulation from the 1986 Canadian Census of Population reporting the industry distribution of regional employment. Jeff Chan uses these data in Chan (2019), and we thank him for generously providing this tabulation. We follow the literature by defining US local labor markets based on Commuting Zones. It is important that these two levels of geographic aggregation (Census Division vs. Commuting Zone) are comparable across the two countries. Figure A8 confirms this comparability by plotting a histogram of regional log employment in 1986 using employment data for Canadian Census Divisions from Chan (2019) and for US Commuting Zones from the 1986 County Business Patterns (CBP), with imputed values from Eckert et al. (2020). ${ }^{71}$ The two distributions have extensive common support, with the US having both smaller and larger locations than those seen in Canada, indicating that neither country's

\footnotetext{
${ }^{71}$ We aggregate from counties to commuting zones using the concordance provided by David Dorn: https://www . ddorn.net/data/cw_cty_czone.zip.
} 
Figure A8: Histograms of 1986 Employment by Canadian Census Division and US Commuting Zone

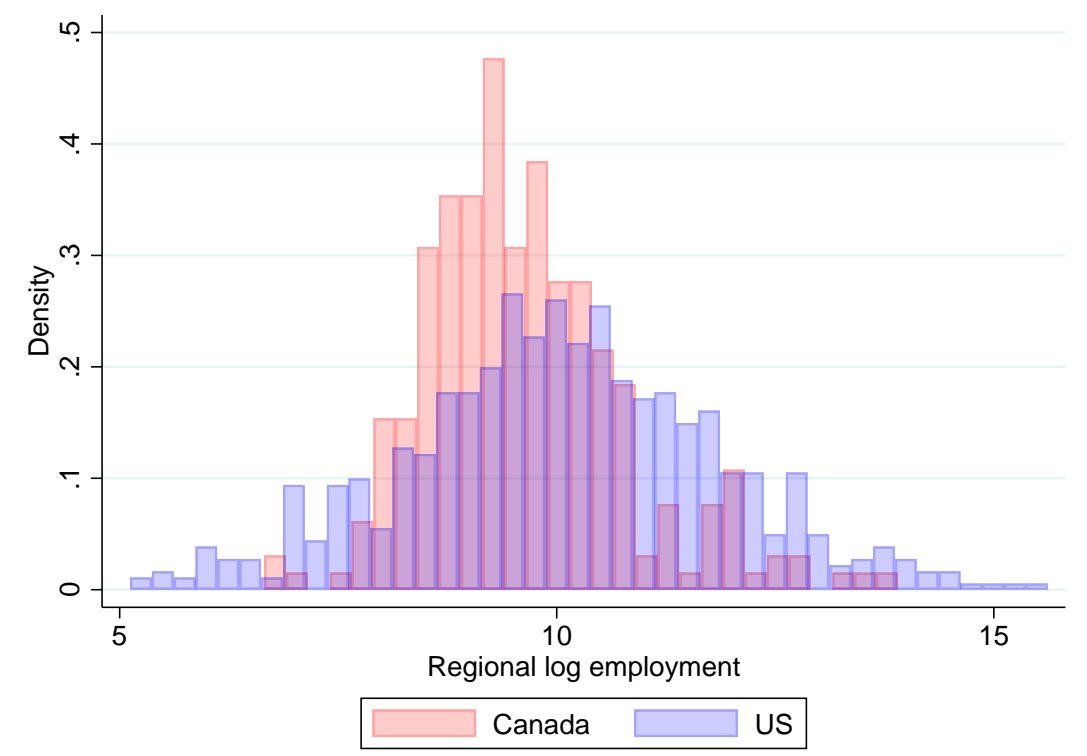

Notes: The red histogram plots log employment across Canadian Census Divisions from a special tabulation of the 1986 Canadian Census of Population generously provided by Jeff Chan. The blue histogram plots log employment across US Commuting Zones from 1986 County Business Patterns with imputed values from Eckert et al. (2020). The bars are semi-transparent, so the overlap appears purple. The extensive common support between the two distributions implies that neither country's regions are systematically more aggregated than the other's.

locations are systematically more aggregated than the other's on average.

\section{C.11.2 Regional Tariff Reductions}

Regional tariff reductions reflect the regional employment-weighted averages of industry-level tariff reductions. Industry $i$ 's share of 1986 employment in region $r$ in country $c \in\{$ CAN,US $\}$ is given by $\varphi_{r i}^{c}$. Note that $\varphi_{r i}^{c}$ is the share of all employment in region $r$, including non-manufacturing and nontradable industries. For each country, we calculate two versions of the regional tariff reduction: one reflecting the average regional tariff reduction within manufacturing $(\mathrm{M})$,

$$
s_{r}^{c, \mathrm{M}} \equiv-\sum_{i \in \mathrm{M}} \frac{\varphi_{r i}^{c}}{\sum_{j \in \mathrm{M}} \varphi_{r j}^{c}} \Delta \ln \left(1+\tau_{i}^{\mathrm{CAN}}\right) \quad \forall r \in c \text { and } c \in\{\mathrm{CAN}, \mathrm{US}\}
$$

and one averaging across all industries, with zero tariff reduction outside manufacturing:

$$
s_{r}^{c} \equiv-\sum_{i} \varphi_{r i}^{c} \mathbf{1}(i \in \mathrm{M}) \cdot \Delta \ln \left(1+\tau_{i}^{\mathrm{CAN}}\right) \quad \forall r \in c \text { and } c \in\{\mathrm{CAN}, \mathrm{US}\} .
$$


Figure A9: Histograms of Tariff Reductions by US and Canadian 3-digit SIC Manufacturing Industries

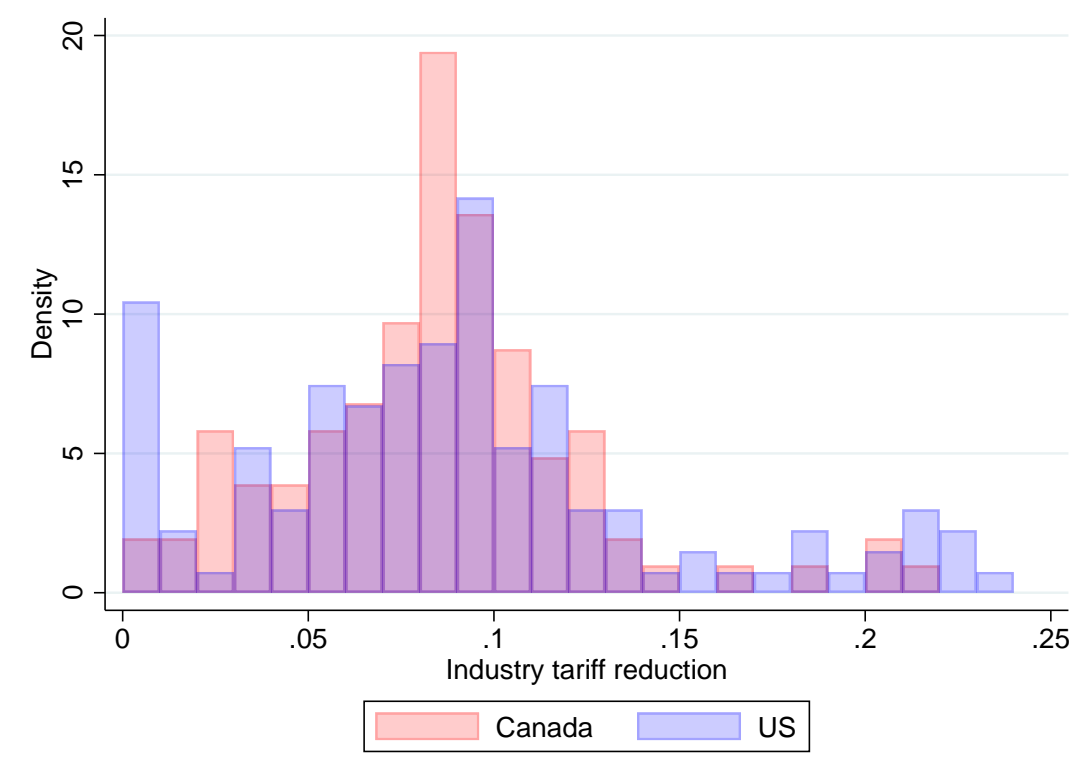

Notes: The red histogram plots tariff reductions $\left(\Delta \ln \left(1+\tau_{i}^{\mathrm{CAN}}\right)\right)$ across Canadian 3-digit SIC industries, while the blue histogram plots tariff reductions across US 3-digit SIC industries. The bars are semi-transparent, so the overlap appears purple. The similarity between the two distributions implies that the two SIC definitions are comparable.

Because our focus is on industrial geography, the regional tariff reductions for both Canada and the US use the same vector of tariff reductions. We choose the CUSFTA tariff reductions facing US exports to Canada, i.e. $\tau^{\mathrm{CAN}}$. By using the same tariff changes in all of the measures, we isolate the implications of differences the industrial geography across the two countries.

To match the level of industry detail available in the Canadian Census data and the 1986 US CBP regional employment data, we use tariff changes at the 3-digit SIC level. ${ }^{72}$ Because the Canadian and US versions of the SIC classification differ somewhat, we are concerned that shocks derived from the same HS-level data might generate different SIC-level shocks. Figure A9 assuages this concern by showing that the cross-industry distribution of tariff reductions is similar across the two versions.

Given comparable industry definitions and levels of geographic aggregation, we calculate the regional tariff reductions in (4) and (5) using the industrial geography of Canada $\left(\varphi_{r i}^{\mathrm{CAN}}\right)$ or the US

\footnotetext{
${ }^{72}$ We begin with CUSFTA tariff reductions provided by Global Affairs Canada at the 8-digit Harmonized System (HS) level. For Canada, then truncate to 6-digit HS codes, map to 5-digit NAICS-1997 codes using the concordance from Pierce and Schott (2012), and then map from 5-digit NAICS to 3-digit 1980 Canadian SIC-E codes using the Statistics Canada crosswalk available here: https://www.statcan.gc.ca/eng/subjects/standard/ concordances/concordance1997-1980. For the US, we truncate to 6-digit HS codes and then map to 3-digit 1980 US SIC codes using the "H0 to SIC" concordance available here: https://wits.worldbank.org/product_ concordance.html. Once we have HS codes mapped to SIC industries, we aggregate the tariff levels, weighting HS codes based on 1988 Canadian imports from the US.
} 
$\left(\varphi_{r i}^{\text {US }}\right) .{ }^{73}$ The resulting shocks appear in Figure A10. The shocks calculated using manufacturing industries only in panel (a) are of higher magnitude than those for all industries in panel (b) because the latter averages in zero tariff changes for non-manufacturing industries. In both cases, it is clear that a number of US regions would have faced larger regional tariff reductions than any of the Canadian regions. Since the tariff reductions are all based upon the vector of Canadian CUSFTA tariff cuts, the differences between Canada and the US are solely due to differences in the industrial geography of employment in each country's regions.

Figure A11 corroborates Figure A10's maps by plotting the distributions of regional tariff reductions across Canadian and US regions, weighted by total employment in each region. Many US regions would have faced substantially larger tariff reductions than the most heavily shocked Canadian regions. For example, for manufacturing-only regional shocks, only 1 percent of the Canadian population lives in regions facing shocks of at least 10 percent, while 11.3 percent of the US population lives in regions facing these large shocks. Similarly, for all-industry shocks, only 5 percent of Canada's population lives in regions facing shocks of at least 2.5 percent, while 19.9 percent of the US population lives in regions facing these large shocks.

One important point to note when considering the all-industry shocks is that the US CBP data omit a number of industries in agriculture and government, which artificially inflates the US manufacturing share of employment observed in the CBP by omitting some non-manufacturing employment that would fall in the denominator of the manufacturing share. Although we have restricted the sample of Canadian industries in an attempt to cover an identical set of industries, it is possible that we nonetheless overstate the manufacturing share by more in the US than in Canada. If so, the all-industry regional tariff reductions will be systematically overstated in the US relative to Canada. In fact, although national data suggest the manufacturing share of employment is extremely similar in Canada and the US (17.1 in Canada and 17.6 in the US in 1986), our sample finds a manufacturing share of employment of 20.1 percent in Canada and 23.4 in the US. ${ }^{74}$ This potential measurement issue will become important in interpreting the all-industry results based on the tariff simulations below. This concern does not apply to the manufacturing-only regional tariff reductions.

\section{C.11.3 Regional Industry Concentration}

A potential explanation why Canadian regions do not face particularly large tariff reductions is that they are more industrially diverse than their US counterparts. This can be because either a larger share of Canadians lives in industrially diverse cities, or because Canadian locations are more industrially diverse than US locations, conditional on size. We check this possibility directly by calculating the Herfindahl-Hirschman Index (HHI) of industry employment shares in each Canadian and US region. Figure A12 shows the distributions of HHI values across regions within each country, weighting by total regional employment. For both manufacturing industries (panel a) and all industries (panel b), the HHI distributions between Canada and the US are not systematically

\footnotetext{
${ }^{73}$ The US County Business Patterns data report the vast majority of county employment at the 3-digit SIC or more detailed level, but a portion of employment is reported at the 2-digit SIC level. We apportion this 2-digit employment to underlying 3-digit industries based on each 3-digit industry's share of national employment within the corresponding 2-digit industry.

${ }^{74}$ National statistics based on the BLS International Comparisons of Annual Labor Force Statistics program, as reported by FRED.
} 
different. While Canada has more locations with low concentration, it also has higher density than the US in more concentrated locations. This suggests that Canadian regions are not systematically more industrially diverse than US regions and that differences in regional shocks are not coming from systematic differences in regional concentration.

\section{C.11.4 Tariff Change Simulations}

Given the apparent similarity between industry concentration in Canadian and US regions, we seek to understand whether there are other systematic differences between the industrial geography of Canada and the US that might drive the apparent differences in regional shocks in Figures A10 and A11. To do so, we fit the observed distribution of Canadian CUSFTA tariff changes across manufacturing industries to a 2-parameter Weibull distribution and use this distribution to generate 1000 simulated IID tariff change vectors. We then calculate regional tariff reductions for the US and Canada using each simulated tariff change vector and the real-world industrial geography of each country. For each simulation we calculate i) the share of national population living in regions facing large shocks (10 percent for the manufacturing-only shock and 2.5 percent for the all-industry shock) and ii) the population-weighted inter-quartile range of regional tariff reductions.

Figures A13 and A14 present histograms of these statistics across the 1000 simulations to see whether systematic differences emerge across countries. Figure A13 shows the results for the manufacturing-only shocks, which are influenced only by differences in the composition of manufacturing employment across regions in each country. The distributions are extremely similar across countries for both statistics, implying that the industrial geographies of manufacturing in Canada and the US yield similar regional tariff reductions across simulated industry tariff reductions.

This conclusion contrasts with the larger tariff reductions facing many US regions in Figure A11 panel (a). While the particular tariff reduction vector employed in Figure A11 (the Canadian CUSFTA tariff cuts) implies large regional tariff reductions in a number of US regions, this feature is specific to that particular vector of tariff changes and not the systematic result of differences in Canadian and US industrial geography.

The results for the simulated all-industry regional tariff reductions in Figure A14 show more substantial differences, but these should be interpreted with care. In particular, the share of the population in regions facing large shocks is substantially larger across simulations in the US than in Canada. In all simulations (as in the actual tariff changes) the tariff reductions outside manufacturing are set to zero, so the difference between the all-industry and manufacturing-only results are driven by differences in the manufacturing share of employment. As mentioned above, although comprehensive national data report very similar manufacturing shares of employment in Canada and the US, the region-by-industry employment data used to construct the regional tariff reductions imply a higher manufacturing share in the US than in Canada. It is therefore likely that the differences between the US and Canada in Panel (a) of Figure A14 are driven by this data artifact. Panel (b) of Figure A14 shows that, if anything, the inter-quartile range in Canada is systematically larger than in the US.

\section{C.11.5 Regional Shocks Summary}

Together, these results provide little evidence in support of the hypothesis that Canadian industrial geography accounts for the relatively smooth and speedy reallocation of workers from industries 
facing more import competition to more favorably affected industries. Canadian workers are not systematically more likely to live in industrially diverse regions than are workers in a natural comparison economy, the US. Nor are Canadian workers systematically less likely to face large shocks or large differences in shocks across regions when facing arbitrary tariff changes. 
Figure A10: Regional Tariff Reductions

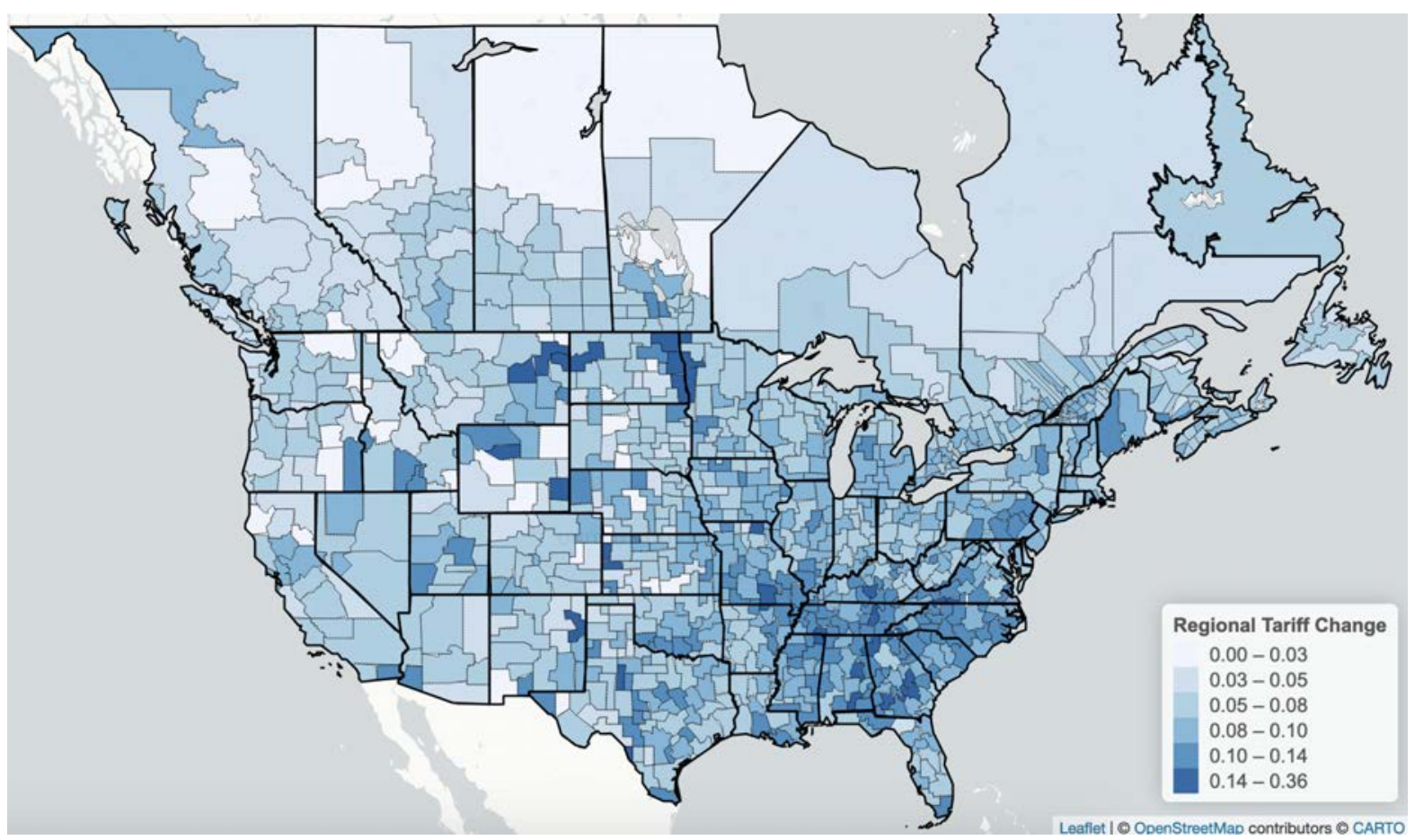

(a) Manufacturing Industries Only

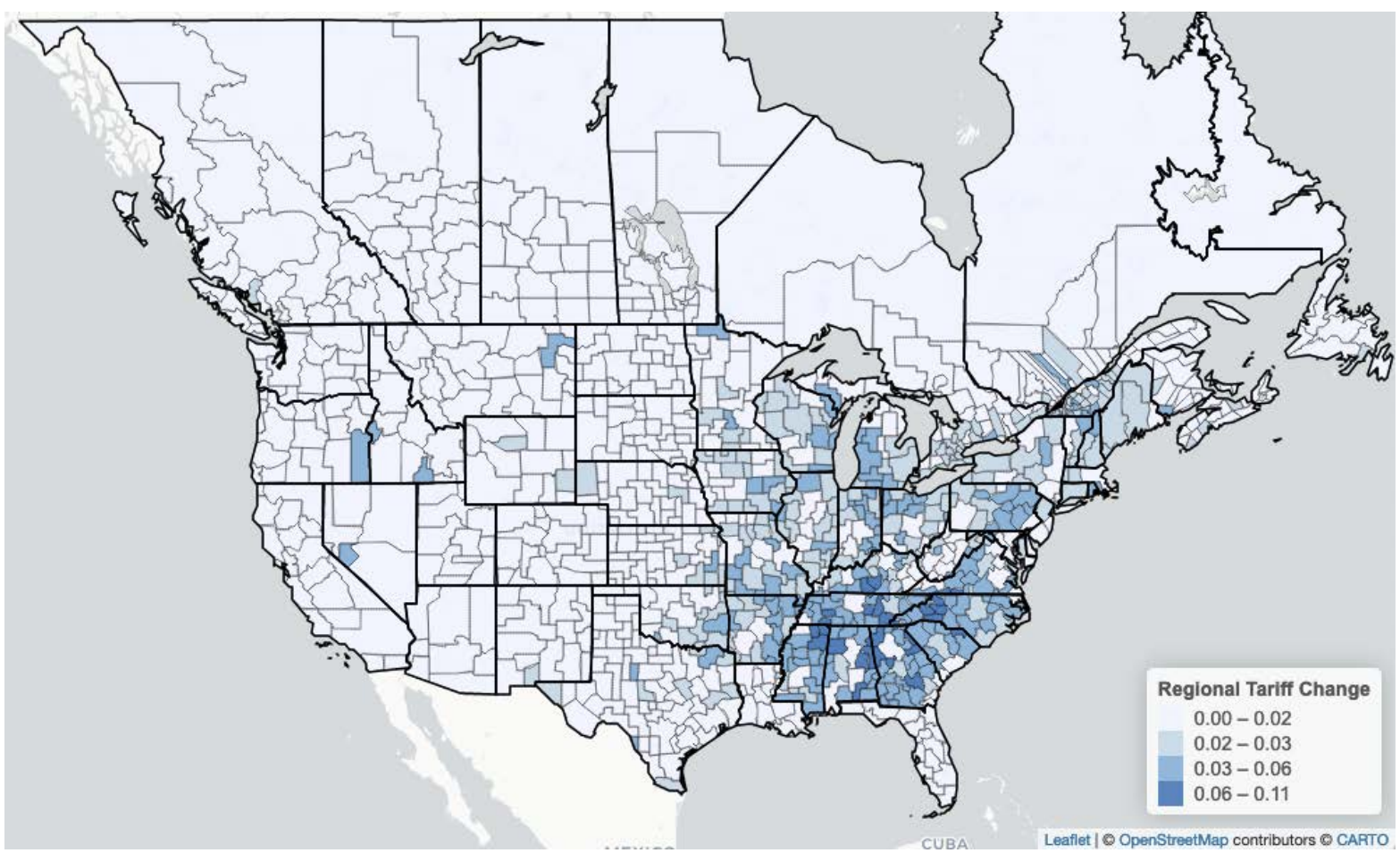

(b) All Industries

Notes: Panel (a) shows regional tariff reductions calculated using only manufacturing industries as in equation (4). Panel (b) shows regional tariff reductions calculated using all industries, with those outside manufacturing facing zero tariff reduction, as in equation (5). 
Figure A11: Regional Tariff Reductions

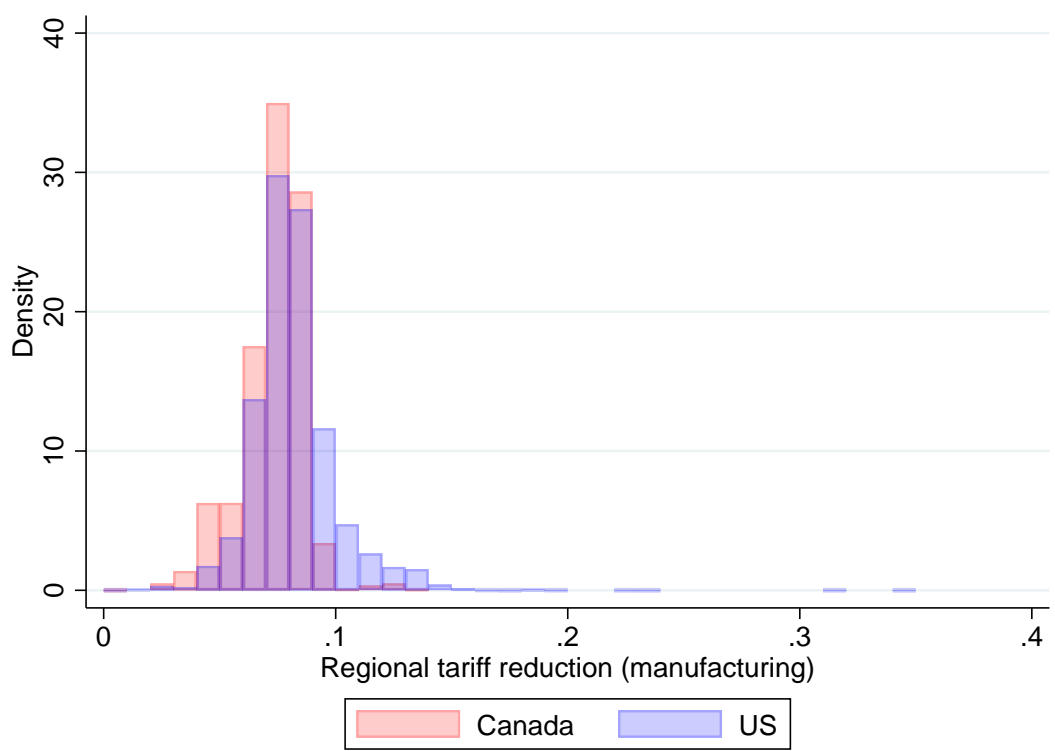

(a) Manufacturing Industries Only

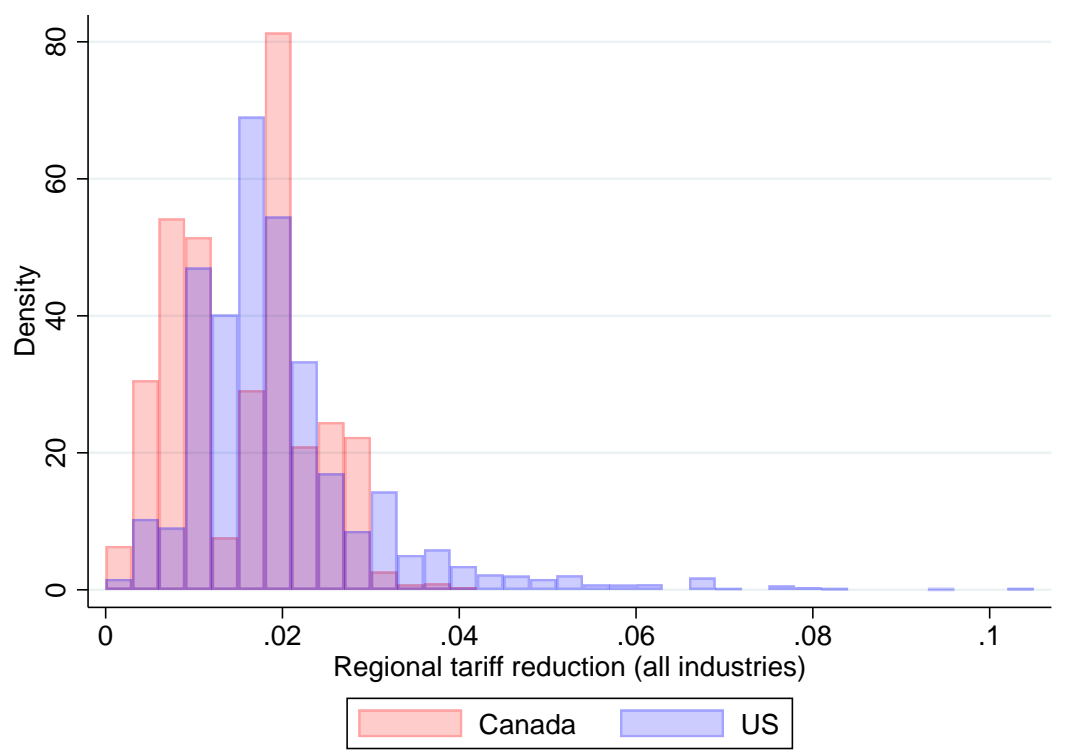

(b) All Industries

Notes: Panel (a) shows the within-country distributions of regional tariff reductions calculated using only manufacturing industries as in equation (4). Each distribution is weighted by total regional employment. Panel (b) shows the within-country distributions of regional tariff reductions calculated using all industries, with those outside manufacturing facing zero tariff reduction, as in equation (5). 


\section{Figure A12: Regional Industry Concentration of Employment (HHI)}

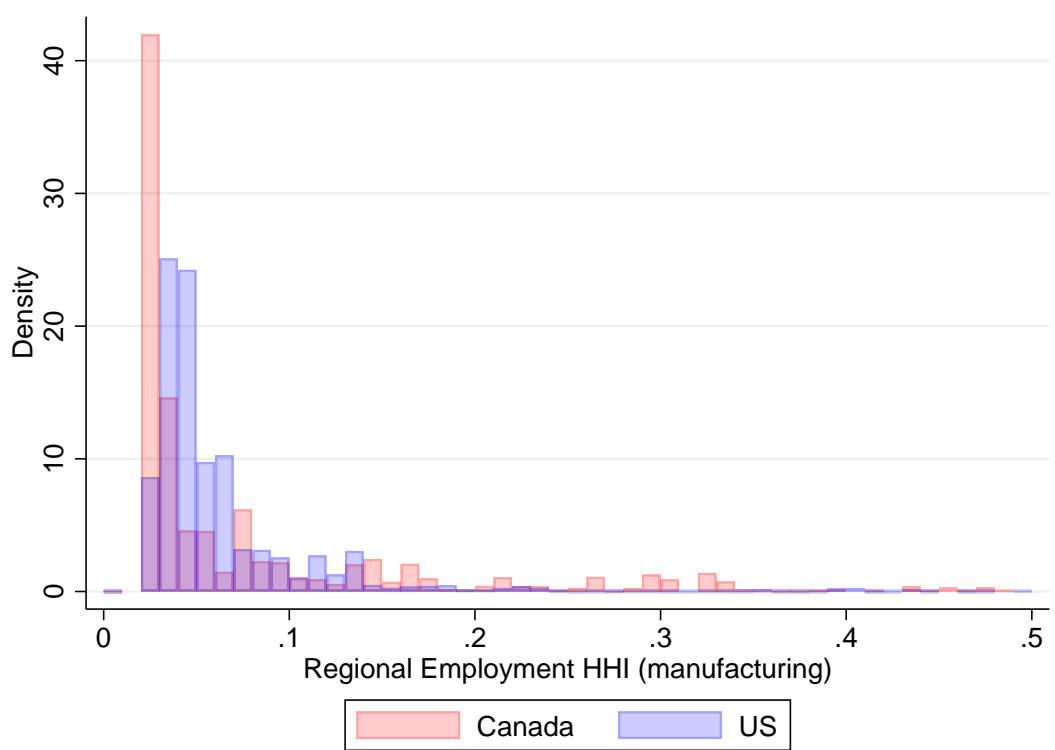

(a) Manufacturing Industries Only

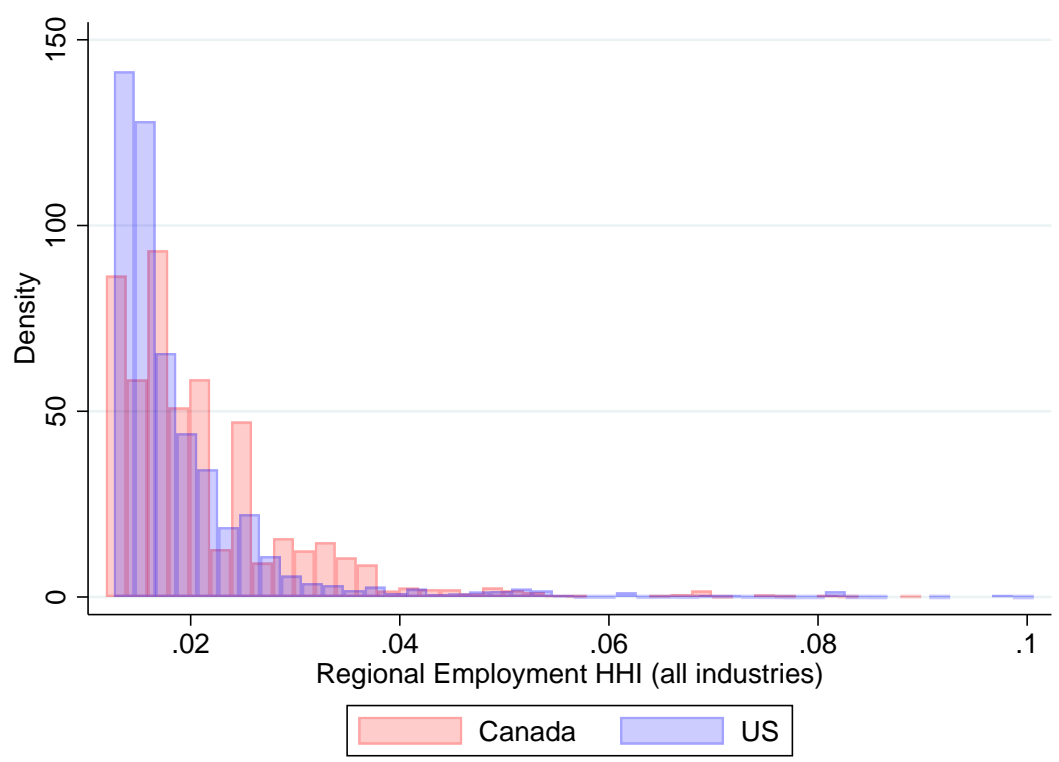

(b) All Industries

Notes: Both panels show the within-country distributions of the Herfindahl-Hirschman Index (HHI) of industry employment concentration within each country. Panel (a) shows industry concentration of employment within manufacturing, while Panel (b) shows industry concentration across all industries. To enhance readability, panel (a) restricts to HHI values of 0.5 or less and panel (b) restricts to HHI values of 0.1 or less, omitting an extremely small share of employment in both cases. 
Figure A13: Simulation Results - Manufacturing-Only Regional Tariff Reductions

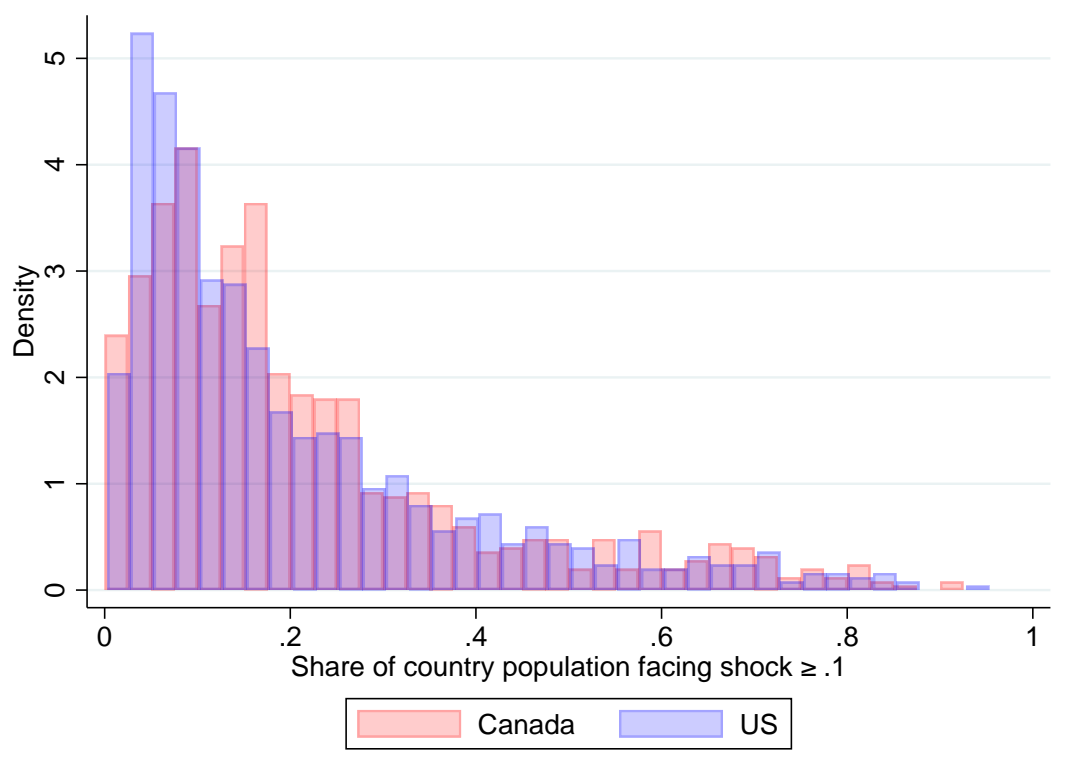

(a) Share of Population in Regions Facing 10 Percent or Larger Tariff Reduction

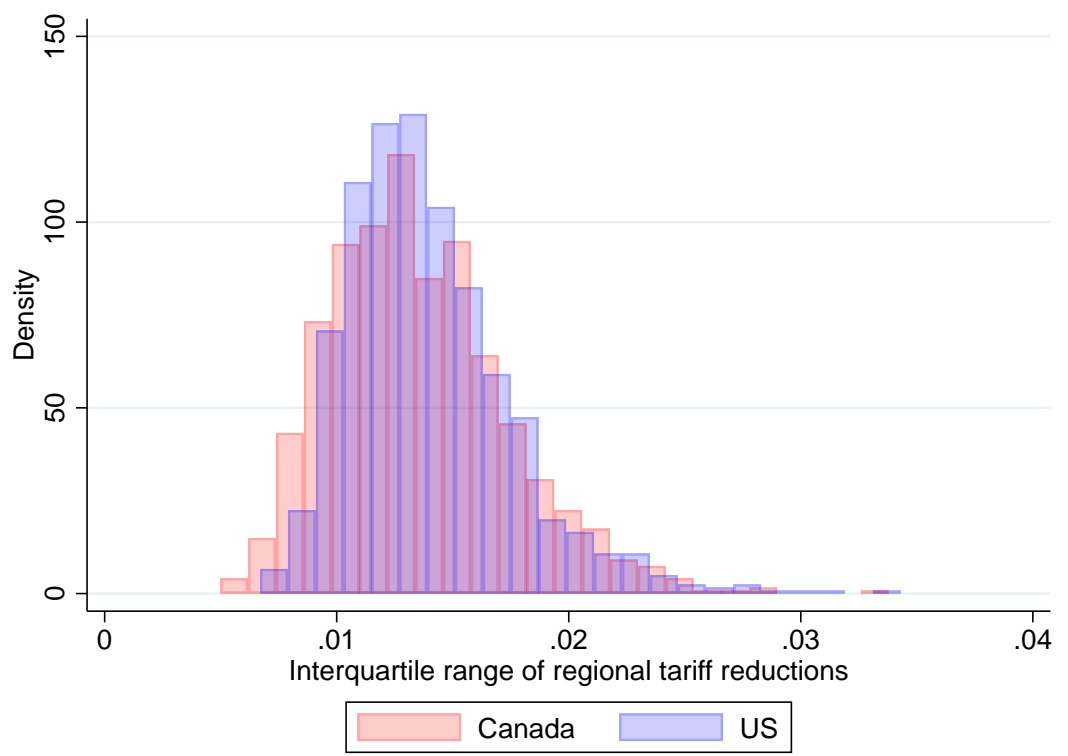

(b) Population-Weighted Inter-Quartile Range of Regional Tariff Reductions

Notes: Summary statistics from manufacturing-only regional tariff reductions based on 1000 simulated vectors of industry tariff changes. Panel (a) shows the share of the relevant country's population facing regional tariff reductions of 10 percent or more. Panel (b) shows the population-weighted inter-quartile range of regional tariff reductions. In both cases, the close agreement between the distributions implies that the industrial geography of manufacturing industries does not lead to systematic differences in the distributions of regional tariff reductions in Canada and the US. 
Figure A14: Simulation Results - All-Industry Regional Tariff Reductions

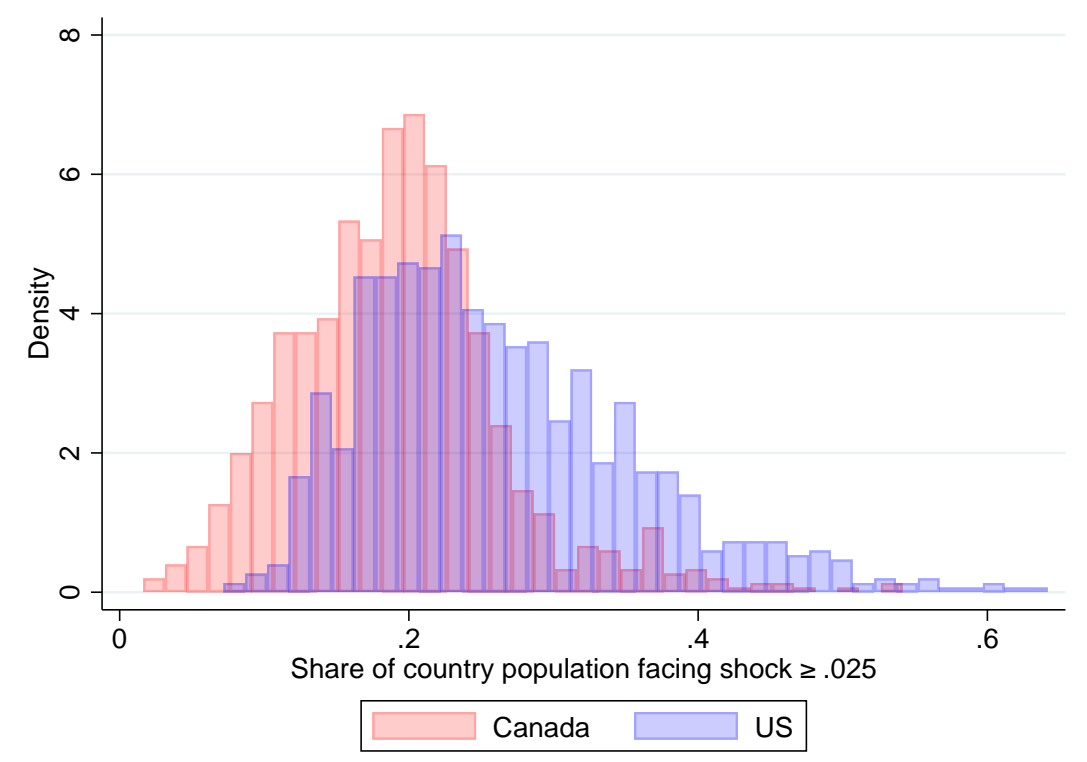

(a) Share of Population in Regions Facing 10 Percent or Larger Tariff Reduction

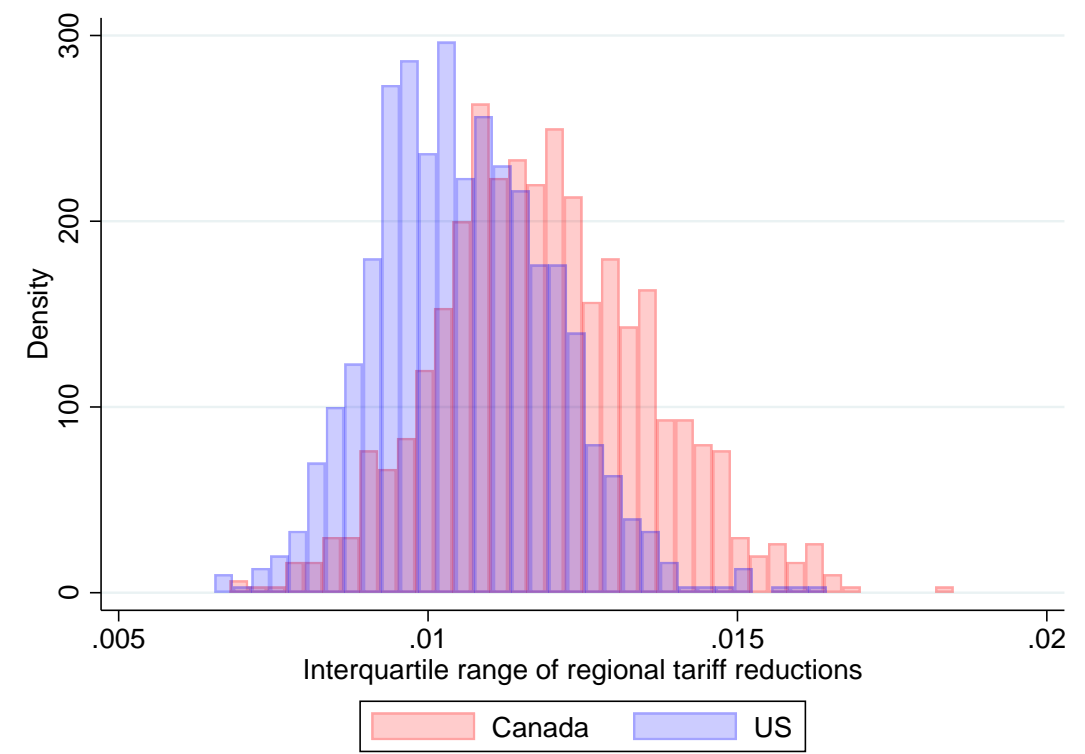

(b) Population-Weighted Inter-Quartile Range of Regional Tariff Reductions

Notes: Summary statistics from all-industry regional tariff reductions based on 1000 simulated vectors of industry tariff changes. Panel (a) shows the share of the relevant country's population facing regional tariff reductions of 2.5 percent or more. Panel (b) shows the population-weighted inter-quartile range of regional tariff reductions. See text for discussion of the apparent differences across Canada and the US. 


\section{C.12 Evolution of Tariff-Cut Exposure}

Figure A15: Evolution of Canadian Tariff-Cut Exposure: High Attachment Workers

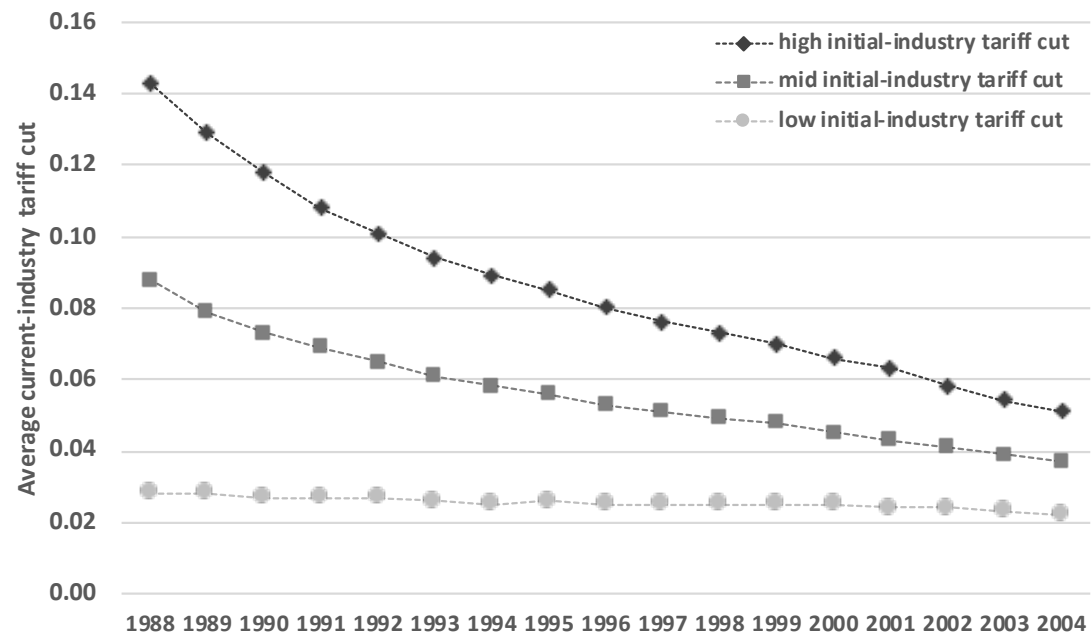

Notes: We divide manufacturing industries into terciles based on the size of the industry's Canadian tariff cut and assign workers to each tercile based on their initial industry of employment. For each initial-tariff-cut tercile, we plot the average Canadian tariff cut faced by workers in their current industry of employment during the year listed on the x-axis. Non-employed individuals in a given year are omitted from that year's average, and we assign zero tariff cut to non-tradable industries. Declining profiles imply that, on average, workers transition into industries that faced smaller Canadian tariff cuts than their initial industry. 
Figure IV in Autor et al. (2014) plots regression coefficients and 90\% confidence intervals obtained from 32 regressions that relate the 1991-2007 trade exposure of a workers industry to the 1991-2007 trade exposure of the workers initial 1991 industry. In their graph, the counterfactual data series sets trade exposure to 0 for all firms except the workers initial employer. We perform an identical exercise here for low attachment workers (Figure A16a) and high attachment workers (Figure A16b).

For each figure, black diamonds correspond to coefficients from a regression of $\Delta \ln \left(1+\tau_{j(i)}^{\mathrm{CAN}}\right)$ on $\Delta \ln \left(1+\tau_{j(i) t}^{\mathrm{CAN}}\right)$ where $\Delta \ln \left(1+\tau_{j(i)}^{\mathrm{CAN}}\right)$ is the tariff cut in worker $i^{\prime} s$ initial industry of employment $j$ and $\Delta \ln \left(1+\tau_{j(i) t}^{\mathrm{CAN}}\right)$ is the tariff cut in the industry in which the worker is employed in year $t$. There are 2x17 of these regressions each corresponding to a year in 1988-2004 with the coefficient for 1988 equal to one by construction. Confidence intervals are at the 95 percent level. Nonemployed individuals in a given year are omitted from the regression in that year, and we assign zero tariff cut to non-tradable industries. Following Autor et al. (2014). The gray circles reflect an otherwise similar exercise in which we assign $\Delta \ln \left(1+\tau_{j(i) t}^{\mathrm{CAN}}\right)=0$ for employment at all firms other than the worker's initial firm when running this regression. The similarity of the black and gray diamonds indicate that Canadian workers quickly moved into industries facing dramatically less import competition as a result of Canadian tariff cuts. 
Figure A16: Persistence of Tariff-Cut Exposure

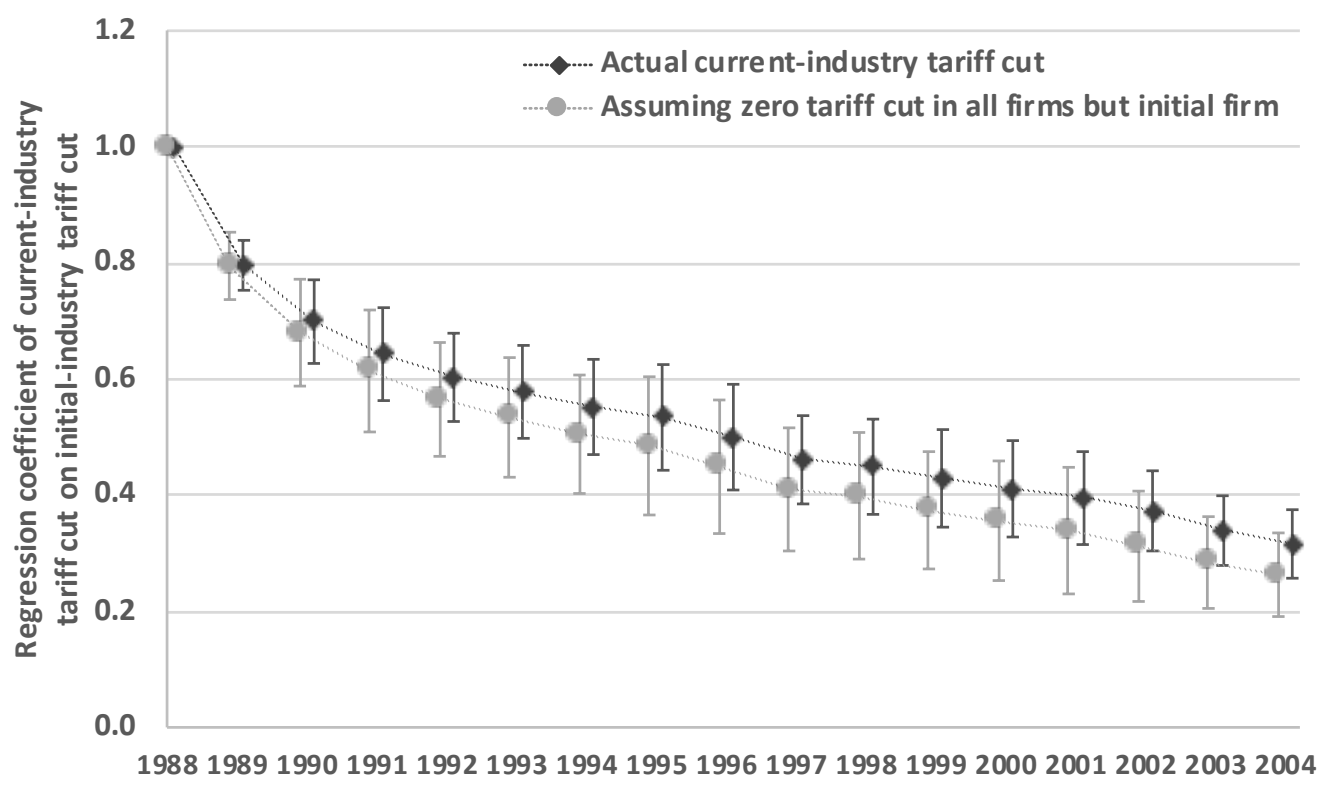

(a) Low Attachment Workers

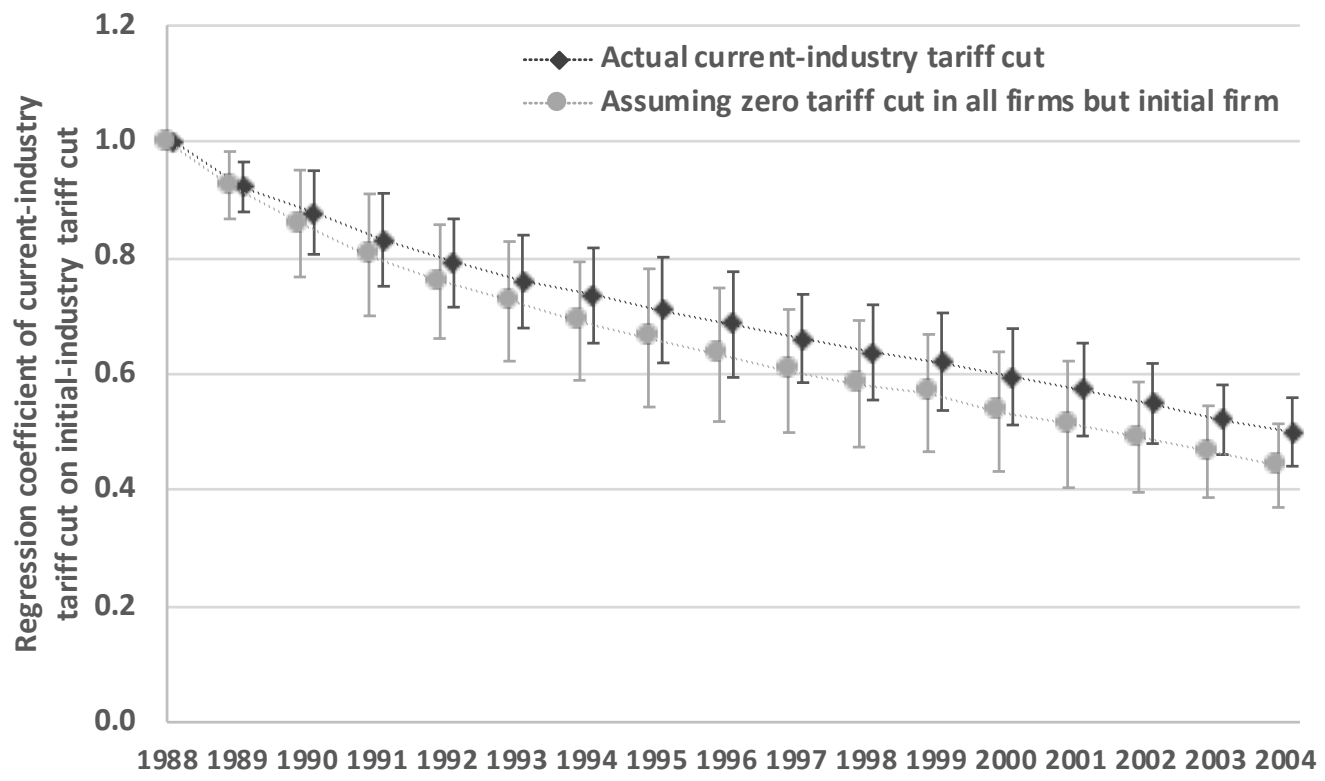

(b) High Attachment Workers

Notes: These figures replicate Figure IV of Autor et al. (2014). Black diamonds represents regression coefficients from regressing each worker's current industry's tariff cut in the relevant year on their initial-industry's tariff cut. Error bars are the associated 95 percent confidence intervals. Non-employed individuals in a given year are omitted from the regression in that year, and we assign zero tariff cut to non-tradable industries. The gray circles reflect an otherwise similar exercise in which all firms other than the worker's initial firm are assigned zero tariff cut. The similarity of the black and gray series indicate that Canadian workers quickly moved into industries facing less import competition as a result of Canadian tariff cuts. 


\section{C.13 Worker Transitions by Initial Firm Size Results Tables}

Table A18: Worker Transitions, by Labor-Force Attachment and Initial Firm Size (1989-1993)

\begin{tabular}{|c|c|c|c|c|c|c|c|c|c|}
\hline & $\begin{array}{c}(1) \\
\text { Total }\end{array}$ & $\begin{array}{c}(2) \\
\text { Initial Ind. }\end{array}$ & $\begin{array}{c}(3) \\
\text { Manuf. }\end{array}$ & $\begin{array}{c}(4) \\
\text { Constr. }\end{array}$ & $\begin{array}{c}(5) \\
\text { Mining }\end{array}$ & $\begin{array}{c}(6) \\
\text { Agric. }\end{array}$ & $\begin{array}{c}(7) \\
\text { Services }\end{array}$ & $\begin{array}{c}(8) \\
\text { Unknown }\end{array}$ & $\begin{array}{c}(9) \\
\text { Unemp. }\end{array}$ \\
\hline \multicolumn{10}{|c|}{ Panel A: Low Attachment $(\mathrm{n}=20,577)$} \\
\hline 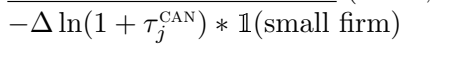 & $\begin{array}{l}-0.378 \\
(0.260)\end{array}$ & $\begin{array}{l}-0.0419 \\
(0.0330)\end{array}$ & $\begin{array}{l}-0.0360 \\
(0.0640)\end{array}$ & $\begin{array}{c}0.000103 \\
(0.0303)\end{array}$ & - & - & $\begin{array}{r}-0.00242 \\
(0.0630)\end{array}$ & - & $\begin{array}{c}-0.401^{* *} \\
(0.182)\end{array}$ \\
\hline$-\Delta \ln \left(1+\tau_{j}^{\mathrm{CAN}}\right) * \mathbb{1}($ medium firm $)$ & $\begin{array}{c}0.448^{* *} \\
(0.180)\end{array}$ & $\begin{array}{l}0.00199 \\
(0.0284)\end{array}$ & $\begin{array}{c}0.0319 \\
(0.0717)\end{array}$ & $\begin{array}{c}-0.00744 \\
(0.0245)\end{array}$ & - & - & $\begin{array}{c}0.0730 \\
(0.0537)\end{array}$ & - & $\begin{array}{c}0.181 \\
(0.179)\end{array}$ \\
\hline$-\Delta \ln \left(1+\tau_{j}^{\mathrm{CAN}}\right) * \mathbb{1}($ large firm $)$ & $\begin{array}{l}-0.204 \\
(0.295)\end{array}$ & $\begin{array}{l}-0.0167 \\
(0.0327)\end{array}$ & $\begin{array}{c}0.0763 \\
(0.0521)\end{array}$ & $\begin{array}{c}0.0153 \\
(0.0225)\end{array}$ & - & - & $\begin{array}{l}-0.0447 \\
(0.0514)\end{array}$ & - & $\begin{array}{l}-0.237 \\
(0.198)\end{array}$ \\
\hline$-\Delta \ln \left(1+\tau_{j}^{\mathrm{US}}\right) * \mathbb{1}($ small firm $)$ & $\begin{array}{c}0.516^{* *} \\
(0.257)\end{array}$ & $\begin{array}{c}0.101^{*} \\
(0.0511)\end{array}$ & $\begin{array}{c}-0.0172 \\
(0.0886)\end{array}$ & $\begin{array}{l}0.0901^{*} \\
(0.0514)\end{array}$ & - & - & $\begin{array}{r}-0.00172 \\
(0.0827)\end{array}$ & - & $\begin{array}{l}0.295 \\
(0.210)\end{array}$ \\
\hline$-\Delta \ln \left(1+\tau_{j}^{\mathrm{US}}\right) * \mathbb{1}($ medium firm $)$ & $\begin{array}{c}-0.611^{* *} \\
(0.280)\end{array}$ & $\begin{array}{c}0.0246 \\
(0.0534)\end{array}$ & $\begin{array}{l}-0.0649 \\
(0.0893)\end{array}$ & $\begin{array}{c}0.0819 \\
(0.0611)\end{array}$ & $\begin{array}{c}0.0101 \\
(0.0121)\end{array}$ & - & $\begin{array}{l}-0.0762 \\
(0.0838)\end{array}$ & - & $\begin{array}{c}-0.472^{*} \\
(0.248)\end{array}$ \\
\hline$-\Delta \ln \left(1+\tau_{j}^{\mathrm{US}}\right) * \mathbb{1}$ (large firm $)$ & $\begin{array}{l}-0.106 \\
(0.314) \\
\end{array}$ & $\begin{array}{l}0.00217 \\
(0.0421) \\
\end{array}$ & $\begin{array}{c}-0.0838 \\
(0.102) \\
\end{array}$ & $\begin{array}{c}0.0711 \\
(0.0455) \\
\end{array}$ & - & - & $\begin{array}{r}-0.00503 \\
(0.0808) \\
\end{array}$ & - & $\begin{array}{l}-0.393 \\
(0.338) \\
\end{array}$ \\
\hline R-squared & 0.043 & 0.005 & 0.006 & 0.010 & 0.005 & 0.005 & 0.006 & 0.005 & 0.047 \\
\hline \multicolumn{10}{|c|}{ Panel B: High Attachment $(\mathrm{n}=63,128)$} \\
\hline$-\Delta \ln \left(1+\tau_{j}^{\text {CAN }}\right) * \mathbb{1}($ small firm $)$ & $\begin{array}{l}-0.142 \\
(0.184)\end{array}$ & $\begin{array}{l}-0.0465 \\
(0.0455)\end{array}$ & $\begin{array}{l}0.00610 \\
(0.0610)\end{array}$ & $\begin{array}{r}-0.00197 \\
(0.0287)\end{array}$ & - & - & $\begin{array}{c}-0.0586 \\
(0.0536)\end{array}$ & - & $\begin{array}{l}-0.0297 \\
(0.0954)\end{array}$ \\
\hline$-\Delta \ln \left(1+\tau_{j}^{\mathrm{CAN}}\right) * \mathbb{1}($ medium firm $)$ & $\begin{array}{c}0.104 \\
(0.137)\end{array}$ & $\begin{array}{l}-0.0192 \\
(0.0245)\end{array}$ & $\begin{array}{c}0.0167 \\
(0.0446)\end{array}$ & $\begin{array}{c}0.0157 \\
(0.0196)\end{array}$ & - & - & $\begin{array}{l}0.00695 \\
(0.0284)\end{array}$ & - & $\begin{array}{l}0.0647 \\
(0.102)\end{array}$ \\
\hline$-\Delta \ln \left(1+\tau_{j}^{\mathrm{CAN}}\right) * \mathbb{1}$ (large firm $)$ & $\begin{array}{c}0.00199 \\
(0.204)\end{array}$ & $\begin{array}{l}-0.0250 \\
(0.0363)\end{array}$ & $\begin{array}{c}0.0535 \\
(0.0585)\end{array}$ & $\begin{array}{c}0.0293 \\
(0.0202)\end{array}$ & - & - & $\begin{array}{c}0.0165 \\
(0.0306)\end{array}$ & - & $\begin{array}{l}-0.0880 \\
(0.116)\end{array}$ \\
\hline$-\Delta \ln \left(1+\tau_{j}^{\mathrm{us}}\right) * \mathbb{1}($ small firm $)$ & $\begin{array}{c}0.231 \\
(0.221)\end{array}$ & $\begin{array}{c}0.0499 \\
(0.0518)\end{array}$ & $\begin{array}{l}-0.0176 \\
(0.0730)\end{array}$ & $\begin{array}{c}0.0884 \\
(0.0667)\end{array}$ & - & - & $\begin{array}{c}0.0788 \\
(0.0658)\end{array}$ & - & $\begin{array}{l}0.0437 \\
(0.135)\end{array}$ \\
\hline$-\Delta \ln \left(1+\tau_{j}^{\mathrm{US}}\right) * \mathbb{1}($ medium firm $)$ & $\begin{array}{l}-0.159 \\
(0.207)\end{array}$ & $\begin{array}{c}0.0312 \\
(0.0482)\end{array}$ & $\begin{array}{l}-0.0567 \\
(0.0670)\end{array}$ & $\begin{array}{c}0.0415 \\
(0.0370)\end{array}$ & - & - & $\begin{array}{l}-0.0447 \\
(0.0437)\end{array}$ & - & $\begin{array}{r}-0.0346 \\
(0.139)\end{array}$ \\
\hline$-\Delta \ln \left(1+\tau_{j}^{\mathrm{US}}\right) * \mathbb{1}($ large firm $)$ & $\begin{array}{l}-0.306 \\
(0.346)\end{array}$ & $\begin{array}{l}-0.0169 \\
(0.0325) \\
\end{array}$ & $\begin{array}{r}-0.0788 \\
(0.107) \\
\end{array}$ & $\begin{array}{c}0.0604 \\
(0.0514) \\
\end{array}$ & - & - & $\begin{array}{l}-0.0935^{*} \\
(0.0499) \\
\end{array}$ & - & $\begin{array}{l}-0.162 \\
(0.211)\end{array}$ \\
\hline R-squared & 0.025 & 0.007 & 0.005 & 0.006 & 0.003 & 0.004 & 0.005 & 0.001 & 0.018 \\
\hline
\end{tabular}

Notes: Dependent variable in column (1) is an indicator for experiencing a permanent work-shortage based separation from the worker's initial firm during 1989-1993. The subsequent columns additively decompose this separation indicator based upon the worker's employment status in the year following separation. The independent variables of interest are the 1988-1998 tariff cuts facing U.S. exports to Canada $\left(-\Delta \ln \left(1+\tau_{j}^{\mathrm{CAN}}\right)\right)$ or facing Canadian exports to the U.S. $\left(-\Delta \ln \left(1+\tau_{j}^{\mathrm{US}}\right)\right)$ in the worker's initial industry, interacted with initial firm size (small=1-99, medium-100-999, large=1000+). Because the transition indicators in columns (2) through (9) additively decompose the overall separation indicator, the coefficients in columns (2) through (9) sum to the overall effect in column (1). All specifications include extensive worker, initial firm, and initial industry controls, described in Section 4 . Estimates suppressed due to data confidentiality concerns are shown as -. Standard errors clustered by 4-digit NAICS industry. ${ }^{* * *} \mathrm{p}<0.01,{ }^{* *} \mathrm{p}<0.05, * \mathrm{p}<0.1$. 
Table A19: Worker Transitions, by Labor-Force Attachment and Initial Firm Size (1989-1998)

\begin{tabular}{|c|c|c|c|c|c|c|c|c|c|}
\hline & $\begin{array}{c}(1) \\
\text { Total }\end{array}$ & $\begin{array}{c}(2) \\
\text { Initial Ind. }\end{array}$ & $\begin{array}{c}(3) \\
\text { Manuf. }\end{array}$ & $\begin{array}{c}(4) \\
\text { Constr. }\end{array}$ & $\begin{array}{c}(5) \\
\text { Mining }\end{array}$ & $\begin{array}{c}(6) \\
\text { Agric. }\end{array}$ & $\begin{array}{c}(7) \\
\text { Services }\end{array}$ & $\begin{array}{c}(8) \\
\text { Unknown }\end{array}$ & $\begin{array}{c}(9) \\
\text { Unemp. }\end{array}$ \\
\hline \multicolumn{10}{|c|}{ Panel A: Low Attachment $(\mathrm{n}=20,577)$} \\
\hline$-\Delta \ln \left(1+\tau_{j}^{\mathrm{CAN}}\right) * \mathbb{1}($ small firm $)$ & $\begin{array}{l}-0.513 \\
(0.316)\end{array}$ & $\begin{array}{l}-0.0394 \\
(0.0453)\end{array}$ & $\begin{array}{l}-0.0262 \\
(0.0702)\end{array}$ & $\begin{array}{c}-0.00804 \\
(0.0335)\end{array}$ & - & - & $\begin{array}{c}0.0253 \\
(0.0607)\end{array}$ & - & $\begin{array}{c}-0.579^{* *} \\
(0.242)\end{array}$ \\
\hline$-\Delta \ln \left(1+\tau_{j}^{\mathrm{CAN}}\right) * \mathbb{1}($ medium firm $)$ & $\begin{array}{l}0.304 \\
(0.213)\end{array}$ & $\begin{array}{l}-0.0218 \\
(0.0391)\end{array}$ & $\begin{array}{c}0.0349 \\
(0.0798)\end{array}$ & $\begin{array}{c}0.0135 \\
(0.0289)\end{array}$ & - & - & $\begin{array}{c}0.0391 \\
(0.0688)\end{array}$ & - & $\begin{array}{c}0.103 \\
(0.225)\end{array}$ \\
\hline$-\Delta \ln \left(1+\tau_{j}^{\text {CAN }}\right) * \mathbb{1}($ large firm $)$ & $\begin{array}{l}0.550^{* *} \\
(0.217)\end{array}$ & $\begin{array}{c}0.0173 \\
(0.0435)\end{array}$ & $\begin{array}{l}0.131^{* *} \\
(0.0629)\end{array}$ & $\begin{array}{c}0.0991^{* *} \\
(0.0463)\end{array}$ & - & - & $\begin{array}{r}-0.00802 \\
(0.0576)\end{array}$ & - & $\begin{array}{c}0.369 \\
(0.245)\end{array}$ \\
\hline$-\Delta \ln \left(1+\tau_{j}^{\mathrm{US}}\right) * \mathbb{1}($ small firm $)$ & $\begin{array}{c}0.657^{* *} \\
(0.299)\end{array}$ & $\begin{array}{l}0.156^{* *} \\
(0.0677)\end{array}$ & $\begin{array}{l}-0.0366 \\
(0.0914)\end{array}$ & $\begin{array}{c}0.116^{*} \\
(0.0653)\end{array}$ & - & - & $\begin{array}{r}-0.00621 \\
(0.0763)\end{array}$ & - & $\begin{array}{c}0.358 \\
(0.253)\end{array}$ \\
\hline$-\Delta \ln \left(1+\tau_{j}^{\mathrm{US}}\right) * \mathbb{1}($ medium firm $)$ & $\begin{array}{l}-0.543^{*} \\
(0.281)\end{array}$ & $\begin{array}{c}0.130 \\
(0.0853)\end{array}$ & $\begin{array}{l}-0.0944 \\
(0.0881)\end{array}$ & $\begin{array}{c}0.0737 \\
(0.0732)\end{array}$ & $\begin{array}{c}0.0105 \\
(0.0124)\end{array}$ & - & $\begin{array}{r}-0.0218 \\
(0.111)\end{array}$ & - & $\begin{array}{c}-0.615^{*} \\
(0.312)\end{array}$ \\
\hline$-\Delta \ln \left(1+\tau_{j}^{\mathrm{US}}\right) * \mathbb{1}($ large firm $)$ & $\begin{array}{c}-0.892^{* *} \\
(0.361)\end{array}$ & $\begin{array}{c}-0.0226 \\
(0.0672)\end{array}$ & $\begin{array}{c}-0.150 \\
(0.125)\end{array}$ & $\begin{array}{r}-0.00607 \\
(0.0652)\end{array}$ & - & - & $\begin{array}{l}-0.0255 \\
(0.0897)\end{array}$ & - & $\begin{array}{c}-1.094^{* *} \\
(0.522)\end{array}$ \\
\hline R-squared & 0.063 & 0.008 & 0.006 & 0.011 & 0.005 & 0.007 & 0.006 & 0.005 & 0.071 \\
\hline \multicolumn{10}{|c|}{ Panel B: High Attachment $(\mathrm{n}=63,128)$} \\
\hline 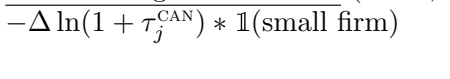 & $\begin{array}{l}-0.197 \\
(0.260)\end{array}$ & $\begin{array}{c}-0.0996 \\
(0.0602)\end{array}$ & $\begin{array}{c}-0.0362 \\
(0.0789)\end{array}$ & $\begin{array}{r}-0.00357 \\
(0.0345)\end{array}$ & - & - & $\begin{array}{c}-0.0331 \\
(0.0653)\end{array}$ & - & $\begin{array}{c}-0.0202 \\
(0.125)\end{array}$ \\
\hline$-\Delta \ln \left(1+\tau_{j}^{\mathrm{CAN}}\right) * \mathbb{1}($ medium firm $)$ & $\begin{array}{c}0.102 \\
(0.211)\end{array}$ & $\begin{array}{l}-0.0356 \\
(0.0321)\end{array}$ & $\begin{array}{c}0.0352 \\
(0.0653)\end{array}$ & $\begin{array}{c}0.0199 \\
(0.0217)\end{array}$ & - & - & $\begin{array}{c}0.0216 \\
(0.0411)\end{array}$ & - & $\begin{array}{l}0.0372 \\
(0.127)\end{array}$ \\
\hline$-\Delta \ln \left(1+\tau_{j}^{\text {CAN }}\right) * \mathbb{1}$ (large firm $)$ & $\begin{array}{l}0.451^{*} \\
(0.233)\end{array}$ & $\begin{array}{l}0.00889 \\
(0.0424)\end{array}$ & $\begin{array}{c}0.169^{* *} \\
(0.0732)\end{array}$ & $\begin{array}{c}0.0931^{* *} \\
(0.0446)\end{array}$ & - & - & $\begin{array}{c}0.0491 \\
(0.0472)\end{array}$ & - & $\begin{array}{c}0.106 \\
(0.195)\end{array}$ \\
\hline$-\Delta \ln \left(1+\tau_{j}^{\mathrm{US}}\right) * \mathbb{1}($ small firm $)$ & $\begin{array}{c}0.394 \\
(0.304)\end{array}$ & $\begin{array}{l}0.173^{* *} \\
(0.0746)\end{array}$ & $\begin{array}{c}0.0292 \\
(0.0939)\end{array}$ & $\begin{array}{c}0.127 \\
(0.0882)\end{array}$ & - & - & $\begin{array}{c}0.0243 \\
(0.0807)\end{array}$ & - & $\begin{array}{l}0.0648 \\
(0.160)\end{array}$ \\
\hline$-\Delta \ln \left(1+\tau_{j}^{\mathrm{US}}\right) * \mathbb{1}($ medium firm $)$ & $\begin{array}{l}-0.145 \\
(0.286)\end{array}$ & $\begin{array}{c}0.127^{*} \\
(0.0687)\end{array}$ & $\begin{array}{c}-0.0599 \\
(0.0864)\end{array}$ & $\begin{array}{c}0.0625 \\
(0.0506)\end{array}$ & - & - & $\begin{array}{l}-0.0925 \\
(0.0648)\end{array}$ & - & $\begin{array}{r}-0.0856 \\
(0.178)\end{array}$ \\
\hline$-\Delta \ln \left(1+\tau_{j}^{\mathrm{US}}\right) * \mathbb{1}($ large firm $)$ & $\begin{array}{c}-0.738^{*} \\
(0.437) \\
\end{array}$ & $\begin{array}{c}-0.0690 \\
(0.0593) \\
\end{array}$ & $\begin{array}{c}-0.162 \\
(0.123) \\
\end{array}$ & $\begin{array}{c}0.0321 \\
(0.0686) \\
\end{array}$ & - & - & $\begin{array}{c}-0.111^{*} \\
(0.0643) \\
\end{array}$ & - & $\begin{array}{c}-0.377 \\
(0.264) \\
\end{array}$ \\
\hline R-squared & 0.036 & 0.015 & 0.006 & 0.008 & 0.002 & 0.005 & 0.005 & 0.001 & 0.027 \\
\hline
\end{tabular}

Notes: Dependent variable in column (1) is an indicator for experiencing a permanent work-shortage based separation from the worker's initial firm during 1989-1998. The subsequent columns additively decompose this separation indicator based upon the worker's employment status in the year following separation. The independent variables of interest are the 1988-1998 tariff cuts facing U.S. exports to Canada $\left(-\Delta \ln \left(1+\tau_{j}^{\mathrm{CAN}}\right)\right)$ or facing Canadian exports to the U.S. $\left(-\Delta \ln \left(1+\tau_{j}^{\mathrm{US}}\right)\right)$ in the worker's initial industry, interacted with initial firm size (small=1-99, medium-100-999, large=1000+). Because the transition indicators in columns (2) through (9) additively decompose the overall separation indicator, the coefficients in columns (2) through (9) sum to the overall effect in column (1). All specifications include extensive worker, initial firm, and initial industry controls, described in Section 4. Estimates suppressed due to data confidentiality concerns are shown as - . Standard errors clustered by 4-digit NAICS industry. $* * * \mathrm{p}<0.01, * * \mathrm{p}<0.05, * \mathrm{p}<0.1$. 
Table A20: Worker Transitions, by Labor-Force Attachment and Initial Firm Size (1989-2003)

\begin{tabular}{|c|c|c|c|c|c|c|c|c|c|}
\hline & $\begin{array}{c}(1) \\
\text { Total } \\
\end{array}$ & $\begin{array}{c}(2) \\
\text { Initial Ind. }\end{array}$ & $\begin{array}{c}(3) \\
\text { Manuf. }\end{array}$ & $\begin{array}{c}(4) \\
\text { Constr. }\end{array}$ & $\begin{array}{c}(5) \\
\text { Mining }\end{array}$ & $\begin{array}{c}(6) \\
\text { Agric. }\end{array}$ & $\begin{array}{c}7) \\
\text { Services }\end{array}$ & $\begin{array}{c}(8) \\
\text { Unknown }\end{array}$ & $\begin{array}{c}9) \\
\text { Unemp. }\end{array}$ \\
\hline \multicolumn{10}{|c|}{ Panel A: Low Attachment $(\mathrm{n}=20,577)$} \\
\hline$-\Delta \ln \left(1+\tau_{j}^{\mathrm{CAN}}\right) * \mathbb{1}($ small firm $)$ & $\begin{array}{c}-0.480 \\
(0.337)\end{array}$ & $\begin{array}{l}-0.0640 \\
(0.0495)\end{array}$ & $\begin{array}{l}-0.0438 \\
(0.0773)\end{array}$ & $\begin{array}{c}-0.000651 \\
(0.0331)\end{array}$ & - & - & $\begin{array}{c}0.0366 \\
(0.0562)\end{array}$ & - & $\begin{array}{c}-0.542^{* *} \\
(0.257)\end{array}$ \\
\hline$-\Delta \ln \left(1+\tau_{j}^{\mathrm{CAN}}\right) * \mathbb{1}($ medium firm $)$ & $\begin{array}{c}0.225 \\
(0.195)\end{array}$ & $\begin{array}{c}-0.0328 \\
(0.0411)\end{array}$ & $\begin{array}{c}0.00232 \\
(0.0780)\end{array}$ & $\begin{array}{c}0.00304 \\
(0.0336)\end{array}$ & - & - & $\begin{array}{c}0.0429 \\
(0.0732)\end{array}$ & - & $\begin{array}{l}0.0505 \\
(0.221)\end{array}$ \\
\hline$-\Delta \ln \left(1+\tau_{j}^{\mathrm{CAN}}\right) * \mathbb{1}$ (large firm) & $\begin{array}{c}0.475^{* *} \\
(0.205)\end{array}$ & $\begin{array}{l}0.00904 \\
(0.0427)\end{array}$ & $\begin{array}{c}0.154^{* *} \\
(0.0622)\end{array}$ & $\begin{array}{l}0.119^{* *} \\
(0.0543)\end{array}$ & - & - & $\begin{array}{c}0.00572 \\
(0.0691)\end{array}$ & - & $\begin{array}{c}0.254 \\
(0.228)\end{array}$ \\
\hline$-\Delta \ln \left(1+\tau_{j}^{\mathrm{US}}\right) * \mathbb{1}($ small firm $)$ & $\begin{array}{c}0.633^{* *} \\
(0.318)\end{array}$ & $\begin{array}{l}0.174^{* *} \\
(0.0731)\end{array}$ & $\begin{array}{c}-0.00310 \\
(0.101)\end{array}$ & $\begin{array}{c}0.125^{*} \\
(0.0710)\end{array}$ & - & - & $\begin{array}{c}-0.0357 \\
(0.0732)\end{array}$ & - & $\begin{array}{c}0.318 \\
(0.261)\end{array}$ \\
\hline$-\Delta \ln \left(1+\tau_{j}^{\mathrm{US}}\right) * \mathbb{1}($ medium firm $)$ & $\begin{array}{c}-0.472^{*} \\
(0.271)\end{array}$ & $\begin{array}{c}0.146^{*} \\
(0.0863)\end{array}$ & $\begin{array}{l}-0.0502 \\
(0.0947)\end{array}$ & $\begin{array}{c}0.111 \\
(0.0941)\end{array}$ & $\begin{array}{c}0.0120 \\
(0.0129)\end{array}$ & - & $\begin{array}{c}-0.0555 \\
(0.117)\end{array}$ & - & $\begin{array}{c}-0.579^{*} \\
(0.321)\end{array}$ \\
\hline$-\Delta \ln \left(1+\tau_{j}^{\mathrm{US}}\right) * \mathbb{1}($ large firm $)$ & $\begin{array}{c}-0.796^{* *} \\
(0.353) \\
\end{array}$ & $\begin{array}{c}-0.0360 \\
(0.0658) \\
\end{array}$ & $\begin{array}{l}-0.164 \\
(0.128)\end{array}$ & $\begin{array}{l}-0.0214 \\
(0.0787) \\
\end{array}$ & - & - & $\begin{array}{r}-0.0471 \\
(0.118)\end{array}$ & - & $\begin{array}{c}-0.959^{*} \\
(0.483)\end{array}$ \\
\hline R-squared & 0.068 & 0.009 & 0.007 & 0.012 & 0.005 & 0.007 & 0.007 & 0.005 & 0.076 \\
\hline \multicolumn{10}{|c|}{ Panel B: High Attachment $(\mathrm{n}=63,128)$} \\
\hline$\overline{-\Delta \ln \left(1+\tau_{j}^{\mathrm{CAN}}\right) * \mathbb{1}(\text { small firm })}$ & $\begin{array}{l}-0.263 \\
(0.289)\end{array}$ & $\begin{array}{c}-0.106 \\
(0.0666)\end{array}$ & $\begin{array}{c}-0.0614 \\
(0.0872)\end{array}$ & $\begin{array}{r}-0.00588 \\
(0.0394)\end{array}$ & - & - & $\begin{array}{l}-0.0459 \\
(0.0758)\end{array}$ & - & $\begin{array}{r}-0.0577 \\
(0.140)\end{array}$ \\
\hline$-\Delta \ln \left(1+\tau_{j}^{\mathrm{CAN}}\right) * \mathbb{1}($ medium firm $)$ & $\begin{array}{l}-0.0300 \\
(0.219)\end{array}$ & $\begin{array}{c}-0.0662^{*} \\
(0.0370)\end{array}$ & $\begin{array}{c}-0.0174 \\
(0.0627)\end{array}$ & $\begin{array}{c}0.0140 \\
(0.0254)\end{array}$ & - & - & $\begin{array}{c}0.0131 \\
(0.0417)\end{array}$ & - & $\begin{array}{c}-0.00396 \\
(0.130)\end{array}$ \\
\hline$-\Delta \ln \left(1+\tau_{j}^{\mathrm{CAN}}\right) * \mathbb{1}($ large firm $)$ & $\begin{array}{c}0.382 \\
(0.271)\end{array}$ & $\begin{array}{c}-0.00223 \\
(0.0441)\end{array}$ & $\begin{array}{c}0.141^{*} \\
(0.0743)\end{array}$ & $\begin{array}{c}0.103^{*} \\
(0.0542)\end{array}$ & - & - & $\begin{array}{c}0.0541 \\
(0.0585)\end{array}$ & - & $\begin{array}{l}0.0671 \\
(0.231)\end{array}$ \\
\hline$-\Delta \ln \left(1+\tau_{j}^{\mathrm{US}}\right) * \mathbb{1}($ small firm $)$ & $\begin{array}{c}0.481 \\
(0.337)\end{array}$ & $\begin{array}{l}0.258^{* * *} \\
(0.0865)\end{array}$ & $\begin{array}{l}0.00679 \\
(0.0998)\end{array}$ & $\begin{array}{c}0.164 \\
(0.110)\end{array}$ & - & - & $\begin{array}{c}0.000381 \\
(0.0890)\end{array}$ & - & $\begin{array}{c}0.112 \\
(0.179)\end{array}$ \\
\hline$-\Delta \ln \left(1+\tau_{j}^{\mathrm{US}}\right) * \mathbb{1}($ medium firm $)$ & $\begin{array}{l}0.0970 \\
(0.337)\end{array}$ & $\begin{array}{l}0.178^{* *} \\
(0.0751)\end{array}$ & $\begin{array}{r}-0.0287 \\
(0.102)\end{array}$ & $\begin{array}{c}0.102 \\
(0.0785)\end{array}$ & - & - & $\begin{array}{l}-0.0453 \\
(0.0714)\end{array}$ & - & $\begin{array}{c}-0.00326 \\
(0.200)\end{array}$ \\
\hline$-\Delta \ln \left(1+\tau_{j}^{\mathrm{US}}\right) * \mathbb{1}($ large firm $)$ & $\begin{array}{l}-0.651 \\
(0.445)\end{array}$ & $\begin{array}{l}-0.0551 \\
(0.0608)\end{array}$ & $\begin{array}{l}-0.173 \\
(0.123)\end{array}$ & $\begin{array}{c}0.0458 \\
(0.0876)\end{array}$ & - & - & $\begin{array}{l}-0.0912 \\
(0.0828)\end{array}$ & - & $\begin{array}{l}-0.303 \\
(0.279)\end{array}$ \\
\hline R-squared & 0.037 & 0.015 & 0.006 & 0.009 & 0.003 & 0.005 & 0.006 & 0.001 & 0.029 \\
\hline
\end{tabular}

Notes: Dependent variable in column (1) is an indicator for experiencing a permanent work-shortage based separation from the worker's initial firm during 1989-2004. The subsequent columns additively decompose this separation indicator based upon the worker's employment status in the year following separation. The independent variables of interest are the 1988-1998 tariff cuts facing U.S. exports to Canada $\left(-\Delta \ln \left(1+\tau_{j}^{\mathrm{CAN}}\right)\right)$ or facing Canadian exports to the U.S. $\left(-\Delta \ln \left(1+\tau_{j}^{\mathrm{US}}\right)\right)$ in the worker's initial industry, interacted with initial firm size (small=1-99, medium-100-999, large=1000+). Because the transition indicators in columns (2) through (9) additively decompose the overall separation indicator, the coefficients in columns (2) through (9) sum to the overall effect in column (1). All specifications include extensive worker, initial firm, and initial industry controls, described in Section 4 . Estimates suppressed due to data confidentiality concerns are shown as -. Standard errors clustered by 4-digit NAICS industry. ${ }^{* * *} \mathrm{p}<0.01,{ }^{* *} \mathrm{p}<0.05,{ }^{*} \mathrm{p}<0.1$. 


\section{C.14 Cumulative Normalized Earnings by Initial Firm Size Results Ta- bles}

Table A21: Cumulative Normalized Earnings, by Labor-Force Attachment and Initial Firm Size (1989-1993)

\begin{tabular}{|c|c|c|c|c|c|c|c|c|c|}
\hline & $\begin{array}{c}(1) \\
\text { Total } \\
\end{array}$ & $\begin{array}{c}(2) \\
\text { Initial Firm }\end{array}$ & $\begin{array}{c}(3) \\
\text { Initial Ind. }\end{array}$ & $\begin{array}{c}(4) \\
\text { Manuf. }\end{array}$ & $\begin{array}{c}5) \\
\text { Constr. }\end{array}$ & $\begin{array}{c}(6) \\
\text { Mining }\end{array}$ & $\begin{array}{c}(7) \\
\text { Agric. }\end{array}$ & $\begin{array}{c}(8) \\
\text { Services }\end{array}$ & $\begin{array}{c}(9) \\
\text { Unknown }\end{array}$ \\
\hline \multicolumn{10}{|c|}{ Panel A: Low Attachment $(\mathrm{n}=20,577)$} \\
\hline 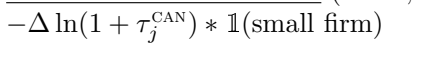 & $\begin{array}{c}1.735 \\
(3.023)\end{array}$ & $\begin{array}{l}-1.498 \\
(2.635)\end{array}$ & $\begin{array}{l}-0.913 \\
(0.983)\end{array}$ & $\begin{array}{c}0.651 \\
(1.667)\end{array}$ & $\begin{array}{c}1.217 \\
(0.903)\end{array}$ & $\begin{array}{c}0.449 \\
(0.334)\end{array}$ & $\begin{array}{c}-0.627 * * * \\
(0.213)\end{array}$ & $\begin{array}{c}2.961 \\
(1.940)\end{array}$ & $\begin{array}{r}-0.0569 \\
(0.270)\end{array}$ \\
\hline$-\Delta \ln \left(1+\tau_{j}^{\mathrm{CAN}}\right) * \mathbb{1}($ medium firm $)$ & $\begin{array}{l}-0.858 \\
(3.274)\end{array}$ & $\begin{array}{l}-1.305 \\
(3.304)\end{array}$ & $\begin{array}{c}-0.912 \\
(1.031)\end{array}$ & $\begin{array}{c}1.541 \\
(1.344)\end{array}$ & $\begin{array}{c}0.576 \\
(0.685)\end{array}$ & $\begin{array}{l}0.0297 \\
(0.174)\end{array}$ & $\begin{array}{c}-0.337^{*} \\
(0.191)\end{array}$ & $\begin{array}{l}-0.423 \\
(1.832)\end{array}$ & $\begin{array}{r}0.00250 \\
(0.0809)\end{array}$ \\
\hline$-\Delta \ln \left(1+\tau_{j}^{\mathrm{CAN}}\right) * \mathbb{1}$ (large firm) & $\begin{array}{c}0.207 \\
(2.414)\end{array}$ & $\begin{array}{l}-1.781 \\
(3.840)\end{array}$ & $\begin{array}{c}-2.051^{* * *} \\
(0.690)\end{array}$ & $\begin{array}{c}1.961 \\
(1.998)\end{array}$ & $\begin{array}{c}0.840 \\
(0.653)\end{array}$ & $\begin{array}{c}0.0556 \\
(0.369)\end{array}$ & $\begin{array}{l}-0.122 \\
(0.268)\end{array}$ & $\begin{array}{c}1.269 \\
(1.233)\end{array}$ & $\begin{array}{c}0.0917 \\
(0.0925)\end{array}$ \\
\hline$-\Delta \ln \left(1+\tau_{j}^{\mathrm{US}}\right) * \mathbb{1}($ small firm $)$ & $\begin{array}{l}-1.038 \\
(3.752)\end{array}$ & $\begin{array}{c}1.873 \\
(3.382)\end{array}$ & $\begin{array}{c}1.845 \\
(1.345)\end{array}$ & $\begin{array}{l}-2.474 \\
(2.191)\end{array}$ & $\begin{array}{c}0.654 \\
(1.019)\end{array}$ & $\begin{array}{c}-0.0159 \\
(0.507)\end{array}$ & $\begin{array}{c}0.102 \\
(0.326)\end{array}$ & $\begin{array}{l}-3.445 \\
(2.860)\end{array}$ & $\begin{array}{c}0.408 \\
(0.484)\end{array}$ \\
\hline$-\Delta \ln \left(1+\tau_{j}^{\mathrm{US}}\right) * \mathbb{1}($ medium firm $)$ & $\begin{array}{c}3.302 \\
(4.203)\end{array}$ & $\begin{array}{l}-0.231 \\
(4.160)\end{array}$ & $\begin{array}{c}1.374 \\
(1.532)\end{array}$ & $\begin{array}{l}-3.721 \\
(2.467)\end{array}$ & $\begin{array}{c}1.326 \\
(1.295)\end{array}$ & $\begin{array}{c}0.366 \\
(0.292)\end{array}$ & $\begin{array}{c}0.210 \\
(0.275)\end{array}$ & $\begin{array}{l}4.167^{*} \\
(2.329)\end{array}$ & $\begin{array}{c}0.177 \\
(0.138)\end{array}$ \\
\hline$-\Delta \ln \left(1+\tau_{j}^{\mathrm{US}}\right) * \mathbb{1}($ large firm $)$ & $\begin{array}{c}4.918 \\
(5.724)\end{array}$ & $\begin{array}{l}-1.031 \\
(7.077)\end{array}$ & $\begin{array}{l}-0.376 \\
(1.024)\end{array}$ & $\begin{array}{c}2.389 \\
(3.222)\end{array}$ & $\begin{array}{c}1.564 \\
(1.104)\end{array}$ & $\begin{array}{l}-0.185 \\
(0.455)\end{array}$ & $\begin{array}{c}0.00729 \\
(0.642)\end{array}$ & $\begin{array}{c}2.186 \\
(2.659)\end{array}$ & $\begin{array}{c}0.178 \\
(0.151)\end{array}$ \\
\hline R-squared & 0.111 & 0.066 & 0.014 & 0.036 & 0.025 & 0.011 & 0.020 & 0.088 & 0.013 \\
\hline \multicolumn{10}{|l|}{ Panel B: High Attachment ( $\mathrm{n}=63,128)$} \\
\hline$-\Delta \ln \left(1+\tau_{j}^{\mathrm{CAN}}\right) * \mathbb{1}$ (small firm $)$ & $\begin{array}{c}1.839 \\
(1.345)\end{array}$ & $\begin{array}{c}2.103 \\
(1.400)\end{array}$ & $\begin{array}{l}-0.629 \\
(0.554)\end{array}$ & $\begin{array}{l}-0.590 \\
(0.821)\end{array}$ & $\begin{array}{l}0.0876 \\
(0.305)\end{array}$ & $\begin{array}{c}0.114 \\
(0.142)\end{array}$ & $\begin{array}{l}-0.155^{* *} \\
(0.0721)\end{array}$ & $\begin{array}{l}1.061^{*} \\
(0.600)\end{array}$ & $\begin{array}{l}-0.0383 \\
(0.0584)\end{array}$ \\
\hline$-\Delta \ln \left(1+\tau_{j}^{\mathrm{CAN}}\right) * \mathbb{1}($ medium firm $)$ & $\begin{array}{c}-0.484 \\
(1.090)\end{array}$ & $\begin{array}{c}0.357 \\
(1.680)\end{array}$ & $\begin{array}{l}-0.533 \\
(0.438)\end{array}$ & $\begin{array}{c}0.199 \\
(0.753)\end{array}$ & $\begin{array}{l}0.0697 \\
(0.166)\end{array}$ & $\begin{array}{l}0.00857 \\
(0.0995)\end{array}$ & $\begin{array}{l}-0.0416 \\
(0.0629)\end{array}$ & $\begin{array}{l}-0.515 \\
(0.669)\end{array}$ & $\begin{array}{l}-0.0200 \\
(0.0257)\end{array}$ \\
\hline$-\Delta \ln \left(1+\tau_{j}^{\mathrm{CAN}}\right) * \mathbb{1}$ (large firm) & $\begin{array}{c}2.534^{* * *} * \\
(0.890)\end{array}$ & $\begin{array}{l}1.190 \\
(2.183)\end{array}$ & $\begin{array}{l}-0.548 \\
(0.480)\end{array}$ & $\begin{array}{c}1.323 \\
(1.393)\end{array}$ & $\begin{array}{c}0.531^{* *} \\
(0.237)\end{array}$ & $\begin{array}{c}0.0467 \\
(0.0970)\end{array}$ & $\begin{array}{l}-0.0557 \\
(0.0944)\end{array}$ & $\begin{array}{l}0.0513 \\
(0.636)\end{array}$ & $\begin{array}{c}0.0423 \\
(0.0427)\end{array}$ \\
\hline$-\Delta \ln \left(1+\tau_{j}^{\mathrm{US}}\right) * \mathbb{1}($ small firm $)$ & $\begin{array}{l}-2.242 \\
(1.447)\end{array}$ & $\begin{array}{l}-0.245 \\
(1.776)\end{array}$ & $\begin{array}{l}1.706^{* *} \\
(0.777)\end{array}$ & $\begin{array}{l}-1.461 \\
(1.077)\end{array}$ & $\begin{array}{c}0.403 \\
(0.623)\end{array}$ & $\begin{array}{l}-0.143 \\
(0.185)\end{array}$ & $\begin{array}{c}0.0164 \\
(0.121)\end{array}$ & $\begin{array}{c}-2.680 * * * \\
(0.843)\end{array}$ & $\begin{array}{c}0.0175 \\
(0.0665)\end{array}$ \\
\hline$-\Delta \ln \left(1+\tau_{j}^{\mathrm{US}}\right) * \mathbb{1}($ medium firm $)$ & $\begin{array}{c}2.020 \\
(1.409)\end{array}$ & $\begin{array}{c}2.431 \\
(2.115)\end{array}$ & $\begin{array}{c}0.923 \\
(0.694)\end{array}$ & $\begin{array}{l}-1.861 \\
(1.174)\end{array}$ & $\begin{array}{c}0.415 \\
(0.326)\end{array}$ & $\begin{array}{l}-0.108 \\
(0.129)\end{array}$ & $\begin{array}{c}-0.0584 \\
(0.0871)\end{array}$ & $\begin{array}{c}0.142 \\
(0.818)\end{array}$ & $\begin{array}{c}0.0277 \\
(0.0368)\end{array}$ \\
\hline$-\Delta \ln \left(1+\tau_{j}^{\text {US }}\right) * \mathbb{1}$ (large firm $)$ & $\begin{array}{l}-1.427 \\
(1.866)\end{array}$ & $\begin{array}{c}1.977 \\
(4.652)\end{array}$ & $\begin{array}{c}-2.225^{* * *} \\
(0.766)\end{array}$ & $\begin{array}{l}-0.129 \\
(2.699)\end{array}$ & $\begin{array}{c}0.180 \\
(0.341)\end{array}$ & $\begin{array}{c}-0.436^{* *} \\
(0.212)\end{array}$ & $\begin{array}{c}0.00286 \\
(0.191)\end{array}$ & $\begin{array}{l}-1.144 \\
(0.741)\end{array}$ & $\begin{array}{l}-0.0878 \\
(0.0707)\end{array}$ \\
\hline R-squared & 0.077 & 0.078 & 0.020 & 0.041 & 0.020 & 0.009 & 0.008 & 0.055 & 0.005 \\
\hline
\end{tabular}

Notes: Dependent variable is the sum of a worker's earnings during 1989-1993, divided by the worker's average yearly earnings in 1986-1988 (omitting years with zero earnings), defined in equation (2). The independent variables of interest are the 1988-1998 tariff cuts facing U.S. exports to Canada $\left(-\Delta \ln \left(1+\tau_{j}^{\mathrm{CAN}}\right)\right)$ or facing Canadian exports to the U.S. $\left(-\Delta \ln \left(1+\tau_{j}^{\mathrm{US}}\right)\right)$ in the worker's initial industry, interacted with initial firm size (small=1-99, medium-100-999, large $=1000+$ ). Column (1) examines total earnings from all sources, (2) earnings from the initial firm, (3) from firms other than the initial firm, but in the same initial 4-digit industry, (4) in manufacturing industries (NAICS $=3 \mathrm{xxx}$ ) other than the initial industry, (5) in construction and utilities (NAICS=22xx, 23xx), (6) in mining (NAICS $=21 \mathrm{xx}$ ), (7) in agriculture (NAICS=1xxx), (8) in services (NAICS $\geq 4 \mathrm{xxx}$ ), or (9) from a firm with unknown industry code. Because earnings in columns (2) through (9) additively decompose total earnings, the coefficients in columns (2) through (9) sum to the overall effect in column (1). All specifications include extensive worker, initial firm, and initial industry controls, described in Section 4. Standard errors clustered by 4-digit NAICS industry. ${ }^{* * *} \mathrm{p}<0.01,{ }^{* *} \mathrm{p}<0.05,{ }^{*} \mathrm{p}<0.1$. 
Table A22: Cumulative Normalized Earnings, by Labor-Force Attachment and Initial Firm Size (1989-1998)

\begin{tabular}{|c|c|c|c|c|c|c|c|c|c|}
\hline & $\begin{array}{c}(1) \\
\text { Total }\end{array}$ & $\begin{array}{c}(2) \\
\text { Initial Firm }\end{array}$ & $\begin{array}{c}(3) \\
\text { Initial Ind. }\end{array}$ & $\begin{array}{c}(4) \\
\text { Manuf. }\end{array}$ & $\begin{array}{c}(5) \\
\text { Constr. }\end{array}$ & $\begin{array}{c}(6) \\
\text { Mining }\end{array}$ & $\begin{array}{l}(7) \\
\text { Agric. }\end{array}$ & $\begin{array}{c}(8) \\
\text { Services }\end{array}$ & $\begin{array}{c}(9) \\
\text { Unknown }\end{array}$ \\
\hline \multicolumn{10}{|c|}{ Panel A: Low Attachment $(\mathrm{n}=20,577)$} \\
\hline$-\Delta \ln \left(1+\tau_{j}^{\mathrm{CAN}}\right) * \mathbb{1}($ small firm $)$ & $\begin{array}{l}1.888 \\
(6.437)\end{array}$ & $\begin{array}{l}-6.067 \\
(4.579)\end{array}$ & $\begin{array}{l}-1.647 \\
(2.543)\end{array}$ & $\begin{array}{c}1.840 \\
(4.666)\end{array}$ & $\begin{array}{c}1.932 \\
(1.592)\end{array}$ & $\begin{array}{l}1.259 \\
(0.807)\end{array}$ & $\begin{array}{c}-1.181^{* *} \\
(0.574)\end{array}$ & $\begin{array}{c}5.945 \\
(4.468)\end{array}$ & $\begin{array}{l}-0.193 \\
(0.275)\end{array}$ \\
\hline$-\Delta \ln \left(1+\tau_{j}^{\mathrm{CAN}}\right) * \mathbb{1}($ medium firm $)$ & $\begin{array}{l}1.631 \\
(7.735)\end{array}$ & $\begin{array}{l}-3.967 \\
(6.273)\end{array}$ & $\begin{array}{l}-0.816 \\
(2.322)\end{array}$ & $\begin{array}{l}5.886 \\
(3.568)\end{array}$ & $\begin{array}{l}1.395 \\
(1.439)\end{array}$ & $\begin{array}{c}0.291 \\
(0.450)\end{array}$ & $\begin{array}{l}-0.697 \\
(0.473)\end{array}$ & $\begin{array}{l}-0.328 \\
(5.019)\end{array}$ & $\begin{array}{l}-0.133 \\
(0.222)\end{array}$ \\
\hline$-\Delta \ln \left(1+\tau_{j}^{\mathrm{CAN}}\right) * \mathbb{1}$ (large firm) & $\begin{array}{l}-6.834 \\
(4.404)\end{array}$ & $\begin{array}{l}-9.988 \\
(7.487)\end{array}$ & $\begin{array}{c}-4.716^{* * *} \\
(1.755)\end{array}$ & $\begin{array}{c}3.756 \\
(4.349)\end{array}$ & $\begin{array}{l}2.120 \\
(1.459)\end{array}$ & $\begin{array}{c}0.276 \\
(0.908)\end{array}$ & $\begin{array}{l}-0.345 \\
(0.780)\end{array}$ & $\begin{array}{l}1.902 \\
(3.180)\end{array}$ & $\begin{array}{c}0.162 \\
(0.131)\end{array}$ \\
\hline$-\Delta \ln \left(1+\tau_{j}^{\mathrm{US}}\right) * \mathbb{1}($ small firm $)$ & $\begin{array}{c}3.492 \\
(8.730)\end{array}$ & $\begin{array}{c}5.542 \\
(6.743)\end{array}$ & $\begin{array}{l}3.198 \\
(3.319)\end{array}$ & $\begin{array}{l}-4.808 \\
(5.699)\end{array}$ & $\begin{array}{c}3.144 \\
(2.108)\end{array}$ & $\begin{array}{l}-0.511 \\
(1.216)\end{array}$ & $\begin{array}{c}0.272 \\
(0.838)\end{array}$ & $\begin{array}{l}-4.229 \\
(7.103)\end{array}$ & $\begin{array}{c}0.885 \\
(0.552)\end{array}$ \\
\hline$-\Delta \ln \left(1+\tau_{j}^{\mathrm{US}}\right) * \mathbb{1}($ medium firm $)$ & $\begin{array}{c}1.666 \\
(10.63)\end{array}$ & $\begin{array}{l}-1.917 \\
(7.328)\end{array}$ & $\begin{array}{l}1.497 \\
(3.702)\end{array}$ & $\begin{array}{l}-10.28 \\
(6.434)\end{array}$ & $\begin{array}{c}2.673 \\
(2.691)\end{array}$ & $\begin{array}{c}0.628 \\
(0.666)\end{array}$ & $\begin{array}{c}0.174 \\
(0.650)\end{array}$ & $\begin{array}{c}8.247 \\
(7.157)\end{array}$ & $\begin{array}{c}0.648^{* *} \\
(0.314)\end{array}$ \\
\hline$-\Delta \ln \left(1+\tau_{j}^{\mathrm{US}}\right) * \mathbb{1}$ (large firm) & $\begin{array}{l}19.98^{*} \\
(11.52)\end{array}$ & $\begin{array}{c}10.01 \\
(15.63)\end{array}$ & $\begin{array}{l}-3.701 \\
(2.691)\end{array}$ & $\begin{array}{c}6.582 \\
(7.476)\end{array}$ & $\begin{array}{c}3.219 \\
(2.559)\end{array}$ & $\begin{array}{c}-0.618 \\
(1.413)\end{array}$ & $\begin{array}{r}-0.0258 \\
(1.920)\end{array}$ & $\begin{array}{c}4.302 \\
(6.867)\end{array}$ & $\begin{array}{c}0.211 \\
(0.192)\end{array}$ \\
\hline R-squared & 0.116 & 0.060 & 0.016 & 0.031 & 0.025 & 0.017 & 0.019 & 0.106 & 0.010 \\
\hline \multicolumn{10}{|c|}{ Panel B: High Attachment $(\mathrm{n}=63,128)$} \\
\hline$-\Delta \ln \left(1+\tau_{j}^{\mathrm{CAN}}\right) * \mathbb{1}($ small firm $)$ & $\begin{array}{c}3.519 \\
(2.883)\end{array}$ & $\begin{array}{c}3.536 \\
(3.814)\end{array}$ & $\begin{array}{l}-1.879 \\
(1.750)\end{array}$ & $\begin{array}{l}-0.259 \\
(2.238)\end{array}$ & $\begin{array}{c}0.113 \\
(0.655)\end{array}$ & $\begin{array}{c}0.456 \\
(0.320)\end{array}$ & $\begin{array}{c}-0.429^{* *} \\
(0.202)\end{array}$ & $\begin{array}{c}1.973 \\
(1.644)\end{array}$ & $\begin{array}{c}0.00709 \\
(0.104)\end{array}$ \\
\hline$-\Delta \ln \left(1+\tau_{j}^{\mathrm{CAN}}\right) * \mathbb{1}($ medium firm $)$ & $\begin{array}{l}-0.462 \\
(2.431)\end{array}$ & $\begin{array}{c}1.003 \\
(4.488)\end{array}$ & $\begin{array}{l}-1.523 \\
(1.141)\end{array}$ & $\begin{array}{l}1.813 \\
(2.070)\end{array}$ & $\begin{array}{c}0.446 \\
(0.389)\end{array}$ & $\begin{array}{l}0.0295 \\
(0.238)\end{array}$ & $\begin{array}{l}-0.186 \\
(0.169)\end{array}$ & $\begin{array}{l}-2.050 \\
(1.980)\end{array}$ & $\begin{array}{l}0.00384 \\
(0.0258)\end{array}$ \\
\hline$-\Delta \ln \left(1+\tau_{j}^{\mathrm{CAN}}\right) * \mathbb{1}($ large firm $)$ & $\begin{array}{c}0.149 \\
(2.187)\end{array}$ & $\begin{array}{l}-5.052 \\
(4.960)\end{array}$ & $\begin{array}{c}-0.567 \\
(1.244)\end{array}$ & $\begin{array}{c}4.722 \\
(3.255)\end{array}$ & $\begin{array}{l}0.922^{*} \\
(0.502)\end{array}$ & $\begin{array}{l}-0.0136 \\
(0.390)\end{array}$ & $\begin{array}{l}-0.0608 \\
(0.267)\end{array}$ & $\begin{array}{c}0.148 \\
(1.825)\end{array}$ & $\begin{array}{c}0.0514 \\
(0.0479)\end{array}$ \\
\hline$-\Delta \ln \left(1+\tau_{j}^{\mathrm{US}}\right) * \mathbb{1}($ small firm $)$ & $\begin{array}{l}-5.820^{*} \\
(3.412)\end{array}$ & $\begin{array}{l}-1.758 \\
(4.781)\end{array}$ & $\begin{array}{c}5.330^{* *} \\
(2.453)\end{array}$ & $\begin{array}{l}-4.090 \\
(2.761)\end{array}$ & $\begin{array}{c}0.925 \\
(1.398)\end{array}$ & $\begin{array}{l}-0.372 \\
(0.467)\end{array}$ & $\begin{array}{l}-0.116 \\
(0.308)\end{array}$ & $\begin{array}{c}-5.724^{* * *} \\
(2.075)\end{array}$ & $\begin{array}{c}-0.0142 \\
(0.123)\end{array}$ \\
\hline$-\Delta \ln \left(1+\tau_{j}^{\mathrm{US}}\right) * \mathbb{1}($ medium firm $)$ & $\begin{array}{l}1.994 \\
(3.550)\end{array}$ & $\begin{array}{c}2.012 \\
(5.790)\end{array}$ & $\begin{array}{l}3.829^{*} \\
(2.157)\end{array}$ & $\begin{array}{l}-5.614^{*} \\
(3.111)\end{array}$ & $\begin{array}{c}0.624 \\
(0.846)\end{array}$ & $\begin{array}{r}-0.0460 \\
(0.356)\end{array}$ & $\begin{array}{l}-0.196 \\
(0.264)\end{array}$ & $\begin{array}{c}1.364 \\
(2.396)\end{array}$ & $\begin{array}{c}0.0221 \\
(0.0399)\end{array}$ \\
\hline$-\Delta \ln \left(1+\tau_{j}^{\mathrm{US}}\right) * \mathbb{1}($ large firm $)$ & $\begin{array}{l}-1.794 \\
(4.200)\end{array}$ & $\begin{array}{c}11.97 \\
(12.20)\end{array}$ & $\begin{array}{c}-8.812^{* * * *} \\
(3.221)\end{array}$ & $\begin{array}{l}-1.681 \\
(6.527)\end{array}$ & $\begin{array}{c}0.775 \\
(0.800)\end{array}$ & $\begin{array}{c}-1.091^{*} \\
(0.642)\end{array}$ & $\begin{array}{l}-0.320 \\
(0.517)\end{array}$ & $\begin{array}{l}-2.548 \\
(1.981)\end{array}$ & $\begin{array}{l}-0.0890 \\
(0.0741)\end{array}$ \\
\hline R-squared & 0.088 & 0.074 & 0.035 & 0.048 & 0.021 & 0.016 & 0.012 & 0.066 & 0.004 \\
\hline
\end{tabular}

Notes: Dependent variable is the sum of a worker's earnings during 1989-1998, divided by the worker's average yearly earnings in 1986-1988 (omitting years with zero earnings), defined in equation (2). The independent variables of interest are the 1988-1998 tariff cuts facing U.S. exports to Canada $\left(-\Delta \ln \left(1+\tau_{j}^{\mathrm{CAN}}\right)\right)$ or facing Canadian exports to the U.S. $\left(-\Delta \ln \left(1+\tau_{j}^{\mathrm{US}}\right)\right)$ in the worker's initial industry, interacted with initial firm size (small=1-99, medium-100-999, large=1000+). Column (1) examines total earnings from all sources, (2) earnings from the initial firm, (3) from firms other than the initial firm, but in the same initial 4-digit industry, (4) in manufacturing industries (NAICS=3xxx) other than the initial industry, (5) in construction and utilities (NAICS=22xx, 23xx), (6) in mining (NAICS $=21 \mathrm{xx}$ ), (7) in agriculture (NAICS=1xxx), (8) in services (NAICS $\geq 4 \mathrm{xxx}$ ), or (9) from a firm with unknown industry code. Because earnings in columns (2) through (9) additively decompose total earnings, the coefficients in columns (2) through (9) sum to the overall effect in column (1). All specifications include extensive worker, initial firm, and initial industry controls, described in Section 4. Standard errors clustered by 4-digit NAICS industry. ${ }^{* * *} \mathrm{p}<0.01,{ }^{* *} \mathrm{p}<0.05,{ }^{*} \mathrm{p}<0.1$. 
Table A23: Cumulative Normalized Earnings, by Labor-Force Attachment and Initial Firm Size (1989-2004)

\begin{tabular}{|c|c|c|c|c|c|c|c|c|c|}
\hline & $\begin{array}{c}(1) \\
\text { Total }\end{array}$ & $\begin{array}{c}(2) \\
\text { Initial Firm }\end{array}$ & $\begin{array}{c}(3) \\
\text { Initial Ind. }\end{array}$ & $\begin{array}{c}(4) \\
\text { Manuf. }\end{array}$ & $\begin{array}{c}(5) \\
\text { Constr. }\end{array}$ & $\begin{array}{c}(6) \\
\text { Mining }\end{array}$ & $\begin{array}{c}(7) \\
\text { Agric. }\end{array}$ & $\begin{array}{c}(8) \\
\text { Services }\end{array}$ & $\begin{array}{c}(9) \\
\text { Unknown }\end{array}$ \\
\hline \multicolumn{10}{|c|}{ Panel A: Low Attachment $(\mathrm{n}=20,577)$} \\
\hline 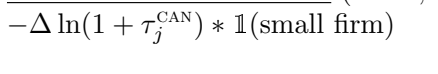 & $\begin{array}{c}0.811 \\
(11.69)\end{array}$ & $\begin{array}{l}-10.20 \\
(7.118)\end{array}$ & $\begin{array}{l}-3.205 \\
(4.919)\end{array}$ & $\begin{array}{l}-1.891 \\
(9.292)\end{array}$ & $\begin{array}{c}3.092 \\
(3.159)\end{array}$ & $\begin{array}{l}2.749^{*} \\
(1.444)\end{array}$ & $\begin{array}{l}-2.123^{*} \\
(1.123)\end{array}$ & $\begin{array}{l}12.48 \\
(9.047)\end{array}$ & $\begin{array}{l}-0.0871 \\
(0.604)\end{array}$ \\
\hline$-\Delta \ln \left(1+\tau_{j}^{\mathrm{CAN}}\right) * \mathbb{1}($ medium firm $)$ & $\begin{array}{c}1.093 \\
(13.71)\end{array}$ & $\begin{array}{l}-7.228 \\
(9.890)\end{array}$ & $\begin{array}{l}-1.719 \\
(4.529)\end{array}$ & $\begin{array}{l}8.224 \\
(6.848)\end{array}$ & $\begin{array}{c}3.962^{* *} \\
(1.893)\end{array}$ & $\begin{array}{c}0.676 \\
(0.880)\end{array}$ & $\begin{array}{l}-0.584 \\
(0.933)\end{array}$ & $\begin{array}{l}-2.191 \\
(10.26)\end{array}$ & $\begin{array}{l}-0.0467 \\
(0.319)\end{array}$ \\
\hline$-\Delta \ln \left(1+\tau_{j}^{\mathrm{CAN}}\right) * \mathbb{1}($ large firm $)$ & $\begin{array}{c}-17.40^{* *} \\
(7.922)\end{array}$ & $\begin{array}{c}-26.71^{* *} \\
(10.52)\end{array}$ & $\begin{array}{c}-8.512^{* *} \\
(3.483)\end{array}$ & $\begin{array}{l}9.028 \\
(7.648)\end{array}$ & $\begin{array}{c}6.320^{* *} \\
(2.548)\end{array}$ & $\begin{array}{c}0.279 \\
(1.891)\end{array}$ & $\begin{array}{l}-1.041 \\
(1.296)\end{array}$ & $\begin{array}{l}3.005 \\
(6.473)\end{array}$ & $\begin{array}{c}0.231 \\
(0.168)\end{array}$ \\
\hline$-\Delta \ln \left(1+\tau_{j}^{\mathrm{US}}\right) * \mathbb{1}($ small firm $)$ & $\begin{array}{c}8.246 \\
(18.27)\end{array}$ & $\begin{array}{c}6.866 \\
(11.40)\end{array}$ & $\begin{array}{c}6.134 \\
(6.228)\end{array}$ & $\begin{array}{l}-1.591 \\
(13.47)\end{array}$ & $\begin{array}{l}7.248^{*} \\
(4.106)\end{array}$ & $\begin{array}{l}-1.248 \\
(2.330)\end{array}$ & $\begin{array}{l}-0.393 \\
(1.613)\end{array}$ & $\begin{array}{l}-10.32 \\
(13.81)\end{array}$ & $\begin{array}{l}1.548 \\
(1.239)\end{array}$ \\
\hline$-\Delta \ln \left(1+\tau_{j}^{\mathrm{US}}\right) * \mathbb{1}($ medium firm $)$ & $\begin{array}{c}5.439 \\
(19.63)\end{array}$ & $\begin{array}{l}-2.648 \\
(11.90)\end{array}$ & $\begin{array}{c}2.972 \\
(7.313)\end{array}$ & $\begin{array}{l}-15.81 \\
(12.04)\end{array}$ & $\begin{array}{c}2.833 \\
(3.675)\end{array}$ & $\begin{array}{c}1.031 \\
(1.306)\end{array}$ & $\begin{array}{l}-1.589 \\
(1.120)\end{array}$ & $\begin{array}{c}17.74 \\
(15.04)\end{array}$ & $\begin{array}{l}0.913^{*} \\
(0.498)\end{array}$ \\
\hline$-\Delta \ln \left(1+\tau_{j}^{\mathrm{US}}\right) * \mathbb{1}($ large firm $)$ & $\begin{array}{l}42.68^{* *} \\
(19.23)\end{array}$ & $\begin{array}{l}28.08 \\
(23.96)\end{array}$ & $\begin{array}{l}-6.863 \\
(5.515)\end{array}$ & $\begin{array}{c}4.014 \\
(13.45)\end{array}$ & $\begin{array}{c}3.779 \\
(4.963)\end{array}$ & $\begin{array}{l}-0.451 \\
(3.205)\end{array}$ & $\begin{array}{l}-0.148 \\
(3.024)\end{array}$ & $\begin{array}{l}13.88 \\
(13.00)\end{array}$ & $\begin{array}{c}0.388 \\
(0.332)\end{array}$ \\
\hline R-squared & 0.141 & 0.049 & 0.019 & 0.038 & 0.030 & 0.021 & 0.018 & 0.123 & 0.005 \\
\hline \multicolumn{10}{|l|}{ Panel B: High Attachment $(\mathrm{n}=63,128)$} \\
\hline$-\Delta \ln \left(1+\tau_{j}^{\mathrm{CAN}}\right) * \mathbb{1}($ small firm $)$ & $\begin{array}{c}5.704 \\
(4.692)\end{array}$ & $\begin{array}{c}5.269 \\
(6.803)\end{array}$ & $\begin{array}{l}-3.169 \\
(3.459)\end{array}$ & $\begin{array}{c}0.920 \\
(4.430)\end{array}$ & $\begin{array}{l}0.00395 \\
(1.264)\end{array}$ & $\begin{array}{l}0.926 \\
(0.624)\end{array}$ & $\begin{array}{c}-0.821^{* *} \\
(0.358)\end{array}$ & $\begin{array}{l}2.466 \\
(3.374)\end{array}$ & $\begin{array}{c}0.110 \\
(0.139)\end{array}$ \\
\hline$-\Delta \ln \left(1+\tau_{j}^{\mathrm{CAN}}\right) * \mathbb{1}($ medium firm $)$ & $\begin{array}{l}-0.179 \\
(3.869)\end{array}$ & $\begin{array}{c}2.759 \\
(8.173)\end{array}$ & $\begin{array}{l}-3.665 \\
(2.286)\end{array}$ & $\begin{array}{c}3.648 \\
(4.027)\end{array}$ & $\begin{array}{c}0.681 \\
(0.761)\end{array}$ & $\begin{array}{c}0.117 \\
(0.415)\end{array}$ & $\begin{array}{l}-0.378 \\
(0.276)\end{array}$ & $\begin{array}{l}-3.355 \\
(3.956)\end{array}$ & $\begin{array}{c}0.0136 \\
(0.0358)\end{array}$ \\
\hline$-\Delta \ln \left(1+\tau_{j}^{\mathrm{CAN}}\right) * \mathbb{1}($ large firm $)$ & $\begin{array}{l}-2.969 \\
(3.715)\end{array}$ & $\begin{array}{l}-13.00 \\
(8.372)\end{array}$ & $\begin{array}{l}-2.293 \\
(2.267)\end{array}$ & $\begin{array}{l}8.858 \\
(5.384)\end{array}$ & $\begin{array}{c}1.692 \\
(1.122)\end{array}$ & $\begin{array}{c}0.301 \\
(1.103)\end{array}$ & $\begin{array}{l}-0.110 \\
(0.460)\end{array}$ & $\begin{array}{l}1.558 \\
(2.852)\end{array}$ & $\begin{array}{c}0.0208 \\
(0.0528)\end{array}$ \\
\hline$-\Delta \ln \left(1+\tau_{j}^{\mathrm{US}}\right) * \mathbb{1}($ small firm $)$ & $\begin{array}{l}-8.002 \\
(5.818)\end{array}$ & $\begin{array}{l}-1.824 \\
(8.409)\end{array}$ & $\begin{array}{l}9.246^{*} \\
(4.723)\end{array}$ & $\begin{array}{l}-8.865^{*} \\
(5.177)\end{array}$ & $\begin{array}{c}2.530 \\
(2.648)\end{array}$ & $\begin{array}{l}-0.407 \\
(0.954)\end{array}$ & $\begin{array}{l}-0.336 \\
(0.495)\end{array}$ & $\begin{array}{l}-8.260^{*} \\
(4.307)\end{array}$ & $\begin{array}{l}-0.0862 \\
(0.173)\end{array}$ \\
\hline$-\Delta \ln \left(1+\tau_{j}^{\mathrm{US}}\right) * \mathbb{1}($ medium firm $)$ & $\begin{array}{l}2.220 \\
(5.525)\end{array}$ & $\begin{array}{c}0.983 \\
(10.23)\end{array}$ & $\begin{array}{c}8.474^{* *} \\
(4.247)\end{array}$ & $\begin{array}{l}-11.36^{*} \\
(5.919)\end{array}$ & $\begin{array}{l}1.715 \\
(1.709)\end{array}$ & $\begin{array}{c}0.184 \\
(0.718)\end{array}$ & $\begin{array}{l}-0.483 \\
(0.420)\end{array}$ & $\begin{array}{c}2.646 \\
(4.981)\end{array}$ & $\begin{array}{c}0.0614 \\
(0.0642)\end{array}$ \\
\hline$-\Delta \ln \left(1+\tau_{j}^{\mathrm{US}}\right) * \mathbb{1}($ large firm $)$ & $\begin{array}{l}-2.101 \\
(6.489)\end{array}$ & $\begin{array}{c}20.08 \\
(20.80)\end{array}$ & $\begin{array}{c}-13.59^{* *} \\
(6.032)\end{array}$ & $\begin{array}{l}-5.846 \\
(11.22)\end{array}$ & $\begin{array}{c}1.897 \\
(1.626)\end{array}$ & $\begin{array}{l}-2.447 \\
(1.480)\end{array}$ & $\begin{array}{l}-1.013 \\
(0.868)\end{array}$ & $\begin{array}{l}-1.112 \\
(3.788)\end{array}$ & $\begin{array}{l}-0.0641 \\
(0.0809)\end{array}$ \\
\hline R-squared & 0.121 & 0.071 & 0.037 & 0.054 & 0.023 & 0.025 & 0.014 & 0.078 & 0.004 \\
\hline
\end{tabular}

Notes: Dependent variable is the sum of a worker's earnings during 1989-2004, divided by the worker's average yearly earnings in 1986-1988 (omitting years with zero earnings), defined in equation (2). The independent variables of interest are the 1988-1998 tariff cuts facing U.S. exports to Canada $\left(-\Delta \ln \left(1+\tau_{j}^{\mathrm{CAN}}\right)\right)$ or facing Canadian exports to the U.S. $\left(-\Delta \ln \left(1+\tau_{j}^{\mathrm{US}}\right)\right)$ in the worker's initial industry, interacted with initial firm size (small=1-99, medium-100-999, large=1000+). Column (1) examines total earnings from all sources, (2) earnings from the initial firm, (3) from firms other than the initial firm, but in the same initial 4-digit industry, (4) in manufacturing industries (NAICS $=3 \mathrm{xxx}$ ) other than the initial industry, (5) in construction and utilities (NAICS=22xx, 23xx), (6) in mining (NAICS=21xx), (7) in agriculture (NAICS=1xxx), (8) in services (NAICS $\geq 4 \mathrm{xxx}$ ), or (9) from a firm with unknown industry code. Because earnings in columns (2) through (9) additively decompose total earnings, the coefficients in columns (2) through (9) sum to the overall effect in column (1). All specifications include extensive worker, initial firm, and initial industry controls, described in Section 4. Standard errors clustered by 4-digit NAICS industry. ${ }^{* * *} \mathrm{p}<0.01,{ }^{* *} \mathrm{p}<0.05,{ }^{*} \mathrm{p}<0.1$. 